Published in final edited form as:

Nat Protoc. 2016 December ; 11(12): 2328-2356. doi:10.1038/nprot.2016.114.

\title{
T-REX on-demand redox targeting in live cells
}

\author{
Saba Parvez ${ }^{1,3}$, Marcus J C Long ${ }^{1,3}$, Hong-Yu Lin ${ }^{1}$, Yi Zhao ${ }^{1}$, Joseph A Haegele ${ }^{1}$, Vanha N \\ Pham ${ }^{1}$, Dustin K Lee ${ }^{1}$, and Yimon Aye ${ }^{1,2}$ \\ ${ }^{1}$ Department of Chemistry and Chemical Biology, Cornell University, Ithaca, New York, USA \\ ${ }^{2}$ Department of Biochemistry, Weill Cornell Medicine, New York, New York, USA
}

\begin{abstract}
This protocol describes targetable reactive electrophiles and oxidants (T-REX)—a live-cell-based tool designed to (i) interrogate the consequences of specific and time-resolved redox events, and (ii) screen for bona fide redox-sensor targets. A small-molecule toolset comprising photocaged precursors to specific reactive redox signals is constructed such that these inert precursors specifically and irreversibly tag any HaloTag-fused protein of interest (POI) in mammalian and Escherichia coli cells. Syntheses of the alkyne-functionalized endogenous reactive signal 4hydroxynonenal (HNE (alkyne)) and the HaloTag-targetable photocaged precursor to HNE (alkyne) (also known as Ht-PreHNE or HtPHA) are described. Low-energy light prompts photouncaging $\left(t_{1 / 2}<1-2 \mathrm{~min}\right)$ and target-specific modification. The targeted modification of the POI enables precisely timed and spatially controlled redox events with no off-target modification. Two independent pathways are described, along with a simple setup to functionally validate known targets or discover novel sensors. T-REX sidesteps mixed responses caused by uncontrolled whole-cell swamping with reactive signals. Modification and downstream response can be analyzed by in-gel fluorescence, proteomics, qRT-PCR, immunofluorescence, fluorescence resonance energy transfer (FRET)-based and dual-luciferase reporters, or flow cytometry assays. T-REX targeting takes $4 \mathrm{~h}$ from initial probe treatment. Analysis of targeted redox responses takes an additional 4-24 h, depending on the nature of the pathway and the type of readouts used.
\end{abstract}

\section{INTRODUCTION}

Chemical redox signals have emerged as major small-molecule modulators in nearly all of life's essential processes ${ }^{1}$. Contrary to their typical pathological role ${ }^{2}$, it is now believed that orchestrated transient fluxes of reactive electrophiles ${ }^{3}$ and/or oxidants ${ }^{4-6}$ at low

\footnotetext{
Reprints and permissions information is available online at http://www.nature.com/reprints/index.html.

Correspondence should be addressed to Y.A. ya222@ cornell.edu.

${ }^{3}$ These authors contributed equally to this work.

Note: Any Supplementary Information and Source Data files are available in the online version of the paper.

AUTHOR CONTRIBUTIONS H.-Y.L. and Y.Z. were joint second authors of this work. S.P., M.J.C.L., H.-Y.L., Y.Z., J.A.H., V.N.P., D.K.L. and Y.A. developed protocols. S.P. and V.N.P. contributed to the data associated with T-REX in E. coli cells. M.J.C.L., Y.Z.,

J.A.H. and D.K.L. obtained the data associated with T-REX in cultured human cells. H.-Y.L. collected LC-MS/MS data. H.-Y.L. and

Y.Z. contributed to chemical synthesis. S.P., M.J.C.L. and H.-Y.L. wrote the protocols. Y.A. wrote the manuscript with proofreading/ editing contributions from S.P., M.J.C.L., Y.Z. and J.A.H.
}

COMPETING FINANCIAL INTERESTS The authors declare competing financial interests: details are available in the online version of the paper. 
concentrations promote physiological fitness. Unlike traditional second messengers such as phosphate signal carriers, redox signals find their target nonenzymatically, relying upon their inherent chemical reactivity, as well as that of their protein target(s). Such a mechanism necessitates a delicate balance and precise spatiotemporal relationship between the reactive small-molecule signal and the target protein(s) that undergo(es) selective chemical modification against an otherwise unperturbed proteome. These intricacies render specific redox responses difficult to model in living systems. Identification of genuine redox-sensor targets that respond to a specific reactive signal in an otherwise unperturbed cellular setting -comprising many endogenous signaling molecules at basal concentrations, such as oxidants, electrophiles and metabolites-also presents a challenging task.

The emerging significance of lipid-derived signaling electrophiles (LDEs)—such as 4hydroxynonenal (HNE) — as endogenous redox-linked signal carriers ${ }^{7,8}$, and small-molecule redox-activator drugs with functional properties similar to these endogenous LDEs $^{9-13}$, warrants a clear understanding of the role of signaling electrophiles in redox regulation. However, many important biological questions underpinning specificity and timing remain largely unresolved by currently used methods.

Redox responses have been studied by many elegant methods, such as mechanical stretching or shear stress (at the cell level) ${ }^{14-18}$, and specific growth-factor or metabolite-targeted stimulation under physiologic or pathologic settings ${ }^{19-21}$ —e.g., $\mathrm{H}_{2} \mathrm{O}_{2}$ signaling through Nox enzymes ${ }^{22}$, and glucose-stimulated mitochondrial ROS production in hyperglycemia ${ }^{23-25}$.

In terms of a general pharmacological (i.e., small molecule-based) strategy, the physiologic impacts of nonenzymatic redox-linked protein modifications in living systems are conventionally studied using bolus dosing approaches: an excess of a reactive signal is administered and a specific phenotype of interest is read out ${ }^{7,8}$, or the gamut of proteins modified are identified by affinity purification followed by mass spectrometry $7,26-34$. These powerful approaches have shed light on the functional importance of LDE signaling, and they have identified novel LDE-sensitive targets and pathways. Importantly, these data collectively suggest that distinct LDEs are capable of driving vastly different pathways spanning inflammation ${ }^{35-38}$, immune response ${ }^{3,39-41}$, epigenetic signaling ${ }^{26,42-44}$, apoptotic signaling ${ }^{45-47}$ and so on.

Many conventional signaling pathways function through a gain of function or a dominant loss of function-mechanisms that are phenotypic even with low-stoichiometry modifications at a single signaling node. By analogy, it is likely that low-stoichiometry modification of intrinsically reactive proteins is important in redox signaling. Under bolus dosing conditions, these key modifications can often be lost in noise stemming from offtarget modification of highly abundant proteins $\mathrm{s}^{1,48,49}$. For example, quantitative proteomics studies have also shown that reactive signals such as HNE covalently label $~ 1,000$ cysteineactive targets under typical global treatment regimens ${ }^{27,30,31}$. Accordingly, bolus dosing strategies with reactive signals typically recapitulate complete loss of function ${ }^{28,50}$, and they are a simple and versatile approach to modeling oxidative damage-associated pathological phenotypes $^{51}$. Whereas modifications of a plethora of targets typically mark the end point of 
oxidative damage $\mathrm{e}^{50-53}$, endogenous physiologic redox signaling is known to occur under localized generation of transient fluxes of basal redox signals $3,6,21,38,54$. Thus, because bolus dosing uses whole-specimen treatment conditions, it has been challenging to shed light on the specific impacts of specific redox events that are on their own necessary and/or sufficient to prompt signaling response downstream. Thus, a simple transposable method would strongly complement this approach to help researchers (i) identify bona fide sensitive proteins from global dosing experiments and (ii) begin to understand how these events specifically affect downstream phenotypes (Fig. 1). The latter is critically important because the broad target spectra of redox signals under super-physiological concentrations probably mask or suppress the phenotypic responses that occur when endogenous amounts of LDEs are generated. LDEs with different chemical structures can have different membrane permeability, stability, toxicity and target affinities, resulting in discrete bioactivities and pathway specificity, as well as differing levels of promiscuity $8,29,41,44,47$. This information can be obtained only by using methods that probe the specificity, timing and extent to which modification of the specific target alone is adequate to elicit a response. The method described herein can be used to (i) investigate the precise consequences of specific redox events on specific signaling response and (ii) enable targeted screening and discovery of novel redox-sensor genes from precision delivery of specific LDEs.

\section{Development of the method: T-REX on-demand redox targeting Temporal control and target specificity}

T-REX technology ${ }^{55-57}$ selectively modifies a specific redox-sensor POI, and it enables the decoding of the functional consequences of specific redox events, against the backdrop of an otherwise unperturbed proteome (Fig. 2). A potential redox-sensor protein is chosen based on previous lists of postulated LDE-modified proteins from global proteomics experiments, or putative redox-sensor POIs. The POI is genetically fused to a HaloTag domain. The TREX assay uses a small organic molecule that is made up of a photocaged LDE and a chloroalkane recognition unit. The HaloTag enzyme ${ }^{58-61}$ rapidly and specifically conjugates to the chloroalkane recognition unit, resulting in an irreversible 1:1 Halo-small-molecule complex. The 15-atom linker between the chloroalkane function and the photocaged LDE renders the inert caged motif solvent exposed such that low-energy light illumination $(0.3$ $\mathrm{mW} / \mathrm{cm}^{2}, 365 \mathrm{~nm}$; Supplementary Fig. 1 and Supplementary Videos 1 and 2$)$ unleashes $\left(t_{1 / 2}\right.$ $<1-2 \mathrm{~min}$ ) a maximum of one LDE molecule per caged precursor in vitro ${ }^{56,57}$ and in cells $\left(t_{1 / 2} \sim 0.5 \pm 0.3 \mathrm{~min}\right.$ ) (Supplementary Fig. 2a). Proximity enhancement ${ }^{62}$ enables targeted LDE modification of the redox-sensitive POI, whereas HaloTag itself does not react with the liberated LDE (Supplementary Fig. 2b).

We performed validation experiments that included the following:

Blocking experiments to check for specificity-Pretreatment of Halo-POIexpressing cells with a HaloTag-targetable photocaged LDE ('photocaged precursor' hereafter) - before the addition of tetramethylrhodamine (TMR) dye-conjugated chloroalkane and subsequent live imaging — confirmed that the photocaged precursors saturate the Halo protein binding site within $2 \mathrm{~h}$ (ref. 55), consistent with HaloTag's rapid second-order reaction ${ }^{60}$ (Box 1). Functionality of HaloTagged POIs was also assessed (Box 
2). Both TMR-dye-conjugated chloroalkane and the photocaged precursor (Fig. 2, inset) labeled HaloTag exclusively. Hence, there is no reaction of caged precursors with other cellular targets or the POI, and the chloroalkane appendage is stable ${ }^{55-57}$. Such a result is common because eukaryotic cells and most bacteria, including E. coll ${ }^{58,59,61}$, do not express haloalkane dehydrogenases, conferring excellent bio-orthogonality.

Cytotoxicity and off-target stress responses-The caged precursors were nontoxic, as judged by AlamarBlue and trypan blue viability assays ${ }^{55,56}$. UV light exposure under TREX conditions also does not elicit upregulation of $\gamma-\mathrm{H}_{2} \mathrm{AX}^{63}$ and does not perturb other stress-sensitive pathways such as the NF- $\mathrm{kB}$ pathway (ref. 64), markers for DNA damage and inflammatory signaling, respectively (Supplementary Fig. 3). In T-REX, the maximum LDE signal delivered is equal to the concentration of the HaloTag fusion protein (Fig. 2). Thus, side reactions of the T-REX-liberated LDE with proteins other than the target POI occur at a much lower rate than whole-cell flooding. By contrast, global treatment with reactive LDEs induces time- and dose-dependent cytotoxicity. The effector concentration for half-maximum response $\left(\mathrm{EC}_{50}\right)$ of viability, for instance, even for the robust cell line HEK-293T, is $\sim 31 \mu \mathrm{M}$ over $18 \mathrm{~h}$ of treatment ${ }^{8,56}$. Because the typical concentrations used in the literature for redox signaling studies with LDEs, for instance HNE, are above $20 \mu \mathrm{M}$ and can reach as high as $1 \mathrm{mM}$ over prolonged treatment, users are encouraged to carefully evaluate the extent of loss of cell viability under these conditions and consider associated off-target responses.

\section{Quantification of the extent of modification}

Alkyne functionalization enables fluorescence-based quantification of the amount of LDE signal delivered to the POI, and that remains unliberated on the HaloTag (Fig. 2) ${ }^{56}$. The low background signal to the overall proteome, along with the fact that targeting is not achieved when the HaloTag is expressed separately with the POI (the 'nonfused' system, Box 3$)^{56,57}$, collectively led us to the conclusion that the majority of liberated lipid electrophile that does not hit its intended target is likely intercepted by small-molecule thiols such as glutathione ${ }^{65-68}$. The percentage of delivery (i.e., the amount of signal that is delivered to the POI with respect to the total initially present in the photocage) is assayed post cell lysis by a series of steps involving TEV (Tobacco etch virus) protease-mediated separation of HaloTag from the POI, click coupling ${ }^{69}$ reaction with Cy5-azide and in-gel fluorescence analysis (Fig. 3). Western blotting of a housekeeping protein (e.g., actin) and the target POI, respectively, normalizes for loading and transfection efficiency across all samples against no-light-exposed and/or no-TEV-treated controls. Subtraction of the amount of signal associated with unreacted photocage on HaloTag accounts for the true percentage of POI molecules modified in the cells (see equation in Step 40A(ix)). The value obtained from this method is broadly similar to that estimated by ion peak integration post liquid chromatography-tandem mass spectrometry (LC-MS/MS) analysis ${ }^{56}$.

\section{Generality in the scope of targetable LDEs}

Tolerance of HaloTag to a range of sterically demanding groups appended to chloroalkane ligands permits versatile functionalization of the caged precursor ${ }^{56}$, which makes it feasible to deliver LDEs of varying chemical architectures (Fig. 2, inset). For all the LDEs studied, 
expressing Halo and POI as two separate proteins, in place of the Halo-POI fusion protein, resulted in no labeling of the POI in the cells, confirming that proximity-based targeting was in operation ${ }^{56,57}$. In vitro kinetic analyses ${ }^{56}$ suggest a two-step targeting mechanism: formation of an initial target-signal encounter complex followed by covalent Michael adduction with Cys residue(s) on the target. Labeling efficiency for a given target is governed by partitioning between the rate of covalent adduct formation and diffusion of the LDE signal out of the coordination shell of the target $\mathrm{POI}^{55,56}$.

\section{A platform for targeted screening and discovery of bona fide sensor genes}

One of the major benefits of T-REX is the commercially available HaloTag human and mouse full-length ORF (open reading frame) clone libraries (Kazusa Collection, Promega). This gives an added dimension because it makes screening of potential electrophile-sensitive gene products very simple. As proof of concept, an in-house screen of ten HaloTag proteins allowed us to identify two proteins that are 'first responders' to basal amounts of HNE (Fig. 4 and Supplementary Fig. 4). The majority of the candidates we chose were previously identified as potentially LDE-sensitive by global proteomic profiling ${ }^{26-28,30,31,34}$ and include the following: (i) human ribonucleotide reductase (RNR) subunits RRM1 and RRM2 (and its isoform p53R2)—each subunit pair, RRM1/RRM2 or RRM1/p53R2, constitutes an active RNR complex that is essential for nuclear or mtDNA replication, respectively ${ }^{70}$; (ii) PI3K and PRKCD—-two of several kinases that regulate the Nrf2transcription-factor-driven antioxidant response (AR) pathway in mammals ${ }^{71}$; (iii) $\mathrm{Cul3}$-a ligase that mediates proteasomal degradation of mammalian Nrf2 (ref. 72); and (iv) DCAF11 - a mammalian analog of a stress-responsive protein in Caenorhabditis elegans. We also screened zebrafish HSPB7-a member of the small heat-shock protein family that is highly and selectively expressed in the heart ${ }^{73,74}$. hspb7 is not upregulated by heat shock ${ }^{75}$, and thus it probably has other regulation mechanisms that are as yet unidentified. Keap1-a redox-sensitive negative regulator of the Nrf2-AR pathway-served as a positive control in the screen ${ }^{56,57}$. Expression of these proteins was assessed by blotting for Halo protein (assumed to be present in a 1:1 ratio with the fused POI). By this metric, most proteins were successfully expressed, although expression varied. However, in addition to the positive control Keap1, only two proteins from this screen-RRM1 and HSPB7-were modified by HNE (Fig. 4a and Supplementary Fig. 4) under the conditions in which HNE signals were delivered in controlled amounts.

As $\mathrm{p} 53 \mathrm{R} 2$ and RRM1 expression was similar and RRM2 (a protein known to have a short half-life ${ }^{70}$ ) was also detectable, these data show that RRM1 is probably the HNE-sensitive subunit of active RNR complexes-RRM1/RRM2 and RRM1/p53R2 heterodimers. Other proteins were not appreciably HNEylated. Remarkably, RRM1, p53R2 and PRKCDpreviously identified HNE-sensitive hits from global treatment approaches ${ }^{26-28,30,34}$ —had expression similar to that of Keap1; yet T-REX-assisted HNE delivery was markedly different. By contrast, whole-cell HNE treatment led to nonspecific targeting under otherwise identical conditions (Fig. 4a and Supplementary Fig. 4a). Although the reasons behind these differences are likely to be multifactorial and system- and/or contextdependent, when an entire cell is swamped with reactive LDE in excess, the time-dependent nature of the underlying covalent chemistry in LDE modification typically controls the 
extent of off-target labeling, and thus unresponsive proteins in the T-REX screen may react too slowly with HNE to serve as 'first responders'. Less reactive subunits or targets could start to react when HNE is in excess. In a multisubunit protein complex such as RNR, HNE transfer to other subunits could also occur under these circumstances. On the other hand, TREX releases a maximum of one LDE molecule per HaloTag-POI unit ${ }^{55-57}$, and the POI is substoichiometrically modified by the liberated $\mathrm{LDE}^{55-57}$. We discuss aspects of existing methods and considerations for potential artifacts below.

\section{Determination of residue specificity}

Once the positive result of LDE sensitivity has been established by gel-based analysis, the identity of specific amino-acid residues modified can be determined by standard affinity enrichment followed by LC-MS/MS characterizations (Fig. 3). For Keap1, the position of the HaloTag ( $\mathrm{N}$ or $\mathrm{C}$ terminus) exerted no influence on cysteine residue labeling by T-REX (Fig. 5 and Supplementary Table 1$)^{56}$. Furthermore, as similar levels of signaling responses are achieved by T-REX and whole-cell LDE stimulation (see Applications section), the ability of T-REX to elicit a response indicates that functionally relevant residues are targeted ${ }^{56,57}$.

Selection of specific Cys residues is likely to be dominated by individual Cys nucleophilicity in its native microenvironment. For example, LC-MS/MS analysis showed C613 modification of Keap1 by a cyclohexenone-derived LDE (namely, CHE, Fig. 2 inset), regardless of N- or C-terminal HaloTag fusion (Fig. 5c and Supplementary Table 1). Mutagenesis studies previously suggested that other Cys residues within Keap1 can compensate for the lack of C613, underscoring functional redundancy across multiple Cys residues on Keap1 (refs. 56,57). Interestingly, global treatment of cells with CHE also resulted in the modification of the same Cys residue on the Halo-Keap1 protein (Supplementary Table 2). Our previous LC-MS analysis of Keap1 modifications by HNE, an LDE of much higher reactivity than CHE, under T-REX versus global conditions resulted in nonoverlapping residues, as well as a wider scope of residues modified.

\section{Versatility in both mammalian cells and $E$. coli}

We also showed that the method can afford similar precision targeting of reactive LDEs in bacteria, using $E$. coli as proof of concept. In this example, recombinantly expressed human Keap1 genetically encoded with HaloTag at the $\mathrm{N}$ terminus was selectively reacted with HNE(alkyne) using T-REX (Fig. 6). As in the case of mammalian cells, photocaged precursors did not show adverse effects on the growth rate of E. coli, and they were able to permeate the E. coli cells within $2 \mathrm{~h}$ during the logarithmic growth phase when Halo-Keap1 expression was induced at $19{ }^{\circ} \mathrm{C}$. The procedures used for photo-uncaging and downstream labeling analysis for mammalian cell samples were also transferable to E. coli.

\section{Applications of the method}

Redox targeting: establishing target-specific biological sufficiency in specific redox events-A major advantage of T-REX is that it has the potential to decode the gainof-function (or dominant loss-of-function) consequences of specific redox events in living systems in a time-resolved manner. This benefit is not offered by any existing tool, despite 
the growing interest from both the academic and pharmaceutical communities. One critical pathway regulated by redox signaling is the Nrf2-AR axis. The conserved Nrf2-AR pathway is a gatekeeper for the expression of hundreds of detoxification and antioxidant genes that are essential for cytoprotective defense in all cell types in metazoa. This pathway also has an essential role in aspects of physiology, such as organogenesis and life-span regulation, and, conversely, in various disease states, such as tumor metastasis and drug resistance ${ }^{71,76,77}$. There are many electrophilic pharmacophores (e.g., tecfidera, bardoxolone, sulforaphane, curcumin $)^{9-13,78}$ with chemical reactivity similar to that of the endogenous AR stimulator HNE-which is a reactive signaling compound known to have $>800$ cysteine targets under bolus dosing conditions ${ }^{27,30,31,34}$. These electrophiles are believed to confer therapeutic benefits by upregulating, among others, the Nrf2-AR pathway ${ }^{9-13,78}$. The use of T-REX in cultured human cells enables targeted Nrf2-AR pathway activation with precise timing and without perturbing other redox-sensor protein networks ${ }^{55-57}$. T-REX has shown that targeted HNEylation of one of the many redoxsensitive AR regulators, Keap1, with low stoichiometry is sufficient to stimulate maximal AR within the complex multisensor protein networks regulating Nrf2. ('HNEylation' is defined as a post-translational modification of a protein by HNE through covalent chemical conjugation to any residue. The target residue is most often cysteine, but HNE can also react with lysine and histidine residues ${ }^{30,79-81}$. Our gel-based analysis of T-REX targeting assessment shows no prejudice regarding residue specificity, nor the specific chemical identity of adducts formed.) In this way, we were also able to rule out the proposed HNEsensing ability of Nrf2 itself, as co-overexpression of Nrf2 (which directly binds HaloKeap1) does not result in HNEylation of Nrf2 in cells ${ }^{57}$. In addition, because reactive LDEs such as HNE will react with any isolated protein bearing Cys (and also His and Lys residues, depending on incubation time and concentration ${ }^{3}$ ), T-REX is an ideal method for determining functionally relevant modification events that are sufficient to trigger signaling.

Gel-based fluorescence quantification shows that the amount of LDE, exemplified by the cyclohexenone analog CHE (Fig. 2 inset), reacted with Keap1 under whole-cell LDE treatment conditions $\left(25 \mu \mathrm{M}, 20 \mathrm{~min}, \mathrm{EC}_{50}\right.$ (viability) $\left.\sim 90 \mu \mathrm{M}\right)$ is $\sim 6$-fold higher than that achieved under T-REX ${ }^{56}$. However, global treatment provides no additional bonus in terms of the magnitude of AR upregulation. The percentage of Keap1 molecules modified under TREX conditions can be determined easily based on two independent methods of quantification: in-gel fluorescence (vide supra) and ion peak integration ${ }^{56}$. For a representative targeted modification of Keap1 with cyclohexenone-derived LDE (Fig. 2, inset), the two methods yielded percentage targeting efficiencies of $19 \%$ and $15 \%$, respectively ${ }^{56}$. Controls showed that the Nrf2-AR upregulation phenotype is not due to TREX affecting the proteasomal pathway that regulates steady-state Nrf2 protein levels ${ }^{57}$. The observed Nrf2-AR upregulation was also not due to untargeted delivery because AR activation did not occur when HaloTag and the target POI, Keap1, were overexpressed as two separate proteins ${ }^{56,57}$. Keap1 is unusually cysteine-rich, and it reacts rapidly with electrophiles, so this experiment gives a high degree of confidence that T-REX does not perturb other sensor proteins that regulate Nrf2-AR in the cell. In fact, the result allowed us to postulate that T-REX proceeds via a target-signal encounter complex formed specifically because the electrophile is juxtaposed to the target upon photo-uncaging ${ }^{56}$. 
Redox targeting: interrogating signal-specific and on-target signaling strength

-We have also developed an integrated electrophile toolbox that enables targeted delivery of various linear enal, enone and cyclic-enone-based LDEs to specific sensor proteins in cells (Fig. 2, inset) ${ }^{56}$. Targeting efficiency is not largely influenced by intrinsic electrophilicity of the reactive signals. This observation is consistent with in vitro kinetic data, which show largely similar initial on-rates of LDE adduction of Keap1 (ref. 56). Thus, T-REX probably creates a microenvironment that behaves as if the target POI has been transiently treated with saturating LDEs. The ability of the T-REX LDE toolbox to provide a range of signaling LDEs opens a new avenue to quantitatively dissect how a specific sensor protein or pathway deals with specific reactive LDEs. Using Keap1 as a model sensor protein in cells, T-REX provides a means to elucidate how reactive LDE modifications directly translate to the strength of Nrf2-AR activation. In addition, the case with a cyclopentenone-based LDE (namely, CPE, Fig. 2 inset) ${ }^{56}$ helps exemplify the potential utility of T-REX in the identification of novel small molecules that elicit pathway activation only through targeted delivery, but fail to activate AR from whole-cell flooding before toxicity ${ }^{56}$.

Quantification of signaling response in subpopulations: We have described various methods that report on average increases in AR signal across the whole population. We stress that to identify new signaling effects of POI-targeted redox modifications on any other transcriptional pathways of interest users can simply replace the Nrf2-AR activation reporter plasmids used herein with any of the tens of signal transduction reporter plasmids that are commercially available in both luciferase- and GFP-reporter formats (e.g., one commercial source that we have used is the Cignal 45-Pathway Reporter Array from Qiagen). So far, we have shown pathway modulation using the dual-luciferase assay, which reports transcriptional activation of Nrf2-driven AR (refs. 56,57), as well as qRT-PCR (ref. 57) and western blotting analyses, which evaluate AR-driven downstream genes at the mRNA and protein levels, respectively ${ }^{56,57}$. These data that look at AR upregulation in ensembles of cells on the whole show little or no difference in the manner in which T-REX and whole-cell HNE exposure stimulate AR. Herein, we report an orthogonal flow cytometry assay that shows the extent of AR-driven GFP expression ('the GFP reporter assay' hereafter) (Fig. 7). This assay allows us to compare the effects of whole-cell HNE flooding and the T-REX approach on AR on a cell-by-cell basis.

In this flow cytometry assay, live cells are first gated by forward (size) and side scatter to give a general population of healthy cells (Fig. 7a). This specific gating is applied to each data set (e.g., photocaged precursor Ht-PreHNE alone, light alone and so on). This population should be a single group, and it should be the largest single population for each data set. We gated the scatter group in several ways, and similar downstream results were obtained, but it is important that each data set (including all appropriate controls) be gated the same way. Analyzing this scatter group for green fluorescence (AR reporter) told a story that was slightly different from that painted by our previous ensemble experiments ${ }^{56,57}$. Intriguingly, whole-cell HNE treatment strongly increases AR in a subset of cells, principally those showing a medium level of AR in the ground state. Notably, there is little change in cells with low basal AR (Fig. 7b). 
On the other hand, with T-REX, the increase in GFP signal stemmed from an increase in AR in all but the cells with the highest basal AR (Fig. 7b-d). We attribute the lack of effect on cells with a high basal AR to the fact that these cells express a lower level of Keap1 protein with respect to Nrf2, rendering them less susceptible to specific AR upregulation by T-REX. Nonetheless, T-REX enables the initiation of AR in a larger fraction of the cell pool than does global HNEylation, and it does not hyperstimulate AR. Given that T-REX shows that most cells can respond to low-occupancy HNE stimulation through Keap1 modification, it is likely that the small number of responders seen with HNE is a result of the compensatory suppression of AR due to alkylation of multiple proteins. Such an observation would be consistent with T-REX being able to mimic endogenous LDE signaling, and it is thus further consistent with the low off-target spectrum associated with T-REX and the fact that T-REX faithfully reports on AR signaling selectively through Keap1 (refs. 56,57).

Generality across other redox-sensor targets and pathways: We further validated the application of T-REX beyond the targeted perturbation of Nrf2-AR signaling axis by selective downregulation of a key redox-sensitive tumor suppressor protein, PTEN ${ }^{82}$. Oxidation or alkylation of PTEN by LDEs is known to inactivate PTEN phosphatase activity $^{83-85}$. PTEN modifications elicit dominant loss of function of PTEN ${ }^{86-88}$, and thus minor modifications can result in measurable accumulation of its cellular substrate, phosphatidylinositol 3,4,5-triphosphate (PIP3). Building on our previous work that establishes T-REX-assisted HNEylation of PTEN ${ }^{55}$, we here showed that T-REX also offers a means to temporally modulate the PTEN signaling. Two different orthogonal and established readouts-immunofluorescence (IF) analysis of endogenous PIP3 levels in fixed cells (Fig. 8) and FRET-based 'InPAkt' (indicator of phosphoinositide based on Akt) reporter assay 89,90 in live cells (Fig. 9)—were used. The representative images of fixed cells in Figure 8 and live cells in Figure 9 both underscore that T-REX coupled with either IF or FRET assays is nonintrusive to cellular integrity - an aspect that we encourage users to be aware of before proceeding to data quantification. Although the fold changes in the measured FRET signals (Fig. 9) are small, they are within the range previously established for growth factor-induced or pharmacological perturbation of the same pathway using the identical lnPAkt FRET reporter plasmid ${ }^{89,90}$ (Figs. 8 and 9). These outcomes also suggest that as in Nrf2-AR signaling 56,57 , single-target redox modulation events can be important physiological events that can fully recapitulate a variety of cellular redox processes.

\section{Identification of novel sensor genes: discovering novel redox regulators} sufficient for a specific response-This can be accomplished using the procedure for the representative HaloTag ORFclone library screen (Fig. 4 and Supplementary Fig. 4) and subsequent probing of transcriptional response (Fig. 2). The initial screen, target validation and downstream response studies are all built on T-REX.

\section{Identification of novel sensor genes: precise assessment of redox sensitivity in combination with proteomics and transcriptomics-based target ID approaches-T-REX, in unison with these existing technologies, provides unparalleled opportunities for accurate characterizations of their precision response to specific LDE}


signals delivered to a specific sensor protein at a specific time (Fig. 4a and Supplementary

Fig. 4a).

\section{Comparison with other methods}

Genetic and chemoproteomics approaches-Redox signaling is a chemical signaling paradigm that is radically different from enzyme-assisted post-translational modifications such as phosphorylation. Accordingly, classic genetic approaches are not optimal for the study of the temporal and spatial dynamics underpinning redox signaling. Targeted knockdown and/or knock-in approaches ${ }^{91,92}$ assume the presence of one protein will be necessary for the desired response to occur. Even though a specific protein may be necessary for a particular signaling event under endogenous signaling conditions, such a scenario is unlikely to be the case under typical bolus dosing because of functional redundancy among sensor proteins and the pathways that they regulate. Knockdown also often disrupts protein-protein interactions that are essential for functional intercommunication within multicomponent signaling networks. Specifically, protein expression levels fluctuate so drastically during dynamic physiological processes such as development ${ }^{93}$ that redox perturbation under steady-state conditions often elicits pleotropic effects that are challenging to interpret. The modifications are also largely nonsequence- and nonsite-specific ${ }^{1}$, and many redox-sensor proteins have multiple functionally redundant $\mathrm{Cys}$ residues ${ }^{1,49}$. Mutagenesis strategies are thus not always effective. Innovative quantitative proteomics platforms, on the other hand, have opened exciting doors to profiling relative Cys reactivity within the human proteome $26,28-30,32,33,94-96$. Chemical biology methods for sitespecific analysis and global mapping of cysteine modifications onto the redoxome are also established $26,28,30,32,33,94-96$. Despite the powerful capability to rank reactivities and define the sites of modifications, the chemoproteomics strategies with global LDE exposure provide no ability to perturb specific targets on demand. Downstream validation is difficult because it typically involves replicating the swamping experiments in knockdown cells and measuring changes to the pleiotropic response, conditions in which temporal and target resolution are both low. T-REX is an exciting starting point in addressing these outstanding biological questions; it generates answers to a subset of important questions that strongly complement those addressed by existing whole-cell probing and profiling methods.

\section{Limitations and considerations}

HaloTagging versus endogenous protein targeting-Although the monomeric nature of HaloTag prevents unintended self-association ${ }^{58-61}$, this $33-\mathrm{kDa}$ protein adds steric bulk to the target POI. Despite the availability of functionally validated HaloTag clones from Promega, HaloTagging of a protein may affect complex protein function in an unpredictable way. This factor should be evaluated for individual target POIs under study. For example, we have confirmed that HaloTag does not perturb functional integrity of proteins thus far investigated in our laboratory. For instance, Halo-Keap1 is, as expected, a dimer ${ }^{57}$, and with both $\mathrm{N}$ - (ref. 57) and C-terminal (Fig. 5a) fusion of the tag the engineered protein binds Nrf2 and maintains cytosolic localization similar to that of native Keap1 (Box 2). Likewise, HaloRRM1 has reductase activity largely similar to that of its non-HaloTagged counterpart. 
To date, T-REX targeting has been demonstrated only with HaloTagging ${ }^{55-57}$. However, one would expect T-REX to function equally well on other similar fusion proteins (e.g., SNAP or CLIP tags ${ }^{97}$ ), provided that the appropriate ligands were available. By extension, in cases in which proteins of interest have high-specificity and/or high-affinity ligands that tolerate chemical modification, a specific T-REX photocaged precursor targeting an endogenous POI could be tailor-made. In other words, the chloroalkane recognition unit within the photocaged precursor (Fig. 10) could be replaced with a known ligand of the endogenous target POI under study. However, one must first ensure that the modified ligand can interact with the POI and determine photo-uncaging efficiency.

Overexpression and nonspecific response-Although the technique currently uses overexpressed proteins, overexpression does not appear to bias the outcomes in favor of delivery ${ }^{55-57}$ - an outcome that was part of the initial design concept and must hold for a pseudo-intramolecular delivery mechanism. Nonetheless, we recommend independent caseby-case assessments using controls similar to the following. In the study of the Nrf2-AR pathway, we ruled out the contribution of untargeted delivery to T-REX-mediated pseudointramolecular delivery, using three independent lines of evidence ${ }^{56}$. The best and most general control is to simultaneously overexpress HaloTag and the target POI as two separate proteins (termed the non-fused system) and to replicate the experiments and look for loss of downstream response ${ }^{56,57}$ (Box 3). To confirm that the photocaged precursor molecule interaction with HaloTag is required for delivery, the D106A HaloTag point mutant ${ }^{60}$, which is unable to form a covalent bond with the chloroalkane unit, is recommended. We have also found empirically that overexpression levels of many proteins can be dialed down by selecting for cell lines that have integrated the plasmid post transfection. This approach also limits potential variability due to transient transfection of the $\mathrm{POI}^{56}$. One can also use less powerful or inducible promoters in mammalian cells or E. coli, which lack a specific importer (lac $Z Y$ ), allowing IPTG concentrations to be more accurately titrated (Tuner, Novagen). Alternatively, overexpression of Halo proteins may be executed in a null background using cells in which the endogenous variant is knocked out ${ }^{91}$.

Comparison with existing methods-Most small-molecule-based methods for identifying HNE-sensitive proteins rely to some extent on bolus dosing 27,30,31. The principal alternative to T-REX is activity profiling. This has been carried out mostly in lysates ${ }^{26,28}$, but also more recently in cells ${ }^{29,30}$. Importantly, several differences between lysate-based and cell-based data have been delineated ${ }^{30}$, which underscores the need for better methods to probe reactivity in biologically relevant contexts. Powerful approaches for profiling both serine and cysteine residues - the latter being the most likely HNE-modified residue 26,28,30_exist in the literature. Histidine and lysine-residues that may react with $\mathrm{HNE}^{79-81}$ - are currently not able to be profiled. Thus, activity profiling can identify many potential LDE-reactive cysteines $(\sim 1,000)$ in a high-throughput manner ${ }^{26,28,30}$ : addition of an excess of LDE that competitively binds to the profiled cysteines can be detected because those cysteines that bind the LDE are lost from the profiling pool. Profiling thus has benefits over T-REX in that it can identify many specific cysteine targets on specific proteins rapidly (T-REX can be used to identify specific cysteines, but it is more time-consuming). Furthermore, because the proteomics profiling method profiles activity, it can potentially 
report on cysteines or enzymes that are not HNEylated but that are functionally coupled to an off-target HNEylation event, e.g., through changes in complexation or cysteines that are on enzymes whose stability is compromised under reaction conditions. Depending on the goal of the experiment, such an outcome may or may not be desired. However, ultimately, a hit on profiling does not necessarily mean that a bona fide HNEylation event has occurred, and thus multiple downstream validations are required after the initial hits have been identified. Furthermore, profiling is limited by the number of cysteines that can be identified by the activity probe used, which, although high, is not exhaustive. Many well-known reactive enzymes, such as Keap1, are rarely observed in reactivity profiling.

By contrast, the whole ORFeome of mouse and human is available as Halo-tagged clones (Kazusa collection, Promega), which makes high-throughput screening with T-REX possible. Although initial screening is more laborious than profiling, T-REX is streamlined to allow downstream pathway interrogation using reporter assays such as dual-luciferaseand GFP-based transcriptional reporters (shown in Steps 40C and 40D of the PROCEDURE). We believe that a combination of profiling (to generate potential hits) and T-REX (for validation and downstream signal interrogation) is the most powerful approach.

Alternatives to profiling include direct identification of HNEylated proteins by MS $35,37,43,44$ pulldown assays using radiolabeled $\mathrm{HNE}^{98,99}$ and in vitro HNEylation ${ }^{43,80}$. These methods are all relatively low throughput and do not lend themselves to downstream signaling pathway interrogation. However, similar to T-REX, they do identify a specific modification of a specific protein, but under uncontrolled swamping conditions.

Further modifications of the LDE signal-LDE signals themselves can be modified by reduction ${ }^{3,98}$, oxidation ${ }^{3}$, alkylation ${ }^{27,98}$ and other secondary processes. This is an intrinsic property of LDEs, and for this reason in all methods using LDEs one cannot assume that the active species is the specific LDE added. Although little work has been carried out to compare how faithfully each method reports on modification by the intended electrophile as opposed to a metabolite thereof, because of the low dose of LDE generated and the 'faster than diffusion' kinetics required for T-REX to occur, it seems likely that TREX will be relatively less susceptible to chemical modification of the LDE than approaches based on bolus dosing (where the electrophile is in excess).

Relevance to 'real-life' situations-T-REX is a tool used to identify and interrogate a single (or potentially a small number of) specific protein modification(s) at a time through a native reactive chemical signal. It is best used to model redox signaling, in which modest perturbations to a pre-existing cellular reactive lipid electrophile pool elicit a

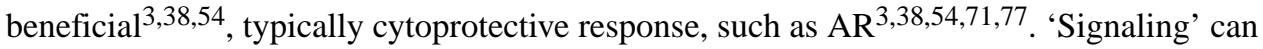
occur because changes in an LDE upregulation can be compartmentalized, or 'directed' to a specific target and because second-order rates of association with an LDE vary widely for different enzymes ${ }^{26,27,34}$. Furthermore, because LDE levels (and hence targeted labeling by T-REX) are low, signaling events probably occur through gain of function or dominant loss of function. (If LDE modification causes inhibition of enzymatic activity, unless this is a dominant phenotype (as is the case for PTEN ${ }^{82,86-88}$ ), the modification may not be phenotypic during redox signaling because of the low concentrations of HNE, leading to low 
target protein occupancy.) Because T-REX can label only a small percentage of the total target protein present, the requirements for observing a response are similar to those for lipid signaling. Furthermore, T-REX 'directs' HNE to a target enzyme in a manner similar to endogenous signaling, thereby mimicking 'redox signaling' reasonably well. Individual pathological effects of overproduction of LDEs can also be interrogated, in principle, using T-REX, for example, to interrogate the extent to which HNEylation of a specific protein may elicit apoptosis. However, as pathological effects stem from hyperproduction of LDEs, in which complete loss of function could occur, ancillary factors or a high percentage of modifications of the target may be required to recapitulate these scenarios, which would render T-REX less useful.

LDE chain length-HaloTag is unreactive to the reactive electrophiles, and it thus generally serves as a good point source of reactive signals ${ }^{56}$. However, we have found that the hydrophobic surface of Halo can interfere with efficient release of long-chain ( $~ 15$ carbons) fatty-acid-derived LDEs-for instance, 2-HD ${ }^{56}$ (Fig. 2, inset). This was presumed to occur because 2-HD binds nonspecifically to Halo, allowing noncovalent association to occur after photo-uncaging. Consistent with this assertion, in vitro 2-HD release assays in the presence of $1 \%(\mathrm{wt} / \mathrm{vol})$ SDS led to efficient liberation, whereas no liberation was observed without $\mathrm{SDS}^{56}$. In principle, the problem may be solved by the use of alternative tags, such as CLIP and SNAP tags, in place of HaloTag, along with modification of the chloroalkane unit of the photocaged precursors to the benzyl-cytosine or benzyl-guanine motif-the covalent recognition units for CLIP- and SNAP tags, respectively ${ }^{97}$.

Number of reactive motifs on LDEs-If the LDE signal houses more than one reactive group, as in the case with 4-oxononenal (ONE, Fig. 2 inset), the specificity will be lost because a reactive enone moiety is exposed within the photocaged precursor itself before photo-uncaging ${ }^{56}$. Dual photocaging of the ketone, as well as of the aldehyde of ONE, is a viable solution. For instance, protecting the aldehyde function with the anthraquinone and the ketone with an o-nitrobenzyl-derived acetal would enable simultaneous uncaging of both ketone and aldehyde. Alternatively, one could use a semistable protecting group for the ketone motif-such as an acetal-with a half-life longer than the 2-h incubation time. In this way, after 2-h incubation of cells with the photocaged precursor, light exposure would liberate the aldehyde, and unmasking of the ketone motif would happen on a similar time scale, only after photo-uncaging of the aldehyde.

Cell type and viability-Although the light source is of low energy (Fig. 2, Supplementary Fig. 1, and Supplementary Videos 1 and 2) and does not affect cellular viability within the time scale and types of cells thus far used (assessed by AlamarBlue and Trypan blue assays ${ }^{56}$ in HEK-293, COS-1 and E. coli), it is important to independently validate potential effects on cell viability. 


\section{MATERIALS \\ REAGENTS}

\section{Reagents for chemical synthesis}

- $\quad$ Ethylenediamine (Sigma-Aldrich, cat. no. E26266)

- $\quad$ Sodium hydride (Fisher Chemical, cat. no. S318 10)

- 3-Heptyn-1-ol (Sigma-Aldrich, cat. no. 630845)

- $\quad 1 \mathrm{~N} \mathrm{HCl}$ (Sigma-Aldrich, cat. no. 38283 Fluka)

- $\quad$ Magnesium sulfate, anhydrous (JT Baker, cat. no. J41620)

- $\quad$ Hexanes (Sigma-Aldrich, cat. no. 227064)

- $\quad$ Ethyl acetate (EtOAc; Sigma-Aldrich, cat. no. 270989)

- $\quad$ Diethyl ether $\left(\mathrm{Et}_{2} \mathrm{O}\right.$; Sigma-Aldrich, cat. no. 673811)

- Dichloromethane (DCM, $\mathrm{CH}_{2} \mathrm{Cl}_{2}$; Sigma-Aldrich, cat. no. 270997)

- $\quad$ Pyridinium chlorochromate (PCC; Sigma-Aldrich, cat. no. 190144)

- 1-Hydroxyanthraquinone (TCI-America, cat. no. H0354)

- 2-Propenal (Sigma-Aldrich, cat. no. 01680)

- 2-(2-(6-chlorohexyloxy)ethoxy)ethanamine (Promega, cat. no. P6711)

- Sodium thiosulfate $\left(\mathrm{Na}_{2} \mathrm{~S}_{2} \mathrm{O}_{4}\right.$; Sigma-Aldrich, cat no. 72049)

- $\quad$ Calcium chloride $\left(\mathrm{CaCl}_{2}\right.$; Sigma-Aldrich, cat no. C1016)

- $\quad$ Sulfuric acid $\left(\mathrm{H}_{2} \mathrm{SO}_{4}\right.$; Sigma-Aldrich, cat. no. 339741)

- $\quad$ Celite (Sigma-Aldrich, cat. no. 22140)

- $\quad$ Piperidine (Sigma-Aldrich, cat. no. 411027)

- $\quad$ Methyl-2-sulfinyl-acetate (Sigma-Aldrich, cat. no. 237582)

- $\quad$ Acetonitrile (ACN; Sigma-Aldrich, cat. no. 271004)

- $\quad$ Dihydropyran (DHP; Sigma-Aldrich, cat. no. D106208)

- $\quad$ Pyridinium p-toluenesulfonate (PPTS; Alfa-Aesar, cat. no. A15708)

- $\quad$ Sodium bicarbonate $\left(\mathrm{NaHCO}_{3}\right.$; Sigma-Aldrich, cat. no. S6014)

- $\quad$ Sodium sulfate (Sigma-Aldrich, cat. no. S9627)

- $\quad$ Toluene (Sigma-Aldrich, cat. no. 244511)

- Diisobutylaluminum hydride (1.0 M solution in hexanes; DIBAL-H; SigmaAldrich, cat. no. 190306)

- $\quad$ Tetrabromomethane $\left(\mathrm{CBr}_{4}\right.$; Sigma-Aldrich, cat. no. C11081)

- $\quad$ Triphenyl phosphine $\left(\mathrm{PPh}_{3}\right.$; Sigma-Aldrich, cat. no. 93092) 
- $\quad p$-Toluenesulfonic acid ( $p$-TsOH) monohydrate (Sigma-Aldrich, cat. no. 402885)

- $\quad$ Methanol (MeOH; Sigma-Aldrich, cat. no. 322415)

- $\quad$ Benzyl bromide (Sigma-Aldrich, cat. no. B17905)

- $\quad$ Potassium carbonate $\left(\mathrm{K}_{2} \mathrm{CO}_{3}\right.$; Sigma-Aldrich, cat. no. P5833)

- $\quad$ Potassium iodide (KI; Sigma-Aldrich, cat. no. P2963)

- $\quad$ Acetone (Sigma-Aldrich, cat. no. 34850)

- $\quad$ Dimethyl sulfide ( $\mathrm{Me}_{2} \mathrm{~S}$; Sigma-Aldrich, cat. no. 274380)

- 2-Methyl-2-butene (Sigma-Aldrich, cat. no. 86262)

- $\quad$ tert-Butanol ( $t$-BuOH; Sigma-Aldrich, cat. no. 471712)

- $\quad$ Sodium phosphate monohydrate $\left(\mathrm{NaH}_{2} \mathrm{PO}_{4} \cdot \mathrm{H}_{2} \mathrm{O}\right.$; Sigma-Aldrich, cat. no. S9638)

- $\quad$ Sodium chlorite $\left(\mathrm{NaClO}_{2}\right.$; Sigma-Aldrich, cat. no. 71388)

- Hydroxybenzotriazole (HOBt; Sigma-Aldrich, cat. no. 157260)

- $\quad N, N$-Diisopropylethyleneamine (DIEA; Sigma-Aldrich, cat. no. D125806)

- 1-Ethyl-3-(3-dimethylaminopropyl) carbodiimide (EDCI; Sigma-Aldrich, cat. no. E6383)

- $\quad$ Palladium on carbon (Pd/C; Sigma-Aldrich, cat. no. 205699)

- $\quad$ Tetra-n-butylammonium fluoride (TBAF; Sigma-Aldrich, cat. no. 241512)

- $\quad$ Tetrahydrofuran (THF; Sigma-Aldrich, cat. no. 401757)

- $\quad$ Dimethylformamide (DMF; Sigma-Aldrich, cat. no. 227056)

- $\quad$ Potassium permanganate $\left(\mathrm{KMnO}_{4}\right.$; Sigma-Aldrich, cat. no. 223468)

- $\quad$ Silica gel (Silicycle; cat. no. SiliaFlash P60)

- Dry ice

- $\quad$ Trifluoroacetic acid (TFA; JT Baker, cat. no. 9470-01)

- $\quad 4 \times$ Laemmli sample buffer (BioRad, cat. no. 1610747)

\section{Reagents for T-REX experiments in E. coli}

- $\quad$ pet28a-Halo-Keap1 plasmid (available from the author upon request)

- $\quad$ E. coli BL21 Codon plus (DE3) RIL competent cells (Agilent, cat. no. 230245)

- $\quad$ Tryptone (IBI Scientific, cat. no. IB49182)

- $\quad$ Yeast extract (Fisher, cat. no. BP1422-2)

- $\quad$ Agar (Fisher, cat. no. EC232-658-1)

- Chloramphenicol (Goldbio, cat. no. C-105-5) 
- $\quad$ Kanamycin (Goldbio, cat. no. K-120-5)

- $\quad$ LB-KAN agar plates (kanamycin $50 \mu \mathrm{g} / \mathrm{ml}$ )

- $\quad$ IPTG (Gold Biotechnology, cat. no. I2481C)

- $\quad$ TCEP-HCl (Goldbio, cat. no. TCEP1)

- $\quad$ Sulfo-Cy5 azide (Lumiprobe, cat. no. B3330)

- $\quad$ Copper Tris[(1-benzyl-1H-1,2,3-triazol-4-yl)methyl]amine (Cu-TBTA;

Lumiprobe, cat. no. 21050)

- HaloTag-targetable precursor to HNE(alkyne) (also known as Ht-PreHNE or HtPHA) (Fig. 10) (Steps 1-37 and Reagent Setup)

- $\quad$ HNE(alkyne) (Fig. 10) (Steps 1-11A and Reagent Setup)

- $\quad$ HEPES (Fisher, cat. no. BP310-1)

- $\quad$ OmniPur lysozyme from egg white (EMD Millipore, cat. no. 5950)

- $\quad$ Dnase-I from bovine pancrease (EMD Millipore, cat. no. 260913)

- $\quad$ DMSO (Fisher, cat. no. D128-500)

- $\quad t$-Butanol (Fisher, cat. no. A401-1)

- $\quad$ SDS (Teknova, cat. no. S9974)

- $\quad$ Copper sulfate pentahydrate (Sigma, cat. no. 209198-100G)

- $\quad \beta$-Mercaptoethanol (BME; Sigma-Aldrich, cat. no. M6250)

- $\quad$ TEV protease (see Box 4)

- Standard reagents for protein gel electrophoresis

\section{Additional reagents for recombinant protein expression in E. coli (optional)}

- $\quad$ Streptomycin B sulfate (Goldbio, cat. no. S-150-100)

- TALON metal affinity resin (Clontech, cat. no. 635502)

\section{Reagents for T-REX experiments in cultured mammalian cells}

- $\quad$ pMIR-DsRed-IRES-His 6 -Halo-Keap1 plasmid, available from Addgene (ID no. 58240)

- Halo-ORF clone library in pFN21a vector, available from Promega

- $\quad$ pcDNA3.1 myc3 Nrf2 plasmid, available from Addgene (ID no. 21555)

- $\quad$ pcDNA3 eGFP-Nrf2, available from Addgene (ID no. 21549)

- $\quad$ pMIR-Halo-PTEN plasmid, available from Addgene (ID no. 58241)

- $\quad$ pcDNA3 InPAkt plasmid (materials transfer from J. Zhang, UCSD) 
- $\quad$ HEK-293 cells (ATCC, cat. no. CRL-1573) ! CAUTION The cell lines used in your research should be regularly checked to ensure that they are authentic and that they are not infected with mycoplasma. $\triangle$ CRITICAL We expect that the procedure will work with other cell types as well.

- $\quad$ TransIT-2020 (Mirus, cat. no MIR5400)

- $\quad$ Polyethyleneimine (PEI; Polyscience, cat. no. 23966-2; see Reagent Setup)

- Standard medium for cell culture

- $\quad$ HaloTag TMR ligand (Promega, cat. no. G8251)

- $\quad$ Luciferase plasmid (Promega, cat. no. E3641)

- $\quad$ pCMV-Renilla luciferase plasmid (Promega, cat. no. E6931)

- $\quad$ ARE-GFP plasmid (Promega, CCS-0020G)

- HaloTag targetable photocaged precursor to HNE(alkyne) (also known as HtPreHNE or HtPHA; Fig. 10; Steps 1-37 and Reagent Setup)

- $\quad$ HNE(alkyne) (Fig. 10; Steps 1-11A and Reagent Setup)

- $\quad$ Quickstart Bradford 1× dye (Bio-Rad, cat. no. 5000205)

- $\quad$ BSA as standard $2 \mathrm{mg} / \mathrm{ml}$ (Pierce, cat. no. 23209)

- TCEP-HCl (Goldbio, cat. no. TCEP1)

- $\quad$ Sulfo-Cy5 azide (Lumiprobe, cat. no. B3330)

- $\quad$ Copper Tris[(1-benzyl-1H-1,2,3-triazol-4-yl)methyl]amine (Cu-TBTA;

Lumiprobe, cat. no. 21050)

- $\quad$ DMSO (Fisher, cat. no. D128-500)

- $\quad t$-Butanol (Fisher, cat. no. A401-1)

- $\quad$ SDS (Teknova, cat. no. S9974)

- $\quad$ Copper sulfate pentahydrate (Sigma, cat. no. 209198-100G)

- $\quad$ TEV protease (see Box 4)

- $\quad$ Ammonium bicarbonate (Sigma-Aldrich, cat. no. 09830)

- $\quad$ Formic acid (Sigma-Aldrich, cat. no. F0507)

- $\quad$ Iodoacetamide (Sigma-Aldrich, cat. no. I1149)

- $\quad$ Sequencing-grade modified trypsin (Promega, cat. no. V5113)

- Standard reagents for protein gel electrophoresis

- $\quad$ Standard reagents for western blotting

- $\quad$ Milk for PVDF membrane blocking (Walmart, Great Value Nonfat Instant Dry Milk) 
- $\quad$ Mouse monoclonal anti-Keap1 primary antibody, 1:5,000 (Abcam, cat. no. Ab119403)

- $\quad$ Rabbit polyclonal anti-HaloTag primary antibody, 1:2,000 (Promega, cat. no. 9281)

- $\quad$ Rabbit polyclonal anti-RRM1 primary antibody, 1:2,000 (Abcam, cat. no. Ab81085)

- $\quad$ Mouse monoclonal anti-phosphatidylinositol 3,4,5-triphosphate (PIP3, 1:500; Echelon Biosciences, cat. no. Z-P345)

- Goat anti-rabbit IgG Alexa Fluor 647 preadsorbed, 1:1,000 (Abcam, cat. no. Ab150083)

- $\quad$ Goat anti-mouse Ig, Human ads-FITC, 1:1,000 (Southern Biotech, cat. no. 1010-02)

- 4,6-Diamidino-2-phenylindole dihydrochloride (DAPI; Sigma-Aldrich, cat. no. D9542)

- $\quad$ Rabbit polyclonal anti-GFP primary antibody, 1:1,000 (Santa Cruz, cat. no. sc-8334)

- $\quad$ Mouse monoclonal anti-actin, 1:30,00 (Sigma-Aldrich, cat. no. A47000)

- $\quad$ Secondary antibody to mouse, 1:5,00 (Abcam, cat. no. Ab67890)

- $\quad$ Secondary antibody to rabbit, 1:8,000 (Abcam, cat. no. Ab97051)

\section{Reagents for making Firefly and Renilla luciferase substrates (optional)}

- $\quad$ HEPES (Fisher, cat no. BP310-1)

- $\quad$ Magnesium sulfate (JT Baker, cat. no. J41620)

- $\quad$ DTT (Goldbio, DTT100)

- $\quad$ EDTA (Fisher Chemical, cat. no. BP120-1)

- $\quad$ ATP disodium salt hydrate (Fisher Chemical, cat. no. AC102800500)

- $\quad$ Coenzyme A (Avanti, cat. no. 870700P)

- $\quad$ D-Luciferin Firefly (Goldbio, cat. no. L-123-250)

- $\quad$ Tris base (Fisher Chemical, cat. no. BP152 10)

- Trans-1,2-Diaminocyclohexane- $N, N, N^{\prime}, N^{\prime}$-tetraacetic acid monohydrate (CDTA; Alfa Aesar, cat. no. B22928-14)

- $\quad$ BSA (Fisher Chemical, cat. no. BP9703-100)

- $\quad$ Goat Serum (Sigma-Aldrich, cat. no. G9023)

- $\quad$ Triton X-100 (Fisher, cat. no. BP-151-100)

- $\quad$ Glycerol (Fisher Chemical, cat. no. BP229 4) 
- $\quad$ Sodium acetate anhydrous (USB, cat. no. 21608)

- $\quad$ Sodium sulfate (Sigma-Aldrich, cat. no. S9627)

- $\quad$ Sodium pyrophosphate (Fisher Chemical, S390-500)

- 2-(4-aminophenyl)-6-methylbenzothiazole (APMBT; Enamine, cat. no. EN300-17374)

- $\quad$ Methanol anhydrous (Sigma-Aldrich, cat. no. 322415)

- $\quad$ Coelenterazine (Goldbio, cat. no. CZ2.5)

\section{EQUIPMENT}

\section{Equipment for chemical synthesis}

- $\quad$ Fume hood

- Weighing balance

- Weighing paper

- $\quad$ Spatulas

- $\quad$ Round-bottom flasks

- Separatory funnel

- $\quad$ Graduated cylinders

- $\quad$ Pasteur pipettes

- $\quad$ Tweezers

- $\quad$ Magnetic stir plate

- $\quad$ Syringes and needles

- $\quad$ Magnetic stir bars

- $\quad$ Glass-backed thin-layer silica chromatography plates

- $\quad 365-n m$ UV lamp (Spectroline E-Series)

- Column for flash chromatography

- $\quad$ Vacuum pump

- Rotary evaporator

- Ozonator

- $\quad$ Nitrogen and Argon gas

- $\quad$ Schlenk line

\section{Equipment for T-REX experiments in E. coli}

- Standard equipment for E. coli cell culture

- Standard equipment for protein gel electrophoresis

Nat Protoc. Author manuscript; available in PMC 2017 January 24. 
- $\quad$ Cell density meter for OD measurement

- $\quad$ Centrifuge capable of spinning culture tubes

- $\quad$ Microcentrifuge tubes

- Temperature-adjustable shaker incubator

- $\quad$ Handheld UV lamp with 365-nm light (Spectroline ENF 240C)

- $\quad$ ChemiDoc-MP imaging system (Bio-Rad)

- $\quad$ Econo column (Bio-Rad, cat. no. 7374251)

- Amicon Ultra-15, MWCO 10 kDa (Millipore, cat. no. UFC901024)

- GE Healthcare Hiload 26/60 Superdex 200 prep grade column (ID no. 0823027)

- $\quad$ Äkta FPLC system (GE Healthcare)

\section{Equipment for T-REX in cultured mammalian cells}

- Standard equipment for mammalian cell culture

- $\quad$ Hand-held UV lamp with 365-nm light (Spectroline ENF 240C)

- $\quad$ Sterile 48 -well cell culture plates

- White, opaque, flat-bottom 96-well plate for luminescence measurement (Corning)

- $\quad$ Glass-bottom dishes for imaging (In Vitro Scientific, 1.5N, D35-20-1).

- $\quad$ Confocal microscope with appropriate filters

- $\quad$ Plate reader for measuring luminescence (Biotek Cytation3)

- $\quad$ Flow cytometer with appropriate lasers and filters (BD LSRII)

- $\quad$ Biosafety level 2 hood

- $\quad$ ChemiDoc-MP imaging system (Bio-Rad)

- $\quad$ Capillary liquid chromatography (CapLC) system (Waters Co.)

- $\quad$ QSTAR XL (ABSciex)

- $\quad$ Everest C18 $(5 \mu \mathrm{m}, 500 \mu \mathrm{m}$ i.d. $\times 15 \mathrm{~mm}$ (Grace)

- Jupiter C18 (3 $\mu \mathrm{m}, 100 \mu \mathrm{m}$ i.d. $\times 150$ mm (Phenomenex)

- $\quad$ Analyst QS 1.1 software (ABSciex)

\section{REAGENT SETUP}

Luria broth medium - To make Luria broth (LB) medium, add $10 \mathrm{~g}$ of $\mathrm{NaCl}, 10 \mathrm{~g}$ of tryptone and $5 \mathrm{~g}$ of yeast extract per liter. Autoclave to sterilize. Store at room temperature $\left(15-22{ }^{\circ} \mathrm{C}\right)$ up to 1 week. 
LB agar-To make LB agar, add $10 \mathrm{~g}$ of $\mathrm{NaCl}, 10 \mathrm{~g}$ of tryptone, $5 \mathrm{~g}$ of yeast extract and 15 $\mathrm{g}$ of agar per liter. Autoclave to sterilize. Add desired antibiotic and pour into a Petri dish once the LB agar is cool to touch. Store the Petri dish at $4{ }^{\circ} \mathrm{C}$ for up to 1 week.

Lysis buffer A-Lysis buffer A is $50 \mathrm{mM}$ HEPES, pH 7.6, $5 \mathrm{mM}$ imidazole and $5 \mathrm{mM}$ BME. Store all buffers at $4{ }^{\circ} \mathrm{C}$ for up to 1 week. Add reducing agent right before use.

Wash buffer A-Wash buffer A is $50 \mathrm{mM}$ HEPES, pH 7.6, $100 \mathrm{mM} \mathrm{NaCl}, 10 \mathrm{mM}$ imidazole and $5 \mathrm{mM}$ BME.

Wash buffer B-Wash buffer B is $50 \mathrm{mM}$ HEPES, $100 \mathrm{mM} \mathrm{NaCl}, 20 \mathrm{mM}$ imidazole and 5 mM BME, pH 7.6.

Elution buffer-The elution buffer is $50 \mathrm{mM}$ HEPES, pH 7.6, $100 \mathrm{mM} \mathrm{NaCl}, 200 \mathrm{mM}$ imidazole and $5 \mathrm{mM}$ BME.

LB-ampicillin-chloramphenicol medium-LB-ampicillin-chloramphenicol medium is $100 \mu \mathrm{g} / \mathrm{ml}$ of ampicillin and $30 \mu \mathrm{g} / \mathrm{ml}$ chloramphenicol in the desired volume of LB medium.

LB-kanamycin medium-LB-kanamycin medium contains $50 \mu \mathrm{g} / \mathrm{ml}$ of kanamycin in the desired volume of LB medium.

HaloTag-targetable precursor to HNE(alkyne) (also known as Ht-PreHNE or HtPHA)-Make a stock of 150-200 mM HtPHA in DMSO. Determine the concentration using a UV-visible spectrophotometer (at $25^{\circ} \mathrm{C}, \varepsilon_{366}=3,950 \mathrm{M}^{-1} \mathrm{~cm}^{-1}$ ). One-shot aliquots can be stored protected from light at $-80^{\circ} \mathrm{C}$ for $>6$ months.

HNE(alkyne)-Make a stock of 150-200 mM HNE(alkyne) in DMSO. Determine the concentration using a UV-visible spectrophotometer (at $25^{\circ} \mathrm{C}, \varepsilon_{225}=16,00 \mathrm{M}^{-1} \mathrm{~cm}^{-}$). Oneshot aliquots can be stored at $-80^{\circ} \mathrm{C}$ for $>6$ months.

$\mathrm{CuSO}_{4}$ solution-Make a $100 \mathrm{mM} \mathrm{CuSO}{ }_{4} \cdot 5 \mathrm{H}_{2} \mathrm{O}$ solution in $\mathrm{ddH}_{2} \mathrm{O}$. The solution can be stored for $>1$ year at $4{ }^{\circ} \mathrm{C}$.

TCEP solution-Make a $100 \mathrm{mM}$ TCEP-HCl solution in $50 \mathrm{mM}$ HEPES (pH 7.6). Aliquots can be stored at $-20^{\circ} \mathrm{C}$ for up to 6 months. Avoid multiple freeze-thaw cycles.

Cy5 azide-Make a $0.5 \mathrm{mM}$ Cy5 azide solution in DMSO. Divide the solution into aliquots and store them at $-20{ }^{\circ} \mathrm{C}$ for $>6$ months protected from light as one-shot aliquots.

$20 \%$ (wt/vol) SDS-Make an aqueous stock containing $10 \mathrm{~g}$ of SDS in $50 \mathrm{ml}$ of $\mathrm{ddH}_{2} \mathrm{O}$. Vortex the mixture to dissolve the contents.

Kanamycin-Make an aqueous stock containing kanamycin at a concentration of 50 $\mathrm{mg} / \mathrm{ml}$ in autoclaved $\mathrm{ddH}_{2} \mathrm{O}(1,000 \times)$ and filter-sterilize $(0.22-\mu \mathrm{m}$ filter) the solution. Aliquots can be stored at $-20{ }^{\circ} \mathrm{C}$ for $>6$ months. 
Chloramphenicol-Dissolve chloramphenicol at a concentration of $30 \mathrm{mg} / \mathrm{ml}$ in 200proof ethanol $(1,000 \times)$. Aliquots can be stored at $-20^{\circ} \mathrm{C}$ for $>6$ months.

IPTG-Make a $1 \mathrm{M}$ solution of IPTG $(1,000 \times)$ in autoclaved $\mathrm{ddH}_{2} \mathrm{O}$, and filter-sterilize $(0.22-\mu \mathrm{m}$ filter $)$ the solution before use.

Polyethyleneimine (25,000 MW linear chain)—Make an aqueous stock containing polyethyleneimine (PEI) to a concentration of $1 \mathrm{mg} / \mathrm{ml}$ in autoclaved $\mathrm{ddH}_{2} \mathrm{O}$ by heating it at $80^{\circ} \mathrm{C}$. Let the solution cool to room temperature. Adjust the $\mathrm{pH}$ of the solution to 7.0. Filtersterilize $(0.22-\mu \mathrm{m}$ filter $)$ the solution. Aliquots can be stored at $-20^{\circ} \mathrm{C}$ for $>6$ months. Avoid multiple freeze-thaw cycles.

Blocking buffer-Add $20 \mu \mathrm{l}$ of Triton X-100 to $9.5 \mathrm{ml}$ of $50 \mathrm{mM}$ HEPES, pH 7.6. Vortex the mixture to mix the contents. Add $0.5 \mathrm{ml}$ of goat serum and mix it well.

Incubation buffer-Add $20 \mu \mathrm{l}$ of Triton X-100 to $100 \mathrm{ml}$ of $50 \mathrm{mM}$ HEPES, pH 7.6. Vortex the mixture to mix the contents. Add $1 \mathrm{ml}$ of goat serum and mix the contents well.

DAPI-Make a $5 \mathrm{mg} / \mathrm{ml}$ stock DAPI solution in DMSO.

5× Passive lysis buffer-Make an aqueous stock containing $125 \mathrm{mM}$ Tris, $\mathrm{pH} 7.8,10$ $\mathrm{mM} \mathrm{1,2-CDTA,} 10 \mathrm{mM}$ DTT, $5 \mathrm{mg} / \mathrm{ml} \mathrm{BSA}$, 5\% (vol/vol) Triton X-100 and 50\% (vol/vol) glycerol in $\mathrm{ddH}_{2} \mathrm{O} .5 \times$ passive lysis buffer (PLB) can be stored at $-20^{\circ} \mathrm{C}$ for at least 2 months ${ }^{100}$.

1 $\times$ Firefly luciferase substrate-Make an aqueous stock containing $75 \mathrm{mM}$ HEPES, $\mathrm{pH}$ 8.0, $4 \mathrm{mM} \mathrm{MgSO}$, $20 \mathrm{mM}$ DTT, $0.1 \mathrm{mM}$ EDTA, $0.53 \mathrm{mM}$ ATP, $0.27 \mathrm{mM}$ coenzyme A and $0.47 \mathrm{mM}$ D-luciferin firefly in $\mathrm{ddH}_{2} \mathrm{O}$. Divide the substrate into aliquots in amber tubes. The substrate can be stored at $-80{ }^{\circ} \mathrm{C}$ for at least 2 months ${ }^{100}$.

1× Renilla luciferase buffer-Make an aqueous stock containing $7.5 \mathrm{mM}$ sodium acetate, $\mathrm{pH}$ 5.0, $400 \mathrm{mM}$ sodium sulfate, $10 \mathrm{mM}$ CDTA, $15 \mathrm{mM}$ sodium pyrophosphate and $0.025 \mathrm{mM}$ APMBT in $\mathrm{ddH}_{2} \mathrm{O}$. Divide the buffer into aliquots in microcentrifuge tubes. The buffer can be stored at $-20{ }^{\circ} \mathrm{C}$ for at least 3 months ${ }^{101}$.

$100 \times$ Renilla luciferase substrate-Dilute coelenterazine to $\sim 0.5 \mathrm{mg} / \mathrm{ml}$ in anhydrous methanol immediately upon receipt. Determine the concentration of the substrate using a UV-visible spectrophotometer. Blank the spectrophotometer with dry methanol. Measure $\mathrm{A}_{345}$. At $25^{\circ} \mathrm{C}, \varepsilon_{345}=9,800 \mathrm{M}^{-1} \mathrm{~cm}^{-1}$ in methanol. Calculate the concentration. Further dilute the stock in dry methanol to make a final concentration of $0.55 \mathrm{mM}$ coelenterazine. Aliquots of stock Renilla luciferase substrate can be stored at $-80{ }^{\circ} \mathrm{C}$ for at least 3 months ${ }^{101}$. Note: Premade substrates for luciferase assay are also available commercially (Dual-Luciferase Reporter Assay System; Promega, cat. no. E1910).

A CRITICAL Moisture can lead to decay of coelenterazine; avoid exposure to wet methanol, for example. 


\section{EQUIPMENT SETUP}

ChemiDoc-MP Imaging system setup for Cy5 florescent gel imaging-Set the

Cy5 excitation source as red epi illumination and emission filter as 695/55 filter.

\section{Automated plate reader protocol for luciferase reporter assays for AR}

pathway activation-Set up the plate reader with the following commands: inject $50 \mu \mathrm{l}$ of firefly substrate; shake the plate for $2 \mathrm{~s}$; pause for $2 \mathrm{~s}$; and read luminescence for $10 \mathrm{~s}$.

Subsequently, run the protocol. Repeat the protocol, except inject $50 \mu \mathrm{l}$ of $1 \times$ Renilla substrate into $50 \mu \mathrm{l}$ of Renilla luciferase buffer. The gain for the detector will need to be optimized based on the signal intensity.

Flow cytometer settings for GFP reporter assays for AR pathway activationRun calibration and cleaning based on the manufacturer's instructions. On the BD LSR-II, GFP is detected in the 488-1 channel with a 488-nm excitation laser, 525/50 filter and 505LP mirror for all of the experiments.

LC-MS/MS setup for the identification of LDE-modified sites on the POI-For the LC step, separate the peptides on a CapLC system coupled to a QSTAR XL. Desalt onto an Everest C18 $(5 \mu \mathrm{m}, 500 \mu \mathrm{m}$ i.d. $\times 15 \mathrm{~mm})$ with solvent A $\left(97: 3 \mathrm{H}_{2} \mathrm{O}: \mathrm{ACN}\right.$ with $0.1 \%$ ( $\mathrm{vol} / \mathrm{vol}$ ) formic acid and $0.01 \%$ ( $\mathrm{vol} / \mathrm{vol}$ ) TFA) at $40 \mu \mathrm{l} / \mathrm{min}$. After a 6 -min wash, separate the peptides on a Jupiter C18 ( $3 \mu \mathrm{m}, 100 \mu \mathrm{m}$ i.d. $\times 150 \mathrm{~mm})$ using a 40 -min linear gradient of $10 \%$ to $40 \%$ solvent B ( $85 \% \mathrm{ACN} / 10 \%$ isopropanol $+0.1 \%$ (vol $/ \mathrm{vol})$ formic acid $+0.0075 \%$ (vol/vol) TFA) at $250 \mathrm{nl} / \mathrm{min}$. In our laboratory, MS/MS data acquisition was performed using Analyst QS 1.1 software in positive ion mode for information-dependent acquisition analysis. To do this, set the nanospray voltage to $2.1 \mathrm{kV}$ for all experiments in a positive ion mode. Use nitrogen as the curtain (value of 20) with heated interface at $130{ }^{\circ} \mathrm{C}$. Set the declustering potential at $80 \mathrm{eV}$ and Gas 1 as 5 (arbitrary units). In informationdependent acquisition analysis, full-scan MS data are acquired after each survey scan from $\mathrm{m} / \mathrm{z} 350$ to 1,300 . The three highest-intensity ions above the predefined threshold of 28 counts per s with multiple charge states $(+2$ and +3 ) are selected for tandem MS (MS/MS), with rolling collision energy applied for detected ions based on different charge states and $\mathrm{m} / z$ values. Each MS/MS acquisition is completed and switched back to survey scan when the precursor intensity falls below a predefined threshold or after a maximum of $65 \mathrm{~s}$ acquisition.

\section{PROCEDURE}

A CRITICAL All chemical reactions are conducted in oven-dried glassware under an atmosphere of nitrogen unless otherwise stated. Concentration involves removal of solvents by means of a rotary evaporator (equipped with a $37-40{ }^{\circ} \mathrm{C}$ water bath) attached to a diaphragm pump (15-60 Torr), followed by removal of residual solvents at $<1$ Torr with a vacuum pump. Flash chromatography is performed on silica gel 60 (230-400 mesh): a typical purification procedure for $5 \mathrm{~g}$ of crude product uses $50 \mathrm{~g}$ of silica gel in a $4 \times 30 \mathrm{~cm}$ (diameter $\times$ length) column, and $10-\mathrm{ml}$ fractions are collected. 


\section{Synthesis of HNE (alkyne) $\bullet$ TIMING 4 d}

1) Add $2.76 \mathrm{~g}$ of $\mathrm{NaH}(69 \mathrm{mmol})$ to $26.8 \mathrm{ml}$ of ethylenediamine $(40 \mathrm{mmol})$ at $0{ }^{\circ} \mathrm{C}$ under an atmosphere of nitrogen. Stir the mixture for $1 \mathrm{~h}$ at room temperature and then for another hour at $60^{\circ} \mathrm{C}$ (Fig. 2 inset and Fig. 10).

! CAUTION NaH releases a flammable gas (hydrogen) on contact with water and other protic solvents. Keep it away from naked flames and use it in a fume hood.

2| Cool the mixture to $45^{\circ} \mathrm{C}$ and add $2 \mathrm{ml}$ of $\mathbf{1}(16.4 \mathrm{mmol})$. Heat the reaction back to $60{ }^{\circ} \mathrm{C}$ and stir it for $1 \mathrm{~h}$.

3| Slowly add $20 \mathrm{ml}$ of $1 \mathrm{~N} \mathrm{HCl}$ at $0{ }^{\circ} \mathrm{C}$, extract it with ether $(50 \mathrm{ml} \times 3)$ and dry it with magnesium sulfate ( $200 \mathrm{mg}$ or more until the newly added powder no longer clumps upon swirling).

4| Purify the residue after concentration in vacuo by using flash chromatography with hexanes:EtOAc $(2: 1 \mathrm{vol} / \mathrm{vol})$ as the eluent to obtain alcohol 2. $\left(R_{\mathrm{f}}=0.5\right.$ hexanes:EtOAC 2:1).

\section{? TROUBLESHOOTING}

- PAUSE POINT Alcohol 2 can be stored in a sealed glass vial in a $-20{ }^{\circ} \mathrm{C}$ freezer for a minimum of 6 months.

5| Dissolve $1.44 \mathrm{~g}$ of the product $2(28 \mathrm{mmol})$ in $40 \mathrm{ml}$ of $\mathrm{CH}_{2} \mathrm{Cl}_{2}$. Add $5.53 \mathrm{~g}$ of PCC (56 mmol) and stir the mixture at room temperature for $1 \mathrm{~h}$.

6| Filter the reaction mix through Celite $(\sim 10 \mathrm{~g})$.

7| Concentrate the filtrate and isolate the aldehyde $\mathbf{3}$ after separation via flash chromatography using hexanes:EtOAc $(2: 1 \mathrm{vol} / \mathrm{vol})$ as the eluent $\left(R_{\mathrm{f}}=0.45\right.$ hexanes:EtOAc 5:1).

\section{? TROUBLESHOOTING}

- PAUSE POINT Aldehyde $\mathbf{3}$ is best used immediately. If a pause is needed, $\mathbf{3}$ can be stored strictly under air-free conditions with minimal exposure to moisture, at $-80^{\circ} \mathrm{C}$ for a few days.

8| Add $1.16 \mathrm{~g}$ of aldehyde $3(10.5 \mathrm{mmol})$ and $1.73 \mathrm{ml}$ of piperidine $(17.6 \mathrm{mmol})$ to a solution of $1.74 \mathrm{~g}$ of methyl 2-phenylsulfinylacetate $(8.78 \mathrm{mmol})$ in $40 \mathrm{ml}$ of $\mathrm{CH}_{3} \mathrm{CN}$.

9| Stir the mixture overnight at room temperature. Add aqueous ammonium chloride $(10 \mathrm{ml})$ and extract the aqueous phase with $\mathrm{CH}_{2} \mathrm{Cl}_{2}(70 \mathrm{ml} \times 3)$.

10| Collect the organic layer, dry it, concentrate it and isolate ester 4 using flash chromatography with hexanes:EtOAc $(10: 1 \mathrm{vol} / \mathrm{vol})$ as the eluent $\left(R_{\mathrm{f}}=0.5\right.$ hexanes:EtOAc 10:1; stain with $\mathrm{KMnO}_{4}$; impurity at 0.95 shows as red under UV). 
- PAUSE POINT Ester 4 can be stored in a sealed glass vial in a $-20{ }^{\circ} \mathrm{C}$ freezer for a minimum of 6 months.

11 Compound $\mathbf{4}$ can be used to prepare either HNE(alkyne) or compound 8 by following the steps in options A and B, respectively.

A. Preparation of HNE(alkyne)

i. $\quad H N E(a l k y n e)$ can be prepared from 4 by reduction of ester with DIBAL-H. To do this, dissolve $0.4 \mathrm{~g}$ of ester 4 (2.2 mmol) in $20 \mathrm{ml}$ of $\mathrm{CH}_{2} \mathrm{Cl}_{2}$. Cool the mixture to $-80^{\circ} \mathrm{C}$.

ii. Dissolve $4.45 \mathrm{ml}$ of DIBAL-H (1 $\mathrm{M}$ in hexane, $4.4 \mathrm{mmol}$ ) in $20 \mathrm{ml}$ of $\mathrm{CH}_{2} \mathrm{Cl}_{2}$ and add it dropwise to the mixture. Stir it for $1 \mathrm{~h}$.

iii. Add $24.7 \mathrm{ml}$ of $1 \mathrm{~N} \mathrm{HCl}$, extract the aqueous phase with diethyl ether, dry it and concentrate it in vacuo.

iv. Isolate the pure product via flash chromatography using hexanes: $\mathrm{Et}_{2} \mathrm{O}(4: 1 \mathrm{vol} / \mathrm{vol})$ as the eluent $\left(R_{\mathrm{f}}=0.5\right.$ in hexanes: $\left.\mathrm{Et}_{2} \mathrm{O} 4: 1\right)$.

$\triangle$ CRITICAL STEP HNE(alkyne) is highly unstable in regard to air oxidation and polymerization. The purified material should be characterized promptly, and during this time it may be stored under argon at room temperature. For long-term storage (at least 1 year), $\mathrm{HNE}$ (alkyne) should be stored as one-shot aliquots in DMSO at $-80{ }^{\circ} \mathrm{C}$ and must be used immediately once thawed.

\section{? TROUBLESHOOTING}

\section{B. Preparation of Compound $8 \bullet$ TIMING $4 \mathrm{~h}$}

i. To $0.4 \mathrm{~g}$ of the ester $4(2 \mathrm{mmol})$, add $1.1 \mathrm{ml}$ of 3,4dihydropyran $(12 \mathrm{mmol})$ and $0.08 \mathrm{~g}$ of pyridinium $p$ toluenesulfonate $(0.32 \mathrm{mmol})$. Stir the mixture for $24 \mathrm{~h}$ at room temperature under argon.

ii. Add saturated $\mathrm{NaHCO}_{3}$ aqueous solution (5 ml), extract the aqueous phase with DCM $(10 \mathrm{ml} \times 3)$. Wash twice with water $(10 \mathrm{ml})$, followed by once with brine $(10 \mathrm{ml})$ and dry with $\mathrm{Na}_{2} \mathrm{SO}_{4}$ (40 mg or more, until the newly added powder no longer clumps upon swirling) to obtain $\mathbf{5}$.

- PAUSE POINT 5 can be stored in a sealed glass vial in a $-20{ }^{\circ} \mathrm{C}$ freezer for at least 6 months.

iii. Dissolve $0.5 \mathrm{~g}$ of the protected ester $5(1.8 \mathrm{mmol})$ in $20 \mathrm{ml}$ of toluene. Cool the mixture to $-80{ }^{\circ} \mathrm{C}$. 
iv. Add two equivalents of DIBAL-H (1 M in hexane) dropwise to the mixture. Stir it for $1 \mathrm{~h}$ and then add $0.5 \mathrm{ml}$ of $3 \mathrm{M}$ $\mathrm{NaOH}$.

v. Purify the desired product using flash chromatography with hexanes:EtOAc $(1: 1 \mathrm{v} / \mathrm{v})$ as the eluent to obtain 6.

PAUSE POINT 6 can be stored in a sealed vial in a $-20{ }^{\circ} \mathrm{C}$ freezer for 1 month.

vi. Brominate $0.35 \mathrm{~g}$ of the resulting alcohol $6(1.4 \mathrm{mmol})$ in 20 $\mathrm{ml}$ of distilled DCM at $4{ }^{\circ} \mathrm{C}$ by adding $0.5 \mathrm{~g}$ of $\mathrm{CBr}_{4}(1.54$ $\mathrm{mmol})$ and $0.44 \mathrm{~g}$ of $\mathrm{PPh}_{3}(1.68 \mathrm{mmol})$. Stir the mixture for 15 min.

vii. Add saturated $\mathrm{NaHCO}_{3}(50 \mathrm{ml})$, extract the aqueous phase with DCM (40 ml ×3), dry it with $\mathrm{Na}_{2} \mathrm{SO}_{4}$ (200 mg or more, until the newly added powder no longer clumps upon swirling) and concentrate it.

viii. Isolate the desired product 7 after flash chromatography using hexanes:EtOAc $(6: 1 \mathrm{vol} / \mathrm{vol})$ as the eluent.

? TROUBLESHOOTING

PAUSE POINT 7 should be promptly used in the subsequent step. Temporary storage ( $<1$ week) is possible in moisture-free conditions and at low temperature $\left(\leq-20^{\circ} \mathrm{C}\right)$.

ix. To deprotect the THP group, weigh out $0.26 \mathrm{~g}$ of $7(0.87$ $\mathrm{mmol})$, add $0.66 \mathrm{~g}$ of $p \mathrm{TsOH}(0.35 \mathrm{mmol})$ and $25 \mathrm{ml}$ of $\mathrm{MeOH}$. Stir the mixture overnight.

x. Add $\mathrm{NaHCO}_{3}(50 \mathrm{ml})$, and extract the aqueous phase with EtOAc $(40 \mathrm{ml} \times 3)$. Wash it with water $(40 \mathrm{ml})$ and concentrate it in vacuo.

xi. Isolate the desired product $\mathbf{8}$ after flash chromatography using hexanes:EtOAc ( $4: 1 \mathrm{vol} / \mathrm{vol})$ as the eluent.

PAUSE POINT 8 is immediately used in the subsequent step. Temporary storage $(<2 \mathrm{~d})$ is possible under air-and moisture-free conditions at low temperature $\left(\leq-20^{\circ} \mathrm{C}\right)$.

\section{Synthesis of the anthrahydroquinone cage 0 TIMING $3 \mathrm{~d}$}

12| Weigh out $1 \mathrm{~g}$ of 1-hydroxyanthraquinone (9) (4.46 mmol). Dissolve it in $100 \mathrm{ml}$ of $5 \% \mathrm{NaOH}$ in 1:1 MeOH: $\mathrm{ddH}_{2} \mathrm{O}$ under argon (Fig. 10).

13 Add $4.3 \mathrm{~g}$ of $\mathrm{Na}_{2} \mathrm{~S}_{2} \mathrm{O}_{4}$. Heat the mixture to $70-75^{\circ} \mathrm{C}$ for $10 \mathrm{~min}$, and then add $3.0 \mathrm{ml}$ of 2-propenal $(44.6 \mathrm{mmol})$. Heat the reaction mix and reflux it overnight.

Nat Protoc. Author manuscript; available in PMC 2017 January 24. 
14 Let the mix cool and then add it to a cold 200-ml solution of $2.5 \% \mathrm{H}_{2} \mathrm{SO}_{4}$. Extract the aqueous phase with $3 \times 50 \mathrm{ml}$ of $\mathrm{CH}_{2} \mathrm{Cl}_{2}$, combine the organic phases and dry the combined organic phases over $\mathrm{CaCl}_{2}(10 \mathrm{~g}, 48 \mathrm{~h})$.

15| Concentrate the sample in vacuo and purify the residue via flash chromatography using 2:1 hexanes: $\mathrm{CH}_{2} \mathrm{Cl}_{2}$ as the eluent to obtain 10 (ref. 102).

16) Weigh out $0.2 \mathrm{~g}$ of $\mathbf{1 0}(0.76 \mathrm{mmol})$ and dissolve it in $10 \mathrm{ml}$ of DMF.

17| Add $0.27 \mathrm{ml}$ of benzyl bromide, $0.628 \mathrm{~g}$ of potassium carbonate and $0.038 \mathrm{~g}$ of potassium iodide. Stir the mixture for $1 \mathrm{~h}$ at $65{ }^{\circ} \mathrm{C}$ and subsequently cool it to room temperature.

A color change from dark purple to orange should be observed as the reaction progresses.

18 Dilute the mixture with $50 \mathrm{ml}$ of water and extract the organic layer using $50 \mathrm{ml}$ of EtOAc.

19| Wash the organic layer with $50 \mathrm{ml}$ of water, $50 \mathrm{ml}$ of brine and $50 \mathrm{ml}$ of $1 \mathrm{~N} \mathrm{HCl}$. Dry and concentrate the mixture in vacuo to yield $\mathbf{1 1}$ as a yellow solid $\left(R_{\mathrm{f}}=0.1\right.$ hexanes:EtOAc 30:1; benzyl bromide 0.8).

- PAUSE POINT 11 can be stored in a sealed glass vial in a $-20{ }^{\circ} \mathrm{C}$ freezer for at least 6 months.

20| Dissolve $0.23 \mathrm{~g}$ of compound $11(0.65 \mathrm{mmol})$ in $50 \mathrm{ml}$ of $\mathrm{CH}_{2} \mathrm{Cl}_{2}$. Cool the solution to $-78{ }^{\circ} \mathrm{C}$ in an ice bath made using acetone and dry ice.

21 Bubble $\mathrm{O}_{3}$ through the mixture using an ozonator for $15 \mathrm{~min}$, followed by the addition of $4.5 \mathrm{ml}$ of $\mathrm{Me}_{2} \mathrm{~S}$. Allow the mixture to warm up to room temperature and let it stir for $10 \mathrm{~h}$.

! CAUTION $\mathrm{Me}_{2} \mathrm{~S}$ has a pungent stench and must be used in a fume hood.

22 Concentrate the reaction mix in vacuo. Dilute the reaction mix with $50 \mathrm{ml}$ of EtOAc and wash it with $50 \mathrm{ml}$ of water.

23 Collect the organic layer, dry it with $\mathrm{Na}_{2} \mathrm{SO}_{4}(100 \mathrm{mg}$ or more until the newly added powder no longer clumps upon swirling $)$ and concentrate it to yield $\mathbf{1 2}\left(R_{\mathrm{f}}\right.$ $=0.6$ hexanes:EtOAc 3:1).

- PAUSE POINT 12 should ideally be promptly used in the subsequent step. If a pause is required, the purified material can be stored for up to $3 \mathrm{~d}$ at $-80{ }^{\circ} \mathrm{C}$ in a moisture-free argon atmosphere.

24 Dissolve $0.23 \mathrm{~g}$ of $\mathbf{1 2}(0.645 \mathrm{mmol})$ and $9 \mathrm{ml}$ of 2-methyl-2-butene in $37.5 \mathrm{ml}$ of $t$ - $\mathrm{BuOH}$ and cool it to $0{ }^{\circ} \mathrm{C}$. Add a solution of $0.633 \mathrm{~g}$ of $\mathrm{NaH}_{2} \mathrm{PO}_{4} \cdot \mathrm{H}_{2} \mathrm{O}(4.59$ $\mathrm{mmol})$ and $0.524 \mathrm{~g}$ of $\mathrm{NaClO}_{2}(5.79 \mathrm{mmol})$ in water dropwise to the reaction mix.

25| Warm up the resulting mix at room temperature and let it stir overnight. 
26 Add $150 \mathrm{ml}$ of $0.1 \mathrm{~N}$ aqueous $\mathrm{HCl}$ and extract the aqueous phase with EtOAc $(200 \mathrm{ml} \times 3)$. Wash the organic extract with water $(200 \mathrm{ml})$ and brine $(200 \mathrm{ml})$, dry it with $\mathrm{Na}_{2} \mathrm{SO}_{4}(200 \mathrm{mg}$ or more, until the newly added powder no longer clumps upon swirling) and concentrate it in vacuo to yield $\mathbf{1 3}$ as a yellow solid $\left(R_{\mathrm{f}}=0.05\right.$ hexanes:EtOAc 3:1).

- PAUSE POINT 13 can be stored in a sealed glass vial in a $-20{ }^{\circ} \mathrm{C}$ freezer for a minimum of 1 year.

\section{Coupling of Halo linker and the anthrahydroquinone cage TIMING $1 \mathrm{~d}$}

27| Dissolve $0.24 \mathrm{~g}$ of $\mathbf{1 3}(0.65 \mathrm{mmol})$ and $0.14 \mathrm{~g}$ of 2-(2-(6chlorohexyloxy)ethoxy)ethanamine $(0.65 \mathrm{mmol})$ in $15 \mathrm{ml}$ of $\mathrm{CH}_{2} \mathrm{Cl}_{2}$, and cool the mixture to $0{ }^{\circ} \mathrm{C}$ (Fig. 10).

28| Sequentially add $0.13 \mathrm{~g}$ of HOBt $(0.78 \mathrm{mmol}), 0.22 \mathrm{ml}$ of DIEA ( $1.95 \mathrm{mmol})$ and $0.14 \mathrm{~g}$ of EDCI $(0.91 \mathrm{mmol})$. Let the mixture warm to room temperature, and stir it overnight.

29| Add water $(20 \mathrm{ml})$ and then $\mathrm{CH}_{2} \mathrm{Cl}_{2}(20 \mathrm{ml})$. Extract the organic layer with $\mathrm{CH}_{2} \mathrm{Cl}_{2}(20 \mathrm{ml} \times 3)$ and concentrate it.

30| Purify the residue via flash chromatography using hexanes:EtOAc ( $1: 2 \mathrm{vol} / \mathrm{vol})$ as the eluent to yield amide $\mathbf{1 4}$ as a yellow oil $\left(R_{\mathrm{f}}=0.3\right.$ hexanes:EtOAc 1:2).

\section{? TROUBLESHOOTING}

PAUSE POINT 14 can be stored in a sealed glass vial in a $-20{ }^{\circ} \mathrm{C}$ freezer for at least 2 years.

\section{Synthesis of HaloTag-targetable precursor to HNE (alkyne) (also known as Ht-PreHNE or HIPHA) ○ TIMING 1 d}

31 To remove the benzyl-protecting group, dissolve $0.16 \mathrm{~g}$ of $\mathbf{1 4}(0.277 \mathrm{mmol})$ in $21 \mathrm{ml}$ of EtOAc in a round-bottom flask and add $10 \% \mathrm{Pd} / \mathrm{C}(0.028 \mathrm{~g}, 0.028$ mmol; Fig. 10).

\section{? TROUBLESHOOTING}

32 Degas the mixture by sequential vacuum exposure, and then by purging with nitrogen (three times); refill the flask with hydrogen gas (1 atm) at room temperature and stir it for $1 \mathrm{~h}$.

$\triangle$ CRITICAL STEP Rigorously degassed solvent must be used to expel dissolved oxygen.

33 Filter the reaction mixture through a 4-cm-deep pad of Celite (5 g), and concentrate it to yield 15 as a yellow solid $\left(R_{\mathrm{f}}=0.5\right.$ hexanes:EtOAc 1:6).

! CAUTION Activated $\mathrm{Pd} / \mathrm{C}$ is pyrophoric; do not let the powder completely dry out when filtering (chase with excess EtOAc), and store waste in a dedicated container that is wetted with water. 
34 Dissolve $0.1 \mathrm{~g}(0.2 \mathrm{mmol})$ of phenol 15 and $0.112 \mathrm{~g}$ of TBAF $(0.4 \mathrm{mmol})$ in 2 $\mathrm{ml}$ of THF and $2 \mathrm{ml}$ of DMF.

35| Add $0.177 \mathrm{~g}$ of bromide $8(0.6 \mathrm{mmol})$ to the mixture, and stir it at room temperature overnight.

36 Add $10 \mathrm{ml}$ of water, and extract the organic layer with ethyl acetate $(20 \mathrm{ml} \times 3)$.

\section{? TROUBLESHOOTING}

37| After concentration in vacuo, purify the residue via flash chromatography using hexanes:EtOAc (1:5 vol/vol) as the eluent to yield HtPHA as a yellow solid $\left(R_{\mathrm{f}}\right.$ $=0.6$ hexanes:EtOAc 1:6).

- PAUSE POINT HtPHA should be stored as one-shot aliquots in DMSO at $-80{ }^{\circ} \mathrm{C}$ for up to 6 months protected from light; it should be used immediately once thawed, and should be handled in dim light.

\section{T-REX in live mammalian cells or in E. coli}

$\triangle$ CRITICAL The two steps of this section are transfection (Step 38) and the T-REX experiment (Step 39). For both steps, option A will give instructions for mammalian cells and option B will give instructions for E. coli

38 Express HaloTagged POIs in the cells following the steps in option A for transfecting mammalian cells and option B for transfecting E. coli cells. HaloKeap1 with a TEV cleavage site between Halo and Keap1 is used as an example of Halo fusion protein in this protocol. A hexa-histidine tag is placed before HaloTag ${ }^{57}$. Option A is carried out using HEK-293 cells cultured in an 8-cm ${ }^{2}$ adherent culture dish in a humidified atmosphere of $5 \% \mathrm{CO}_{2}$ at $37^{\circ} \mathrm{C}$. The amounts of reagents used in this procedure can be scaled up or down according to the size of the adherent culture dish that is used in experiments.

\section{A. Transient transfection of mammalian cells with PEI $\bigcirc$ TIMING 1}

h

i. Allow cells to reach $60-70 \%$ confluence at the point of transfection.

ii. $\quad$ Mix $6 \mu \mathrm{l}$ of $1 \mathrm{mg} / \mathrm{ml}$ PEI stock solution with $1.5 \mu \mathrm{g}$ of plasmid DNA (pMIR-CMV-Dsred-IRES-Halo-Keap1 in 150 $\mu \mathrm{l}$ of antibiotic-free, serum-free medium in a microcentrifuge tube. Incubate this solution for $15 \mathrm{~min}$ at room temperature.

$\triangle$ CRITICAL STEP This step will need to be modified depending on the requirements of the experiment. For LCMS/MS analysis experiments (see Step 40B), the experiment should be done in a $4 \times 21 \mathrm{~cm}^{2}$ adherent culture dish. For each $21-\mathrm{cm}^{2}$ dish, mix $12 \mu \mathrm{l}$ of $1 \mathrm{mg} / \mathrm{ml}$ PEI stock solution with $6.0 \mu \mathrm{g}$ of plasmid DNA (pMIR-CMV-Dsred-IRES-His $6^{-}$ Halo-Keap1) in $200 \mu \mathrm{l}$ of antibiotic-free, serum-free medium. 
iii. Meanwhile, aspirate the old medium from the dishes and replace it with $1.5 \mathrm{ml}$ of fresh medium. $\triangle$ CRITICAL STEP If you are using $21-\mathrm{cm}^{2}$ dishes, replace the medium with $3 \mathrm{ml}$ of fresh medium.

iv. Subsequent to a 15-min incubation period, add the plasmid DNA solution dropwise to the cells.

v. Subsequent experiments are performed $24 \mathrm{~h}$ post transfection. To do this, proceed to Step 39A.

\section{B. Transformation and cell growth of $E$. coli cells for T-REX TIMING $2 \mathrm{~h}$}

i. Transform chemically competent BL21 codon plus (DE3) RIL cells with pet28a-Halo-Keap1, and plate them on an LBkanamycin plate. Incubate the plate overnight at $37^{\circ} \mathrm{C}$.

ii. Pick one colony from the plate and inoculate $5 \mathrm{ml}$ of LBkanamycin-chloroamphenicol medium $(50 \mu \mathrm{g} / \mathrm{ml}$ kanamycin and $30 \mu \mathrm{g} / \mathrm{ml}$ chloramphenicol) with the colony. Shake the flask at 200 r.p.m. at $37^{\circ} \mathrm{C}$ overnight.

iii. Dilute the 5-ml overnight culture in another $5 \mathrm{ml}$ of LBkanamycin medium to a final OD of 0.1-0.2. Shake the culture flask at 200 r.p.m. at $37{ }^{\circ} \mathrm{C}$ until the OD value reaches $0.6-0.8$.

iv. Induce the culture with IPTG at $19^{\circ} \mathrm{C}$ to a $0.5 \mathrm{mM}$ final concentration. Shake the culture at $19^{\circ} \mathrm{C}$ overnight at 200 r.p.m.

$\triangle$ CRITICAL STEP It is important to induce expression when the OD is $0.6-0.8$.

v. Proceed to Step 39B.

39| Perform the T-REX experiment by performing the steps in option A for mammalian cells and those in option B for E. coli.

\section{A. Treatment of mammalian cells with T-REX photocaged precursor, photo-uncaging and harvest of cells 9 TIMING $4 \mathrm{~h}$}

$\triangle$ CRITICAL STEP The subsequent steps should be done under dim light.

i. Treat the cells with HtPHA for $2.5 \mathrm{~h}$ in $1.5 \mathrm{ml}$ of serum-free medium at a final concentration of $25 \mu \mathrm{M}$.

$\triangle$ CRITICAL STEP Remove the old medium. Medium that contains serum affects the uptake of T-REX photocaged precursors by cells and thus should be avoided. The solubility of the T-REX photocaged precursor is low; therefore, 
vigorous mixing during dilution of the compound (from the DMSO stock aliquot) in $37^{\circ} \mathrm{C}$ serum-free medium is required to make sure that the solution is homogeneous.

ii. Rinse three times (each time with $1.5 \mathrm{ml}$ of serum-free medium) every 30 min over $1.5 \mathrm{~h}$.

$\triangle$ CRITICAL STEP Medium should be added slowly along the side wall of the dish to prevent cells from detaching.

Adding and removing the medium should be done as gently as possible to avoid cells detaching from the culture dish, and it should be done as efficiently as possible to avoid cells being dried out during this step. Marking the point of the plate where you will add and aspirate the medium and performing all operations at that point minimizes loss of cells.

iii. For the samples designated for light exposure, remove lids from the plates and irradiate monolayered adherent cultures with 365-nm UV light for $20 \mathrm{~min}$ at room temperature (Supplementary Fig. 1 and Supplementary Video 1), and subsequently re-incubate at $37^{\circ} \mathrm{C}$ for a further $5 \mathrm{~min}$.

! CAUTION Wear UV-protective safety eyeglasses while shining light.

iv. Trypsinize the cells with $500 \mu \mathrm{l}$ of trypsin, transfer them to microcentrifuge tubes and harvest them by centrifugation at $500 \mathrm{~g}$ for $8 \mathrm{~min}$ at room temperature.

v. Wash the cell pellets twice with $1 \times$ PBS. Flash-freeze the cell pellets in liquid $\mathrm{N}_{2}$.

PAUSE POINT The cell pellets can be stored at $-80{ }^{\circ} \mathrm{C}$ for up to $3 \mathrm{~d}$.

\section{B. Treatment of bacterial cells with T-REX photocaged precursor, photo-uncaging and harvest of cells TIMING $4 \mathrm{~h}$}

$\triangle$ CRITICAL STEP The subsequent steps should be done in dim light.

i. After overnight growth, dilute the cells to an OD of 0.3-0.4 in LB-kanamycin medium.

ii. Treat the cells with $25 \mu \mathrm{M}$ HtPHA for $2 \mathrm{~h}$ while shaking them at 200 r.p.m. at $19^{\circ} \mathrm{C}$.

iii. Remove $1 \mathrm{ml}$ of cell suspension and transfer it to a microcentrifuge tube. Centrifuge the mixture at $5,000 \mathrm{~g}$ for 5 min at $4{ }^{\circ} \mathrm{C}$. Discard the supernatant. Wash the cell pellet by resuspending it in $1 \mathrm{ml}$ of PBS and centrifuging to collect the pellet. 
iv. Repeat the wash step four additional times.

v. After the fifth rinse, resuspend the cells in $500 \mu \mathrm{l}$ of PBS and irradiate them by placing the samples under a $365-\mathrm{nm}$ UV light source for $30 \mathrm{~min}$ at room temperature, while constantly shaking the samples at 80-100 r.p.m. (Supplementary Video 2).

! CAUTION Wear UV-protective safety eyeglasses while shining light.

$\triangle$ CRITICAL STEP The microcentrifuge tubes must be uncapped during irradiation.

vi. Incubate the mixture for an additional $10 \mathrm{~min}$ post light shining at room temperature.

vii. Collect the cells by centrifugation at $5,000 \mathrm{~g}$, for $5 \mathrm{~min}$ at $4{ }^{\circ} \mathrm{C}$.

PAUSE POINT Cell pellets can be stored at $-80^{\circ} \mathrm{C}$ for up to $3 \mathrm{~d}$.

\section{Downstream analyses}

40| The nature of the downstream analyses used will depend on the objectives of the experiment. Using Nrf2-AR signaling as a model response pathway, here we describe six different methods for analyzing the effects of protein-specific modification with LDEs. Option A describes how to quantify targeting efficiency using click coupling; the first step in this process is to lyse the cells (mammalian or bacterial) obtained at the end of Step 39.

Option B describes steps for liquid-chromatography-coupled tandem mass spectrometry (LC-MS/MS) analysis to determine which residue(s) on the POI are modified by HNE(alkyne). His6-Halo-Keap1, with a TEV cleavage site between Halo and Keap1, is used as an example of a Halo fusion protein that contains cysteines to be modified in this protocol. The following protocol is carried out with HEK-293 cells in a $4 \times 21 \mathrm{~cm}^{2}$ adherent culture dish. The amounts of reagents used in this protocol can be scaled up or down according to the size of the adherent culture dish used.

Options $\mathrm{C}$ and $\mathrm{D}$ describe how to evaluate the extent of downstream transcriptional activation as a consequence of targeted redox modification on a specific sensor POI upstream, either by dual-luciferase reporter assays with the use of a plate reader detecting bioluminescence in cell lysates (option C) or by GFP reporter assays with the use of a flow cytometer detecting GFP fluorescence in live cells (option D). In both cases, the Nrf2-AR transcriptional activation is used as an example readout as a result of Keap1-targeted HNEylation. 
Options $\mathrm{E}$ and $\mathrm{F}$ describe how to probe the functional downstream impact on endogenous biological entities triggered by targeted redox modification of an upstream sensor POI, either by antibody staining of the endogenous species in fixed cells (option E) or by FRET-based biosensor readout reporting cellular levels directly in live cells (option F). The measurement of changes in endogenous PIP3 phosphoinositides is used as an example of the result of targeted HNEylation of PTEN lipid phosphatase that is coupled to the accumulation of cellular PIP3 levels.

\section{A. Quantification of targeting efficiency by click coupling TIMING} $6 \mathrm{~h}$

i. For mammalian cells, add $15 \mu \mathrm{l}$ of lysis buffer, consisting of $50 \mathrm{mM}$ HEPES, $\mathrm{pH}$ 7.6, $0.3 \mathrm{mM}$ TCEP and $1 \%$ Nonidet p-40, to mammalian cell pellets from Step $2 \mathrm{~A}$ above and subject them to three cycles of freeze-thaw.

For $E$. coli cells, resuspend the cell pellet in $100 \mu \mathrm{l}$ of lysis buffer consisting of $50 \mathrm{mM}$ HEPES, $\mathrm{pH}$ 7.6, $2 \mathrm{mM}$ TCEP, $1 \%$ Nonidet p-40, $150 \mu \mathrm{g} / \mathrm{ml}$ Lysozyme and $5 \mu \mathrm{g} / \mathrm{ml}$ DNAse-I. Incubate the mixture for $20 \mathrm{~min}$ at room temperature with agitation.

A CRITICAL STEP (for mammalian cells) Make sure that the cells are resuspended well in lysis buffer.

$\triangle$ CRITICAL STEP (for E. coli cells) Do not vortex the cells after adding lysozyme or DNAse-I.

ii. Remove debris by centrifugation $(18,000 \mathrm{~g}, 8 \mathrm{~min})$ at $4{ }^{\circ} \mathrm{C}$.

iii. Measure the lysate concentration by Bradford assay relative to BSA as standard.

iv. Dilute a portion of the clarified lysate to $1 \mathrm{mg} / \mathrm{ml}$ in a final volume of $\sim 25 \mu$ l containing $50 \mathrm{mM}$ HEPES, pH 7.6, $0.3 \mathrm{mM}$ TCEP and $0.2 \mathrm{mg} / \mathrm{ml} \mathrm{His} 6_{6}-\mathrm{TEV}-\mathrm{S} 219 \mathrm{~V}$ (prepared as described in Box 4). Incubate the mixture at $37{ }^{\circ} \mathrm{C}$ for $45 \mathrm{~min}$.

$\triangle$ CRITICAL STEP The optimal concentration of lysate protein is $\sim 1.0 \mathrm{mg} / \mathrm{ml}$. A high concentration of lysate protein causes failure of click coupling. Precipitates may appear upon

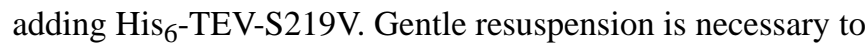
ensure the success of click coupling. For samples without light exposure, $\mathrm{His}_{6}$-TEV-S219V should be omitted.

v. For click coupling in a final volume of $\sim 30 \mu \mathrm{l}$, add the following reagents to a final concentration of $1.7 \mathrm{mM}$ TCEP, $5 \%$ (vol/vol) t-BuOH, $1 \%$ (wt/vol) SDS, $1 \mathrm{mM} \mathrm{CuSO}_{4}, 0.1$ $\mathrm{mM}$ TBTA, $10 \mu \mathrm{M}$ Cy5 azide and the TEV protease-treated 
lysate above. Incubate the resulting mixture at $37^{\circ} \mathrm{C}$ for 30 min.

$\triangle$ CRITICAL STEP All the concentrations above are critical to the success of click coupling. Mix well to make sure that the solution is homogeneous. Generally, SDS is needed to obtain good results.

vi. Quench with $5 \mu \mathrm{l}$ of $4 \times$ Laemmli buffer that contains $6 \%$ (vol/ vol) BME, and further incubate for $5 \mathrm{~min}$ at $37{ }^{\circ} \mathrm{C}$. Load $20 \mu \mathrm{l}$ into each well of a $10 \%(\mathrm{wt} / \mathrm{vol})$ polyacrylamide gel, and resolve by electrophoresis.

$\triangle$ CRITICAL STEP $4 \times$ Laemmli buffer should be warmed in advance to ensure homogeneity. Fresh SDS-PAGE buffer should be used to reduce the background signal. It is recommended that the wells of polyacrylamide gel (remove buffer in the wells using a P-200 Pipetman with a loading tip, repeat for 4-5 times) be rinsed before loading the samples with fresh SDS-PAGE buffer to enhance the signal-to-noise ratio.

vii. Upon completion of the gel electrophoresis, rinse the gel with $20 \mathrm{ml}$ of $\mathrm{ddH}_{2} \mathrm{O}(\times 2,5 \mathrm{~min})$ and analyze for a Cy5 signal using a ChemiDoc-MP imaging system (Bio-Rad; see Equipment Setup). Any alternative fluorescence gel imager platforms can be used in this step.

$\triangle$ CRITICAL STEP Rinsing reduces the background signal. It is recommended that the gel be rinsed several times and that it be analyzed after each rinse to obtain the optimal result (highest signal-to-noise ratio).

viii. Transfer the gel to a PVDF membrane for western blot analysis. After transfer is complete, block the membrane with $10 \%$ (wt/vol) milk in Tris-buffered saline containing $0.2 \%$ (vol/vol) Tween 20 (i.e., TBST), and then probe it with antiKeap1 and anti-actin antibodies (see materials list for dilutions).

ix. Use the following equation to calculate the targeting efficiency:

$$
\left[\frac{C y 5_{x} / W B_{x}}{\left(C y 5_{y}-C y 5_{\text {Halo }}\right) / W B_{y}}\right] \times 100 \%
$$

where $\mathrm{Cy} 5_{\mathrm{x}}$ is the amount of Cy 5 signal from the target protein in the sample exposed to light; $\mathrm{WB}_{\mathrm{x}}$ is the amount of 
western blot signal on the target protein in the sample exposed to light; $\mathrm{Cy} 5 \mathrm{y}$ is the amount of Cy5 signal on the Halo-fusion protein in the sample not exposed to light; $\mathrm{Cy} 5_{\mathrm{Halo}}$ is the amount of Cy5 signal on the Halo protein in the sample exposed to light; $\mathrm{WB}_{\mathrm{y}}$ is the amount of western blot signal on the Halo-fusion protein in the sample not exposed to light.

x. In our laboratory, Bio-Rad Image Lab software is used to quantify the intensities of the $\mathrm{Cy} 5$ and western blot signals. If you are also using this software, open your Cy5 or western blot image using the software. From the 'Analysis Tool Box', pick 'Volume Tools' followed by 'Rectangle'. Draw rectangles of the same sizes around each of the desired bands. Draw another rectangle of the same size in an area without any bands, and use this for background subtraction.

(Designate this rectangle as the background by doubleclicking and choosing 'background'.) Under the 'Subtraction Method' menu, choose 'Global'. Click on 'Analysis table' to generate the quantitated signal intensities corresponding to your selected bands. Export the analysis table to Excel. Use the 'Adjusted volume' values as the signal intensities of your desired bands.

\section{? TROUBLESHOOTING}

\section{B. LC-MS/MS analysis of modified cysteines TIMING 2-3 d}

$\triangle$ CRITICAL STEP The starting material for option B is prepared as described in Steps 38A and 39A.

i. Enrichment of (His-tagged) protein from mammalian cells. Harvest confluent monolayer cultures of cells from $4 \times 21$ $\mathrm{cm}^{2}$ cultured plates.

PAUSE POINT While immediate lysing is recommended, as HNE modifications are unstable, if a pause is needed the cell pellets can be flash-frozen in liquid $\mathrm{N}_{2}$ and stored at $-80{ }^{\circ} \mathrm{C}$ for up to $3 \mathrm{~d}$.

ii. Pool the pellets and lyse them in $100 \mu$ of lysis buffer A with 3 cycles of rapid freeze-thaw.

$\triangle$ CRITICAL STEP Make sure that the cells are resuspended well in lysis buffer A.

iii. Remove debris by centrifugation at $18,000 \mathrm{~g}$ for $8 \mathrm{~min}$ at $4{ }^{\circ} \mathrm{C}$.

iv. Equilibrate a $20-\mu \mathrm{l}$ bed volume of TALON resin by washing it three times with $500 \mu \mathrm{l}$ of lysis buffer A. 
v. Determine the lysate concentration using a Bradford assay with BSA as standard.

vi. Dilute the lysate to $1.0 \mathrm{mg} / \mathrm{ml}$ with lysis buffer $\mathrm{A}$, and add it to the TALON resin in a $1.7-\mathrm{ml}$ centrifuge tube.

Incubate the suspension in the dark at $4{ }^{\circ} \mathrm{C}$ for $1.5 \mathrm{~h}$ with endover-end rotation.

$\triangle$ CRITICAL STEP A high concentration of lysate protein enhances nonspecific binding, and therefore incorporates impurities into the final pulled-down Keap1. A portion of clarified lysate (typically $5-10 \mu \mathrm{l}$ ) should be saved before treatment with TALON resin to confirm the modification of cysteines by electrophiles using click coupling. See Steps 3 and $40 \mathrm{~A}$ above.

vii. Centrifuge the sample at $500 \mathrm{~g}$ for $3 \mathrm{~min}$ at $4{ }^{\circ} \mathrm{C}$. Remove the supernatant and add $360 \mu \mathrm{l}$ of wash buffer $\mathrm{A}$ to the resin. Incubate the suspension in the dark at $4{ }^{\circ} \mathrm{C}$ for 3 min with end-over-end rotation.

$\triangle$ CRITICAL STEP Do not remove any resin in this step or subsequent steps.

viii. Remove the supernatant after centrifugation at $500 \mathrm{~g}$ for $3 \mathrm{~min}$ at $4{ }^{\circ} \mathrm{C}$. Add $240 \mu \mathrm{l}$ of wash buffer B, followed by incubation in the dark at $4{ }^{\circ} \mathrm{C}$ for $3 \mathrm{~min}$ with end-over-end rotation.

ix. Repeat Step 40B(viii) above.

x. Remove the wash buffer after centrifugation at $500 \mathrm{~g}$ for $3 \mathrm{~min}$ at $4{ }^{\circ} \mathrm{C}$. Add $25 \mu \mathrm{l}$ of elution buffer and incubate the resin in the dark at $4{ }^{\circ} \mathrm{C}$ for $5 \mathrm{~min}$ with end-over-end rotation.

$\triangle$ CRITICAL STEP The supernatant from the wash step should be removed thoroughly to maximize the yield of His $_{6}$ Halo-Keap1 in the elution.

xi. Collect the eluent after centrifugation at $18,000 \mathrm{~g}$ for $3 \mathrm{~min}$ at $4{ }^{\circ} \mathrm{C}$. Mix the eluent with $4 \times$ Laemmli buffer with $6 \%$ (vol/ vol) $\mathrm{BME}$, incubate it for $5 \mathrm{~min}$ at $37{ }^{\circ} \mathrm{C}$ and resolve it on a $10 \%$ SDS-PAGE gel. Stain the gel with Coomassie R-250 stain (or freshly prepared Colloidal Coomassie G-250 stain for enhanced sensitivity) for 24-48 h until the desired sensitivity is achieved.

xii. Rinse the gel with $\mathrm{ddH}_{2} \mathrm{O}$ for $30 \mathrm{~min}$, and excise the band corresponding to $\mathrm{His}_{6}$-Halo-Keap1.

PAUSE POINT The gel slices can be stored at $-80{ }^{\circ} \mathrm{C}$ with $50 \mu \mathrm{l}$ of ddH2O for up to 2 weeks. 
xiii. LC-MS/MS analysis. Wash the gel pieces with $100 \mu \mathrm{l}$ of $\mathrm{ddH}_{2} \mathrm{O}$. Remove and discard water.

xiv. Add $100 \mu \mathrm{l}$ (50:50) of $100 \mathrm{mM} \mathrm{NH}_{4} \mathrm{HCO}_{3}(\mathrm{pH}$

7.8):acetonitrile to the gel pieces and let them sit for $10 \mathrm{~min}$. Remove and discard the liquid.

xv. Add $50 \mu \mathrm{l}$ of acetonitrile and let the sample sit for $5 \mathrm{~min}$. Remove and discard acetonitrile. Dry the gel pieces in a fume hood for $10 \mathrm{~min}$.

xvi. Reduce the proteins with $5 \mathrm{mM}$ TCEP in $50 \mathrm{mM} \mathrm{NH}_{4} \mathrm{HCO}_{3}$ solution, pH 7.8, for $45 \mathrm{~min}$ at $37^{\circ} \mathrm{C}$ and alkylate with $20 \mathrm{mM}$ iodoacetamide in $50 \mathrm{mM} \mathrm{NH}_{4} \mathrm{HCO}_{3}$ in the dark for $45 \mathrm{~min}$.

$\triangle$ CRITICAL STEP Use of TCEP instead of DTT is very important, as DTT can reduce labeling of proteins by LDEs.

xvii. Repeat Step 40B(xiii-xv).

xviii. Rehydrate the gel pieces by adding $60 \mu \mathrm{l}(10 \mu \mathrm{g} / \mathrm{ml}$ solution $)$ of trypsin in $50 \mathrm{mM} \mathrm{NH}_{4} \mathrm{HCO}_{3}, \mathrm{pH} 7.8$; keep on ice for 30 min and then at $37^{\circ} \mathrm{C}$ overnight.

xix. To stop the enzymatic reaction, add formic acid to a final concentration of $1 \%$. Remove and save the supernatant.

xx. Add $120 \mu \mathrm{l}$ of $50 \%$ acetonitrile containing $5 \%$ (vol/vol) formic acid to the trypsinized gel pieces. Let the sample sit for $45 \mathrm{~min}$. Sonicate the sample for $5 \mathrm{~min}$. Remove the supernatant and combine it with the supernatant from Step 40B(xix).

xxi. Repeat Step 40B(xx).

xxii. Add $90 \%$ acetonitrile containing 5\% (vol/vol) formic acid. Let the sample sit for $5 \mathrm{~min}$. Remove and combine the supernatants. Dry the supernatant under vacuum.

xxiii. Resuspend peptides in $60 \mu \mathrm{l}$ of $0.1 \%$ ( $\mathrm{vol} / \mathrm{vol}$ ) formic acid and inject the solution into the LC system described in the Equipment Setup section of the Protocol.

xxiv. Collect LC-MS/MS data using the setup described in the Equipment Setup section of the Protocol.

$\triangle$ CRITICAL STEP To prevent loss of modification, the ionization temperature should not be too high (in this case it should be $130^{\circ} \mathrm{C}$ ).

xxv. After data acquisition, combine the individual MS/MS spectra acquired for each of the precursors within a single LC run, 
smoothen, de-isotope using an Analyst 'script', mascot.dll, to create a peak list and save the peak list to a file.

xxvi. Subsequently, use the peak list file to query the NCBI human subdatabase and contaminations using Mascot 2.4 from Matrix Science (London, UK) with the following parameters: peptide mass tolerance, $0.3 \mathrm{Da}$; MS/MS ion mass tolerance, 0.3 Da. Allow up to two missed cleavages. In our case, several variable modifications were applied, including methionine oxidation and cysteine carbamidomethylation, along with electrophile Michael adduct, reduced electrophile Michael adduct, dehydrated electrophile Michael adduct, dehydrated electrophile (1,2)-addition adduct or electrophile Michael adduct in Schiff-based form on cysteine residues ${ }^{56}$. Only significant scores for the peptides, defined by Mascot probability analysis (http://www.matrixscience.com/help/ scoring_help.html\#PBM) as greater than 'identity' with $95 \%$ confidence, should be considered for the peptide identification and modification site determinations.

xxvii. Manually inspect and validate all MS/MS spectra for the identified peptides with HNE-type modifications.

xxviii. To approximate the extent of modifications on a given site, extract the modified peptide signal (XIC) from the chromatogram and compare it with the XIC of the unmodified peptide.

\section{? TROUBLESHOOTING}

\section{Analysis using Luciferase reporter assay for evaluating AR activation TIMING $3 \mathrm{~d}$ \\ A CRITICAL STEP Option C starts with a new transfection.}

i. Transient transfection using TransIT-2020. Plate HEK-293 cells in a 48 -well plate $\left(0.9-\mathrm{cm}^{2}\right.$ surface area). For a single well, seeding $\sim 5 \times 10^{4}$ cells in $300 \mu$ of complete cell culture medium should result in cells that are $50-60 \%$ confluent after $24 \mathrm{~h}$, which is optimal for transfection with TransIT-2020. It is important to have at least triplicate samples for each condition. If you are seeding in multiple wells, make a stock of $1.5 \times 10^{5}$ cells $/ \mathrm{ml}$ and add $300 \mu \mathrm{l}$ of the stock to each well after careful suspension.

$\triangle$ CRITICAL STEP A cell density that is too low or too high may result in excessive cell death or poor transfection efficiency, respectively. 
ii. Premix ARE-Firefly Luciferase plasmid and pCMV-Renilla luciferase plasmid in a 40:1 ratio by mass. Transfect the cells with the following plasmids: premixed 40:1 AREFirefly:pCMV Renilla luciferase plasmids, pCMV HaloKeap1 and pcDNA3.1 myc-Nrf2.

iii. For transient transfection of cells in a single well of a 48-well plate, in $26 \mu \mathrm{l}$ of antibiotic-free, serum-free medium, add 120 ng of each plasmid (Halo-Keap1 and myc-Nrf2) and $120 \mathrm{ng}$ of the ARE-Firefly:pCMV Renilla luciferase plasmid mix (360 $\mathrm{ng}$ total), followed by the addition of $0.78 \mu \mathrm{l}$ of TransIT-2020. The solution should be mixed gently and incubated at room temperature for $20 \mathrm{~min}$.

$\triangle$ CRITICAL STEP The amounts of DNA and TransIT-2020 reagent may need to be optimized for different cell lines.

iv. Subsequent to the 20-min incubation, The resultant lipoplex should be added dropwise to the cells in complete medium.

v. Subsequent steps should be performed $24 \mathrm{~h}$ post transfection.

vi. Treatment of cells with T-REX photocaged precursor and photo-uncaging. Treat the cells as described in Step 39A, except:

Cells should be treated with the T-REX photocaged precursor at a concentration of $25 \mu \mathrm{M}$ in $300 \mu \mathrm{l}$ of serum-free medium; rinsing should be performed with $300 \mu$ of serum-free medium; and post light shining, the cells should be incubated for $18 \mathrm{~h}$ before measuring luciferase activity.

vii. Measurement of luciferase activity. To analyze the level of AR activation using a luciferase reporter assay, wash the cells with $150 \mu \mathrm{l}$ of $1 \times$ PBS.

$\triangle$ CRITICAL STEP PBS should be added dropwise along the side walls of the wells to prevent cells from detaching.

viii. Lyse cells by adding $65 \mu \mathrm{l}$ of $1 \times$ PLB (ref. 101) and incubating them at room temperature on a shaker for $15-20$ $\min$.

A CRITICAL STEP Lysate should not be left at room temperature for longer than $1 \mathrm{~h}$.

ix. Meanwhile, thaw the Firefly substrate and prepare $1 \times$ Renilla luciferase substrate by adding the $100 \times$ coelenterazine stock in methanol in $1 \times$ Renilla luciferase buffer (ref. 102). 
x. Pipette out $20 \mu \mathrm{l}$ of the well-mixed lysate into a 96-well white opaque plate (Corning) for measuring chemiluminescence. Read the Firefly luciferase signal on a plate reader (in our case, a BioTek Cytation 3-cell imaging multimode microplate reader was used) after adding $50 \mu$ of Firefly luciferase substrate. Subsequently, read the Renilla luciferase signal after adding $50 \mu \mathrm{l}$ of the $1 \times$ Renilla substrate.

$\triangle$ CRITICAL STEP If handling multiple wells simultaneously, an automated dispenser can be used to add Firefly and Renilla luciferase substrates in order to minimize decay of signal intensity.

xi. Analyze the data by calculating the ratio of Firefly luciferase signal intensity to Renilla luciferase signal.

\section{? TROUBLESHOOTING}

\section{Analysis using a GFP reporter assay for evaluating AR activation \\ TIMING 3 d}

A CRITICAL STEP Option D starts with a new transfection.

i. Transient transfection using TransIT-2020. Perform the transfection as described in Step 40C(i).A brief description is as follows: transfect the cells with ARE:GFP, pFN21a-HaloKeap1 and pcDNA3.1 myc-Nrf2 in a 3:1:1 ratio by mass. For transient transfection of cells in a single well of a 48-well plate, to $26 \mu \mathrm{l}$ of antibiotic-free, serum-free medium, add 156 ng of ARE::GFP, 52 ng of pFN21a-Halo-TEV-Keap1 and 52 ng of pcDNA3.1 myc-Nrf2 (260 ng total), followed by the addition of $0.78 \mu \mathrm{l}$ of TransIT-2020. The lipoplex should be mixed gently and incubated at room temperature for $20 \mathrm{~min}$.

A CRITICAL STEP It is important to use plasmids that do not express another fluorescent protein.

ii. Subsequent to $20 \mathrm{~min}$ of incubation, the lipoplex should be added dropwise onto the cells.

iii. The following steps are performed $24 \mathrm{~h}$ post transfection.

iv. Treatment of cells with T-REX photocaged precursor and photo-uncaging. Treat the cells with photocaged precursor, as described in Step 40C(vi).

v. Measurement of the GFP fluorescence using flow cytometry. Set up the flow cytometer equipment.

vi. Harvest the cells by adding $100 \mu \mathrm{l}$ of trypsin TrypLE and incubating them at room temperature for $1 \mathrm{~min}$. Transfer the cell solution to an FACS tube and rinse the well with another 
$900 \mu \mathrm{l}$ of FACS buffer. Resuspend the culture several times to ensure a single-cell suspension before loading onto the flow cytometer.

vii. Perform the flow cytometry experiment to determine the GFP signal. Measure at least 10,000 events per well.

viii. Data analysis. Any cytometry software can be used to process the data. Here, we used FlowJo (v 10).

\section{? TROUBLESHOOTING}

\section{E. Immunofluorescence analysis TIMING $4 \mathrm{~d}$}

i. Transient transfection using TransIT-2020. Split HEK-293 cells into four 35-mm glass-bottom dishes. For each dish, seeding $\sim 4 \times 10^{5}$ cells in $2.0 \mathrm{ml}$ of total cell culture medium should result in cells that are $\sim 40-50 \%$ confluent after $24 \mathrm{~h}$, which represents optimal cell density.

A CRITICAL STEP A cell density that is too low or too high may result in excessive cell death or poor transfection efficiency, respectively. Higher cell density is also not optimal for imaging.

ii. Transfect each plate with 2,000 ng of Halo-PTEN plasmid. Transfect with TransIT-2020 according to the manufacturer's protocol.

iii. The subsequent steps should be performed $24-36 \mathrm{~h}$ post transfection.

iv. Treatment of cells with T-REX photocaged precursor, photouncaging and cell fixation. Treat the cells with photocaged precursor, as described in Step 39A. The amounts of reagents used should be scaled up for a $4 \times 35 \mathrm{~mm}$ adherent culture dish.

v. After shining light on the sample, incubate the plates at $37^{\circ} \mathrm{C}$ for $10 \mathrm{~h}$.

vi. Aspirate old medium and wash the sample once gently with $1.5 \mathrm{ml}$ of $1 \times$ PBS. Fix the cells by adding $1.5 \mathrm{ml}$ of $2 \%$ formaldehyde (prechilled at $4{ }^{\circ} \mathrm{C}$ ). Incubate the plates for 20 $\min$ at $4{ }^{\circ} \mathrm{C}$.

vii. Aspirate formaldehyde. Add $1.5 \mathrm{ml}$ of $1 \times$ PBS to the plates.

- PAUSE POINT Fixed cells can be stored at $4{ }^{\circ} \mathrm{C}$ for up to 2 weeks.

viii. Permeabilization of cell membrane and antibody binding. Aspirate PBS from the plates. 
Add $1.5 \mathrm{ml}$ of blocking-permeabilization buffer to each plate. Incubate the plates at $37^{\circ} \mathrm{C}$ for $1 \mathrm{~h}$.

ix. Meanwhile, prepare antibodies to Halo $(1: 1,000)$ and PIP3 (1:500) in $600 \mu \mathrm{l}$ of incubation buffer.

x. Remove blocking-permeabilization buffer, wash the cells once with $50 \mathrm{mM}$ HEPES, pH 7.6, and add $150 \mu \mathrm{l}$ of primary antibody solution. Add primary antibody solution only in the recessed region in order to minimize the amount of antibody usage. Incubate the mixture for $2 \mathrm{~h}$ at room temperature.

xi. Gently remove the primary antibody solution using a pipette. The solution can be stored at $4{ }^{\circ} \mathrm{C}$ and reused.

xii. Wash the cells by adding $1.5 \mathrm{ml}$ of $1 \times \mathrm{PBS}$ to the plates. Incubate them at $37^{\circ} \mathrm{C}$ for $5 \mathrm{~min}$. Aspirate the PBS and repeat the rinse step two additional times.

xiii. Prepare 1:1,000 dilutions of fluorophore-conjugated secondary antibodies in $600 \mu \mathrm{l}$ of PBS with $0.02 \%$ Triton $\mathrm{X}-100$.

A CRITICAL STEP Avoid exposure of fluorophoreconjugated antibodies to stray light.

xiv. Add $150 \mu \mathrm{l}$ of secondary antibody solution to each plate. Incubate the cells for $1 \mathrm{~h}$ at room temperature, protected from light.

xv. Remove the secondary antibody solution and add $1.5 \mathrm{ml}$ of $1 \times$ PBS to the plates. Incubate the cells at $37^{\circ} \mathrm{C}$ for $5 \mathrm{~min}$. Aspirate the PBS and repeat the rinse step two additional times.

xvi. Prepare a $1 \mu \mathrm{g} / \mathrm{ml}$ dilution of DAPI in $1 \times$ PBS. Add $1.5 \mathrm{ml}$ of DAPI solution to the plates. Incubate the cells for $1 \mathrm{~min}$ at room temperature. Aspirate and rinse the plates once with $1 \times$ PBS.

- PAUSE POINT Cells can be imaged immediately or they can be stored protected from light at $4{ }^{\circ} \mathrm{C}$ in $1 \times$ PBS for $1-2$ d.

xvii. Imaging and data analysis. Image cells using a confocal microscope according to the instruments protocol. (In our case, a Zeiss 710 confocal microscope was used for image acquisition.)

xviii. Images should be analyzed using ImageJ software (NIH). Briefly, the average green fluorescence intensity (intensity of signal due to PIP3) for each cell should be determined by 
drawing a free-hand circle around the image. This should be repeated for each condition such that 50-100 cells are analyzed each time from multiple different frames. A global average of the green fluorescence intensity should be calculated for each condition, and then these values can be plotted and analyzed using Prism.

A CRITICAL STEP To get reliable results, it is important to collect images from at least 50 individual cells per condition.

\section{F. FRET analysis TIMING $4 \mathrm{~d}$}

A CRITICAL STEP Option F starts with a new transfection.

i. Transient transfection using TransIT-2020. See Step 40E(i and ii).

ii. Transfect each plate with 1,000 ng of Halo-PTEN and 1,000 ng of InPAkt reporter plasmid. Transfect with TransIT-2020 according to the manufacturer's protocol.

iii. The subsequent steps are performed $24-36 \mathrm{~h}$ post transfection.

iv. Treatment of cells with T-REX photocaged precursor, photouncaging and cell fixation. Treat the cells with photocaged precursor, as described in Step 39A. The amounts of reagents used should be scaled up for a $4 \times 35 \mathrm{~mm}$ adherent culture dish.

v. Irradiate the cells with UV light for only $3 \mathrm{~min}$. Incubate the plates at $37^{\circ} \mathrm{C}$ for $10 \mathrm{~h}$.

$\triangle$ CRITICAL STEP A longer irradiation time will result in photobleaching of the FRET reporter proteins.

vi. Imaging and data analysis. Image cells using a confocal microscope according to the previously described protocol ${ }^{89}$. In our laboratory, a blue laser (408 nm) is used for excitation. Record the signals in the cyan channel (463-498 nm) and the yellow channel $(525-620 \mathrm{~nm})$.

vii. Analyze the images using ImageJ software. To do this, determine the average cyan and yellow fluorescence intensity for each cell by drawing a free-hand circle around the image. Repeat this for each condition such that 150-200 cells are analyzed each time from multiple different frames. Calculate the ratio of mean yellow to mean cyan fluorescence intensity for each condition, and then plot these values and analyze the results using Prism. 
$\triangle$ CRITICAL STEP To get reliable results, it is important to collect images from at least 150 individual cells per condition.

\section{? TROUBLESHOOTING}

Troubleshooting advice can be found in Table 1.

\section{- TIMING}

Steps 1-11A, chemical synthesis of HNE(alkyne): $4 \mathrm{~d}$

Step 11B, preparation of compound $\mathbf{8}: 4 \mathrm{~h}$

Steps 12-26, synthesis of the anthrahydroquinone cage: $3 \mathrm{~d}$

Steps 27-30, coupling of Halo linker and the anthrahydroquinone cage: $1 \mathrm{~d}$

Steps 31-37, synthesis of HaloTag-targetable precursor to HNE(alkyne) (also known as HtPreHNE or HtPHA): $1 \mathrm{~d}$

Step 38A, transient transfection of mammalian cells with polyethylenimine (PEI): $1 \mathrm{~h}$

Step 38B, transformation and cell growth of E. coli cells for T-REX: $2 \mathrm{~h}$

Step 39A, treatment of mammalian cells with T-REX photocaged precursor, photo-uncaging and harvest of cells: $4 \mathrm{~h}$

Step 39B, treatment of bacterial cells with T-REX photocaged precursor, photo-uncaging and harvest of cells: $4 \mathrm{~h}$

Step 40A, targeting efficiency quantification: $6 \mathrm{~h}$

Step 40B, LC-MS/MS analysis of modified cysteines: $2-3 \mathrm{~d}$ h (including enrichment of (his-tagged) protein from mammalian cells, $4 \mathrm{~h}$; and LC-MS/MS analysis, 2-3 d)

Step 40C, dual-luciferase reporter assays evaluating AR pathway activation: $3 \mathrm{~d}$ (including transient transfection using TransIT-2020, $1 \mathrm{~h}$; treatment of cells with T-REX photocaged precursor and photo-uncaging, $4 \mathrm{~h}$; and measurement of luciferase activity, $2 \mathrm{~h}$ )

Step 40D, analysis using a GFP reporter assay for evaluating AR pathway activation: $3 \mathrm{~d}$ (including transient transfection using TransIT-2020, $1 \mathrm{~h}$; treatment of cells with T-REX photocaged precursor and photo-uncaging, $4 \mathrm{~h}$; and measurement of GFP fluorescence using flow cytometry, $2 \mathrm{~h}$ )

Step 40E, immunofluorescence analysis, $4 \mathrm{~d}$ (including transient transfection using TransIT-2020, $1 \mathrm{~h}$; treatment of cells with T-REX photocaged precursor, photo-uncaging and cell -fixation, $4 \mathrm{~h}$; permeabilization of cell membrane and antibody binding, $6 \mathrm{~h}$; and imaging and data analysis, $6 \mathrm{~h}$ ) 
Step 40F, FRET analysis: $4 \mathrm{~d}$ (including transient transfection using TransIT-2020, $1 \mathrm{~h}$; treatment of cells with T-REX photocaged precursor, photo-uncaging and cell fixation, $4 \mathrm{~h}$; and imaging and data analysis: $6 \mathrm{~h}$ )

\section{ANTICIPATED RESULTS}

\section{Analytical data}

HNE(alkyne) (see Fig. 2 inset and Fig. 10 for chemical structure)- ${ }^{1} \mathrm{H}-\mathrm{NMR}$ (300 MHz) $\delta 1.50-1.76(4 \mathrm{H}, \mathrm{m}), 1.92(1 \mathrm{H}, \mathrm{t}, J=2.7 \mathrm{~Hz}), 2.19(2 \mathrm{H}, \mathrm{dt}, J=2.7,6.3 \mathrm{~Hz}), 2.61(1 \mathrm{H}$, br), 4.39-4.44 (1H, m), 6.25 (H, ddd, $J=1.2,7.8,15.9 \mathrm{~Hz}), 6.79(1 \mathrm{H}, \mathrm{dd}, J=4.5,15.6 \mathrm{~Hz})$, $9.50(1 \mathrm{H}, \mathrm{d}, J=7.5 \mathrm{~Hz}) .{ }^{13} \mathrm{C}-\mathrm{NMR}(75 \mathrm{MHz}) \delta 18.1,24.0,35.1,69.1,70.4,83.8,130.7$, 159.2, 193.9.

HtPHA (also known as Ht-PreHNE) (see Fig. 10 for chemical structure)- ${ }^{1} \mathrm{H}-$ NMR spectroscopy (0.02 g, 24\% yield): ${ }^{1} \mathrm{H}-\mathrm{NMR}(300 \mathrm{MHz}) \delta 1.59-1.69(4 \mathrm{H}, \mathrm{m}), 1.96$ $(1 \mathrm{H}, \mathrm{t}, J=2.1 \mathrm{~Hz}), 2.23-2.26(2 \mathrm{H}, \mathrm{m}), 3.57(2 \mathrm{H}, \mathrm{d}, J=6.6 \mathrm{~Hz}), 4.23-4.29(1 \mathrm{H}, \mathrm{m}), 4.55$ $(2 \mathrm{H}, \mathrm{d}, J=5.7 \mathrm{~Hz}), 5.10-5.18(2 \mathrm{H}, \mathrm{m}), 5.91-6.16(3 \mathrm{H}, \mathrm{m}), 7.64(1 \mathrm{H}, \mathrm{d}, J=7.8 \mathrm{~Hz}), 7.75-$ $7.79(2 \mathrm{H}, \mathrm{m}), 8.10-8.12(1 \mathrm{H}, \mathrm{d}, J=8.1 \mathrm{~Hz}), 8.24-8.29(2 \mathrm{H}, \mathrm{m}) .{ }^{13} \mathrm{C}-\mathrm{NMR}(75 \mathrm{MHz}) \delta 18.3$, 24.3, 34.4, 35.9, 68.6, 71.7, 74.3, 84.2, 117.2, 123.6, 124.7, 126.2, 126.7, 127.2, 131.2, 131.4, 133.5, 134.2, 134.8, 135.6, 135.8, 137.1, 142.7, 157.2, 182.7, 183.1. LRMS (LDI) calculated for $\mathrm{C}_{26} \mathrm{H}_{24} \mathrm{O}_{4} 400.2\left(\mathrm{M}^{+}\right)$, found 400.1 .

\section{TEV purification}

The typical yield of TEV protease is $0.5 \mathrm{mg}$ of pure protein per gram of cell pellet.

\section{In-gel fluorescence to determine labeling}

Typical labeling results with HNE are shown in Figures 4a, 5b and 6a and Supplementary Figure 4a. Targeting efficiency (calculated using the equation shown in Step 40A(ix)) ranges from 10 to $40 \%$.

\section{Supplementary Material}

Refer to Web version on PubMed Central for supplementary material.

\section{Acknowledgments}

\footnotetext{
We thank the laboratories of T. Evans (Weill Cornell Medicine, New York) and J. Zhang (University of California, San Diego) for plasmids encoding zebrafish $h s p b 7$ and the lnPAkt (PIP3-reporter) construct, respectively. We acknowledge all of the Aye Laboratory members who have contributed to T-REX redox targeting protocols, particularly J. Li, X. Fang and Y. Fu, as well as Q. Lin of the State University of New York at Albany for assistance with the LC-MS/MS analysis of modifications on the protein pulled down from cells. Funding was provided by the NIH Director's New Innovator award (1DP2GM114850), the National Science Foundation (NSF) CAREER award (CHE-1351400), the Beckman Young Investigator award and the Sloan Research Fellowship (to Y.A.) and the Burroughs Wellcome Funds CTRG (to principal investigator (PI) Y.A. and host T. Evans). S.P. is a Howard Hughes Medical Institute international predoctoral fellow (59108350). J.A.H. acknowledges the CBI training grant (T32GM008500, PI - H. Lin). V.N.P. thanks the Douglas family for an undergraduate research fellowship. D.K.L. thanks the Cornell University P3 scholars program. Imaging and flow cytometry data were acquired at the Cornell University Biotechnology Resource Center (NIH 1S10RR025502) and the Cornell University cytometry core (supported in part by the Empire State Stem Cell Fund), respectively. We acknowledge the NSF (NSF MRI: CHE-1531632 to Y.A. (PI)) for NMR instrumentation support at Cornell University.
} 


\section{References}

1. Jacob, C., Winyard, PG. Redox Signaling and Regulation in Biology and Medicine. Wiley-VCH; 2009.

2. Stadtman ER. Protein oxidation and aging. Science. 1992; 257:1220-1224. [PubMed: 1355616]

3. Schopfer FJ, Cipollina C, Freeman BA. Formation and signaling actions of electrophilic lipids. Chem. Rev. 2011; 111:5997-6021. [PubMed: 21928855]

4. Winterbourn CC. Reconciling the chemistry and biology of reactive oxygen species. Nat. Chem. Biol. 2008; 4:278-286. [PubMed: 18421291]

5. Murphy MP, et al. Unraveling the biological roles of reactive oxygen species. Cell Metab. 2011; 13:361-366. [PubMed: 21459321]

6. Holmstrom KM, Finkel T. Cellular mechanisms and physiological consequences of redox-dependent signalling. Nat. Rev. Mol. Cell Biol. 2014; 15:411-421. [PubMed: 24854789]

7. Jacobs AT, Marnett LJ. Systems analysis of protein modification and cellular responses induced by electrophile stress. Acc. Chem. Res. 2010; 43:673-683. [PubMed: 20218676]

8. Delmastro-Greenwood M, Freeman BA, Wendell SG. Redox-dependent anti-inflammatory signaling actions of unsaturated fatty acids. Annu. Rev. Physiol. 2014; 76:79-105. [PubMed: 24161076]

9. Crunkhorn S. Deal watch: Abbott boosts investment in NRF2 activators for reducing oxidative stress. Nat. Rev. Drug Discov. 2012; 11:96.

10. Dinkova-Kostova AT, Kostov RV. Glucosinolates and isothiocyanates in health and disease. Trends Mol. Med. 2012; 18:337-347. [PubMed: 22578879]

11. Gupta SC, Patchva S, Aggarwal BB. Therapeutic roles of curcumin: lessons learned from clinical trials. AAPS J. 2013; 15:195-218. [PubMed: 23143785]

12. Fernandez-Fernandez B, Ortiz A, Gomez-Guerrero C, Egido J. Therapeutic approaches to diabetic nephropathy--beyond the RAS. Nat. Rev. Nephrol. 2014; 10:325-346. [PubMed: 24802062]

13. Bomprezzi R. Dimethyl fumarate in the treatment of relapsing-remitting multiple sclerosis: an overview. Ther. Adv. Neurol. Disord. 2015; 8:20-30. [PubMed: 25584071]

14. Hermann C, Zeiher AM, Dimmeler S. Shear stress inhibits $\mathrm{H}_{2} \mathrm{O}_{2}$-induced apoptosis of human endothelial cells by modulation of the glutathione redox cycle and nitric oxide synthase. Arterioscler Thromb. Vasc. Biol. 1997; 17:3588-3592. [PubMed: 9437209]

15. De Keulenaer GW, et al. Oscillatory and steady laminar shear stress differentially affect human endothelial redox state: role of a superoxide-producing NADH oxidase. Circ. Res. 1998; 82:10941101. [PubMed: 9622162]

16. Cunningham KS, Gotlieb AI. The role of shear stress in the pathogenesis of atherosclerosis. Lab. Invest. 2005; 85:9-23. [PubMed: 15568038]

17. Kim SK, Woodcroft KJ, Oh SJ, Abdelmegeed MA, Novak RF. Role of mechanical and redox stress in activation of mitogen-activated protein kinases in primary cultured rat hepatocytes. Biochem. Pharmacol. 2005; 70:1785-1795. [PubMed: 16242670]

18. Lehoux S. Redox signalling in vascular responses to shear and stretch. Cardiovasc Res. 2006; 71:269-279. [PubMed: 16780820]

19. Sundaresan M, Yu ZX, Ferrans VJ, Irani K, Finkel T. Requirement for generation of $\mathrm{H}_{2} \mathrm{O}_{2}$ for platelet-derived growth factor signal transduction. Science. 1995; 270:296-299. [PubMed: 7569979]

20. Bae YS, Oh H, Rhee SG, Yoo YD. Regulation of reactive oxygen species generation in cell signaling. Mol. Cells. 2011; 32:491-509. [PubMed: 22207195]

21. Schieber M, Chandel NS. ROS function in redox signaling and oxidative stress. Curr. Biol. 2014; 24:R453-R462. [PubMed: 24845678]

22. Brewer TF, Garcia FJ, Onak CS, Carroll KS, Chang CJ. Chemical approaches to discovery and study of sources and targets of hydrogen peroxide redox signaling through NADPH oxidase proteins. Annu. Rev. Biochem. 2015; 84:765-790. [PubMed: 26034893]

23. Brownlee M. Biochemistry and molecular cell biology of diabetic complications. Nature. 2001; 414:813-820. [PubMed: 11742414] 
24. Green K, Brand MD, Murphy MP. Prevention of mitochondrial oxidative damage as a therapeutic strategy in diabetes. Diabetes. 2004; 53(Suppl. 1):S110-S118. [PubMed: 14749275]

25. Nishikawa T, Araki E. Impact of mitochondrial ROS production in the pathogenesis of diabetes mellitus and its complications. Antioxid. Redox Signal. 2007; 9:343-353. [PubMed: 17184177]

26. Weerapana E, et al. Quantitative reactivity profiling predicts functional cysteines in proteomes. Nature. 2010; 468:790-795. [PubMed: 21085121]

27. Codreanu SG, et al. Alkylation damage by lipid electrophiles targets functional protein systems. Mol. Cell. Proteomics. 2014; 13:849-859. [PubMed: 24429493]

28. Wang C, Weerapana E, Blewett MM, Cravatt BF. A chemoproteomic platform to quantitatively map targets of lipid-derived electrophiles. Nat. Methods. 2014; 11:79-85. [PubMed: 24292485]

29. Niphakis MJ, et al. A global map of lipid-binding proteins and their ligandability in cells. Cell. 2015; 161:1668-1680. [PubMed: 26091042]

30. Yang J, Tallman KA, Porter NA, Liebler DC. Quantitative chemoproteomics for site-specific analysis of protein alkylation by 4-hydroxy-2-nonenal in cells. Anal. Chem. 2015; 87:2535-2541. [PubMed: 25654326]

31. Kim HY, Tallman KA, Liebler DC, Porter NA. An azido-biotin reagent for use in the isolation of protein adducts of lipid-derived electrophiles by streptavidin catch and photorelease. Mol. Cell Proteomics. 2009; 8:2080-2089. [PubMed: 19483245]

32. Furdui CM, Poole LB. Chemical approaches to detect and analyze protein sulfenic acids. Mass Spectrom. Rev. 2014; 33:126-146. [PubMed: 24105931]

33. Yang J, Carroll KS, Liebler DC. The expanding landscape of the thiol redox proteome. Mol. Cell Proteomics. 2016; 15:1-11. [PubMed: 26518762]

34. Codreanu SG, Zhang B, Sobecki SM, Billheimer DD, Liebler DC. Global analysis of protein damage by the lipid electrophile 4-hydroxy-2-nonenal. Mol. Cell Proteomics. 2009; 8:670-680. [PubMed: 19054759]

35. Rossi A, et al. Anti-inflammatory cyclopentenone prostaglandins are direct inhibitors of IkappaB kinase. Nature. 2000; 403:103-108. [PubMed: 10638762]

36. Straus DS, et al. 15-deoxy-delta 12,14-prostaglandin J2 inhibits multiple steps in the NF-kappa B signaling pathway. Proc. Natl. Acad. Sci. USA. 2000; 97:4844-4849. [PubMed: 10781090]

37. Ji C, Kozak KR, Marnett LJ. IkappaB kinase, a molecular target for inhibition by 4-hydroxy-2nonenal. J. Biol. Chem. 2001; 276:18223-18228. [PubMed: 11359792]

38. Rudolph TK, Freeman BA. Transduction of redox signaling by electrophile-protein reactions. Sci. Signal. 2009; 2:re7. [PubMed: 19797270]

39. Diab A, et al. Peroxisome proliferator-activated receptor-gamma agonist 15 -deoxy-Delta(12,14)prostaglandin $\mathrm{J}(2)$ ameliorates experimental autoimmune encephalomyelitis. J. Immunol. 2002; 168:2508-2515. [PubMed: 11859145]

40. Uchida K. Redox-derived damage-associated molecular patterns: ligand function of lipid peroxidation adducts. Redox Biol. 2013; 1:94-96. [PubMed: 24024141]

41. Cubillos-Ruiz JR, et al. ER stress sensor XBP1 controls anti-tumor immunity by disrupting dendritic cell homeostasis. Cell. 2015; 161:1527-1538. [PubMed: 26073941]

42. Doyle K, Fitzpatrick FA. Redox signaling, alkylation (carbonylation) of conserved cysteines inactivates class I histone deacetylases 1, 2, and 3 and antagonizes their transcriptional repressor function. J. Biol. Chem. 2010; 285:17417-17424. [PubMed: 20385560]

43. Fritz KS, et al. 4-Hydroxynonenal inhibits SIRT3 via thiol-specific modification. Chem. Res. Toxicol. 2011; 24:651-662. [PubMed: 21449565]

44. Galligan JJ, et al. Stable histone adduction by 4-oxo-2-nonenal: a potential link between oxidative stress and epigenetics. J. Am. Chem. Soc. 2014; 136:11864-11866. [PubMed: 25099620]

45. Kondo M, et al. 15-Deoxy-Delta(12,14)-prostaglandin J(2): the endogenous electrophile that induces neuronal apoptosis. Proc. Natl. Acad. Sci. USA. 2002; 99:7367-7372. [PubMed: 12032289]

46. Jacobs AT, Marnett LJ. HSF1-mediated BAG3 expression attenuates apoptosis in 4hydroxynonenal-treated colon cancer cells via stabilization of anti-apoptotic Bcl-2 proteins. J. Biol. Chem. 2009; 284:9176-9183. [PubMed: 19179333] 
47. Chipuk JE, et al. Sphingolipid metabolism cooperates with BAK and BAX to promote the mitochondrial pathway of apoptosis. Cell. 2012; 148:988-1000. [PubMed: 22385963]

48. Droge W. Free radicals in the physiological control of cell function. Physiol. Rev. 2002; 82:47-95. [PubMed: 11773609]

49. Foyer, C.Faragher, R., Thornalley, P., editors. Redox Metabolism and Longevity Relationships in Animals and Plants. Taylor \& Francis; 2009.

50. Stadtman ER, Berlett BS. Reactive oxygen-mediated protein oxidation in aging and disease. Chem. Res. Toxicol. 1997; 10:485-494. [PubMed: 9168245]

51. Dalleau S, Baradat M, Gueraud F, Huc L. Cell death and diseases related to oxidative stress: 4hydroxynonenal (HNE) in the balance. Cell Death Differ. 2013; 20:1615-1630. [PubMed: 24096871]

52. Levine RL. Carbonyl modified proteins in cellular regulation, aging, and disease. Free Radic. Biol. Med. 2002; 32:790-796. [PubMed: 11978480]

53. Dalle-Donne I, Rossi R, Colombo R, Giustarini D, Milzani A. Biomarkers of oxidative damage in human disease. Clin. Chem. 2006; 52:601-623. [PubMed: 16484333]

54. Paulsen CE, Carroll KS. Cysteine-mediated redox signaling: chemistry, biology, and tools for discovery. Chem. Rev. 2013; 113:4633-4679. [PubMed: 23514336]

55. Fang X, et al. Temporally controlled targeting of 4-hydroxynonenal to specific proteins in living cells. J. Am. Chem. Soc. 2013; 135:14496-14499. [PubMed: 24015839]

56. Lin HY, Haegele JA, Disare MT, Lin Q, Aye Y. A generalizable platform for interrogating targetand signal-specific consequences of electrophilic modifications in redox-dependent cell signaling. J. Am. Chem. Soc. 2015; 137:6232-6244. [PubMed: 25909755]

57. Parvez S, et al. Substoichiometric hydroxynonenylation of a single protein recapitulates wholecell-stimulated antioxidant response. J. Am. Chem. Soc. 2015; 137:10-13. [PubMed: 25544059]

58. Janssen DB. Evolving haloalkane dehalogenases. Curr. Opin. Chem. Biol. 2004; 8:150-159. [PubMed: 15062775]

59. Los GV, Wood K. A novel technology for cell imaging and protein analysis. Methods Mol. Biol. 2007; 356:195-208. [PubMed: 16988404]

60. Los GV, et al. HaloTag: a novel protein labeling technology for cell imaging and protein analysis. ACS Chem. Biol. 2008; 3:373-382. [PubMed: 18533659]

61. Ohana RF, et al. HaloTag7: a genetically engineered tag that enhances bacterial expression of soluble proteins and improves protein purification. Protein Expr. Purif. 2009; 68:110-120. [PubMed: 19464373]

62. Long MJC, Poganik JR, Aye Y. On-demand targeting: investigating biology with proximitydirected chemistry. J. Am. Chem. Soc. 2016; 138:3610-3622. [PubMed: 26907082]

63. Rogakou EP, Pilch DR, Orr AH, Ivanova VS, Bonner WM. DNA double-stranded breaks induce histone H2AX phosphorylation on serine 139. J. Biol. Chem. 1998; 273:5858-5868. [PubMed: 9488723]

64. Morgan MJ, Liu ZG. Crosstalk of reactive oxygen species and NF-kappaB signaling. Cell Res. 2011; 21:103-115. [PubMed: 21187859]

65. Tjalkens RB, Cook LW, Petersen DR. Formation and export of the glutathione conjugate of 4hydroxy-2, 3-E-nonenal (4-HNE) in hepatoma cells. Arch. Biochem. Biophys. 1999; 361:113-119. [PubMed: 9882435]

66. Volkel W, et al. Glutathione conjugates of 4-hydroxy-2(E)-nonenal as biomarkers of hepatic oxidative stress-induced lipid peroxidation in rats. Free Radic. Biol. Med. 2005; 38:1526-1536. [PubMed: 15890627]

67. Banerjee, R. Redox Biochemistry. Wiley; 2007.

68. Cao Z, Hardej D, Trombetta LD, Li Y. The role of chemically induced glutathione and glutathione S-transferase in protecting against 4-hydroxy-2-nonenal-mediated cytotoxicity in vascular smooth muscle cells. Cardiovasc. Toxicol. 2003; 3:165-177. [PubMed: 14501034]

69. Kolb HC, Finn MG, Sharpless KB. Click chemistry: diverse chemical function from a few good reactions. Angew. Chem. Int. Ed. Engl. 2001; 40:2004-2021. [PubMed: 11433435] 
70. Aye Y, Li M, Long MJC, Weiss RS. Ribonucleotide reductase and cancer: biological mechanisms and targeted therapies. Oncogene. 2015; 34:2011-2021. [PubMed: 24909171]

71. Hayes JD, Dinkova-Kostova AT. The Nrf2 regulatory network provides an interface between redox and intermediary metabolism. Trends Biochem. Sci. 2014; 39:199-218. [PubMed: 24647116]

72. Kobayashi A, et al. Oxidative stress sensor Keap1 functions as an adaptor for Cul3-based E3 ligase to regulate proteasomal degradation of Nrf2. Mol. Cell Biol. 2004; 24:7130-7139. [PubMed: 15282312]

73. Krief S, et al. Identification and characterization of cvHsp: a novel human small stress protein selectively expressed in cardiovascular and insulin-sensitive tissues. J. Biol. Chem. 1999; 274:36592-36600. [PubMed: 10593960]

74. Rosenfeld GE, Mercer EJ, Mason CE, Evans T. Small heat shock proteins Hspb7 and Hspb12 regulate early steps of cardiac morphogenesis. Dev. Biol. 2013; 381:389-400. [PubMed: 23850773]

75. Marvin M, et al. Developmental expression patterns of the zebrafish small heat shock proteins. Dev. Dyn. 2008; 237:454-463. [PubMed: 18161059]

76. Ma Q. Role of nrf2 in oxidative stress and toxicity. Annu. Rev. Pharmacol. Toxicol. 2013; 53:401426. [PubMed: 23294312]

77. Sporn MB, Liby KT. NRF2 and cancer: the good, the bad and the importance of context. Nat. Rev. Cancer. 2012; 12:564-571. [PubMed: 22810811]

78. Garber K. Biochemistry: a radical treatment. Nature. 2012; 489:S4-S6. [PubMed: 23013714]

79. Uchida K, Stadtman ER. Modification of histidine residues in proteins by reaction with 4hydroxynonenal. Proc. Natl. Acad. Sci. USA. 1992; 89:4544-4548. [PubMed: 1584790]

80. Uchida K, Stadtman ER. Covalent attachment of 4-hydroxynonenal to glyceraldehyde-3-phosphate dehydrogenase. A possible involvement of intra- and intermolecular cross-linking reaction. J. Biol. Chem. 1993; 268:6388-6393. [PubMed: 8454610]

81. Nadkarni DV, Sayre LM. Structural definition of early lysine and histidine adduction chemistry of 4-hydroxynonenal. Chem. Res. Toxicol. 1995; 8:284-291. [PubMed: 7766813]

82. Papa A, et al. Cancer-associated PTEN mutants act in a dominant-negative manner to suppress PTEN protein function. Cell. 2014; 157:595-610. [PubMed: 24766807]

83. Covey TM, Edes K, Coombs GS, Virshup DM, Fitzpatrick FA. Alkylation of the tumor suppressor PTEN activates Akt and $\beta$-catenin signaling: a mechanism linking inflammation and oxidative stress with cancer. PLoS One. 2010; 5:e13545. [PubMed: 20975834]

84. Shearn CT, et al. Increased carbonylation of the lipid phosphatase PTEN contributes to Akt2 activation in a murine model of early alcohol-induced steatosis. Free Radic. Biol. Med. 2013; 65:680-692. [PubMed: 23872024]

85. Shearn CT, et al. Phosphatase and tensin homolog deleted on chromosome 10 (PTEN) inhibition by 4-hydroxynonenal leads to increased Akt activation in hepatocytes. Mol. Pharmacol. 2011; 79:941-952. [PubMed: 21415306]

86. Leslie NR, Foti M. Non-genomic loss of PTEN function in cancer: not in my genes. Trends Pharmacol. Sci. 2011; 32:131-140. [PubMed: 21236500]

87. Trotman LC, et al. Pten dose dictates cancer progression in the prostate. PLoS Biol. 2003; 1:E59. [PubMed: 14691534]

88. Covey TM, Edes K, Fitzpatrick FA. Akt activation by arachidonic acid metabolism occurs via oxidation and inactivation of PTEN tumor suppressor. Oncogene. 2007; 26:5784-5792. [PubMed: 17369849]

89. Ananthanarayanan B, Ni Q, Zhang J. Signal propagation from membrane messengers to nuclear effectors revealed by reporters of phosphoinositide dynamics and Akt activity. Proc. Natl. Acad. Sci. USA. 2005; 102:15081-15086. [PubMed: 16214892]

90. Antal CE, Newton AC. Spatiotemporal dynamics of phosphorylation in lipid second messenger signaling. Mol. Cell Proteomics. 2013; 12:3498-3508. [PubMed: 23788531]

91. Doudna JA, Charpentier E. Genome editing. The new frontier of genome engineering with CRISPR-Cas9. Science. 2014; 346:1258096. [PubMed: 25430774] 
92. Fellmann CL, Scott W. Stable RNA interference rules for silencing. Nat. Cell Biol. 2014; 16:1018. [PubMed: 24366030]

93. Assou S, et al. Dynamic changes in gene expression during human early embryo development: from fundamental aspects to clinical applications. Hum. Reprod. Update. 2011; 17:272-290. [PubMed: 20716614]

94. García-Santamarina S, et al. Monitoring in vivo reversible cysteine oxidation in proteins using ICAT and mass spectrometry. Nat. Protoc. 2014; 9:1131-1145. [PubMed: 24743420]

95. Lo Conte M, Lin J, Wilson MA, Carroll KS. A chemical approach for the detection of protein sulfinylation. ACS Chem. Biol. 2015; 10:1825-1830. [PubMed: 26039147]

96. Yang J, et al. Global in situ, site-specific analysis of protein S-sulfenylation. Nat. Protoc. 2015; 10:1022-1037. [PubMed: 26086405]

97. Gautier A, et al. An engineered protein tag for multiprotein labeling in living cells. Chem. Biol. 2008; 15:128-136. [PubMed: 18291317]

98. Grune T, Siems WG, Zollner H, Esterbauer H. Metabolism of 4-hydroxynonenal, a cytotoxic lipid peroxidation product, in Ehrlich mouse ascites cells at different proliferation stages. Cancer Res. 1994; 54:5231-5235. [PubMed: 7923145]

99. Srivastava S, et al. Metabolism of the lipid peroxidation product, 4-hydroxy-trans-2-nonenal, in isolated perfused rat heart. J. Biol. Chem. 1998; 273:10893-10900. [PubMed: 9556565]

100. Blankespoor RL, et al. Photochemistry of 1-alkoxy- and 1-(benzyloxy)-9,10-anthraquinones in methanol: a facile process for the preparation of aldehydes and ketones. J. Org. Chem. 1995; 60:6852-6859.

101. Wood, KV. Luciferase Assay Method. US patent. 5,283,179. 1994.

102. Sherf, BA., Wood, KV., Schenborn, ET. Quenching Reagents and Assays for Enzyme-mediated Luminescence. US patent. 5,744,320. 1998.

103. Grune T, Davies KJA. The proteasomal system and HNE-modified proteins. Mol. Aspects Med. 2003; 24:195-204. [PubMed: 12892997] 
Box 1

Live imaging: assessment of complete HaloTag conjugation (i.e., blocking experiment with HaloTag TMR ligand) - TIMING 2 d

\section{Transient transfection using TransIT-2020}

i. Split HEK-293 cells in two 35-mm glass-bottom dishes. For each dish, seeding $\sim 4 \times 10^{5}$ cells in $2.0 \mathrm{ml}$ of total cell culture medium should result in cells that are $\sim 40-50 \%$ confluent after $24 \mathrm{~h}$, which is optimal.

$\triangle$ CRITICAL STEP A cell density that is too low or too high may result in excessive cell death or poor transfection efficiency, respectively. Higher cell density is also not optimal for imaging.

ii. Transfect cells with the HaloTag-conjugated POI using TransIT-2020 according to the manufacturer's protocol.

iii. The subsequent steps should be performed 24-36 $\mathrm{h}$ post transfection.

\section{Blocking with HaloTag TMR (Halo-TMR) ligand and imaging}

$\triangle$ CRITICAL STEP The following steps should be performed under dim light.

i. Treat the cells in one dish with HtPHA in $2 \mathrm{ml}$ of serum-free medium. The protocol for treatment with the T-REX photocaged precursor is identical to that in Step 39A(i-ii).

ii. Treat the second dish with serum-free medium containing DMSO instead.

iii. Rinse both sets of cells three times (each time with $1.5 \mathrm{ml}$ of serum-free medium) every $30 \mathrm{~min}$ over $1.5 \mathrm{~h}$.

iv. After the third rinse cycle, remove the rinse medium from both dishes and replace it with $2 \mathrm{ml}$ of serum-free medium containing $3 \mu \mathrm{M}$ Halo-TMR ligand (both dishes).

$\triangle$ CRITICAL STEP Make sure that the Halo-TMR ligand is thoroughly mixed by pipetting up and down at least $8-10$ times.

v. Incubate the cells for $1-2 \mathrm{~h}$ at $37^{\circ} \mathrm{C}$.

vi. Rinse $3 \times$ with $1.5 \mathrm{ml}$ of serum-free medium.

vii. Image cells using a confocal microscope according to the instruments protocol. (In our case, a Zeiss 710 confocal microscope was used for image acquisition. Images were analyzed using ImageJ software.) 
Box 2

Functional assay for Halo-Keap1 binding to Nrf2 TIMING $2 \mathrm{~d}$

\section{Transient transfection using TransIT-2020}

i. Split HEK-293 cells in two 35-mm glass-bottom dishes. For each dish, seeding $\sim 4 \times 10^{5}$ cells in 2.0 -ml total cell culture medium should result in cells that are $\sim 40-50 \%$ confluent after $24 \mathrm{~h}$, which represents optimal cell density.

$\triangle$ CRITICAL STEP A cell density that is too low or too high may result in excessive cell death or poor transfection efficiency, respectively. Higher cell density is also not optimal for imaging.

ii. Transfect one plate with 1,500 ng of eGFP-Nrf2 plasmids and transfect the second plate with $750 \mathrm{ng}$ of eGFP-Nrf2 and $750 \mathrm{ng}$ of pMIR-DsRed-IRESHalo-Keap1. Transfect with TransIT-2020 according to the manufacturer's protocol.

iii. Incubate the cells at $37^{\circ} \mathrm{C}$ for $24-36 \mathrm{~h}$ in a humidified incubator in the presence of a $5 \% \mathrm{CO}_{2}$ atmosphere, and then proceed with imaging and data analysis.

\section{Imaging and data analysis}

i. Image cells using a confocal microscope according to the instrument's protocol. (In our case, a Zeiss 710 confocal microscope was used for image acquisition.)

ii. Images were analyzed using ImageJ software. Briefly, the average green fluorescence intensity in the nucleus ( $F_{\text {nucleus }}$ ) was quantified by tracing a free-hand circle around the nucleus. Next, the average green florescence intensity of the cytosol was measured by tracing a free-hand circle around the cytosol, excluding the nucleus. The ratio of nuclear to cytosolic green fluorescence was subsequently calculated.

$\triangle$ CRITICAL STEP To get reliable results, it is important to collect images from at least 100 individual cells per condition. 
Box 3

Blockage of pathway activation by HaloTag nonfused control: analysis using western blotting $\bigcirc$ TIMING $4 \mathrm{~d}$

Transient transfection using polyethylenimine (PEI; PolyScience) TIMING 1 d

i. Plate HEK-293 cells in a $35-\mathrm{mm}\left(8 \mathrm{~cm}^{2}\right.$ surface area) dish. For a $35-\mathrm{mm}$ dish, seeding $\sim 7 \times 10^{5}$ cells in $1.5 \mathrm{ml}$ of total cell culture medium should result in cells that are $\sim 70 \%$ confluent after $24 \mathrm{~h}$, which is optimal for transfection with PEI.

A CRITICAL STEP A cell density that is too low or too high may result in excessive cell death or poor transfection efficiency, respectively.

ii. Transfect the cells with $500 \mathrm{ng}$ of each of the following plasmids: pMIRDsred-IRES-Halo-HA, pMIR-DsRed-IRES-His-Keap1 and pcDNA3.1 mycNrf2. For transient transfection using PEI, see Section 2, Step 38A above.

Treatment of cells with T-REX photocaged precursor, photo-uncaging and harvest of cells

i. Perform Section 2, Step 39A, except harvest the cells $4 \mathrm{~h}$ post illumination.

\section{SDS-PAGE and western blotting}

i. Lyse cells by adding $30 \mu \mathrm{l}$ of freshly prepared and prechilled lysis buffer and subjecting them to 3 flash freeze-thaw cycles.

$\triangle$ CRITICAL STEP Make sure that the cells are resuspended well in lysis buffer.

ii. Remove debris by centrifugation $(18,000 \mathrm{~g}, 8 \mathrm{~min})$ at $4{ }^{\circ} \mathrm{C}$. Determine protein concentration using the Bradford assay using BSA as standard. Analyze $\sim 30$ $\mu \mathrm{g}$ of lysate protein by SDS-PAGE and western blotting using a standard protocol. 
Box 4

His6-TEV-S219V expression and purification - TIMING 4-5 d

Expression of His $_{6}$-TEV-S219V in E. coli

i. Transform chemically competent BL21 (DE3) RIL cells with His6-TEVS219V (Addgene, Plasmid no. 8827), and plate it on an LB-ampicillin-agar $(100 \mu \mathrm{g} / \mathrm{ml})$ plate. Incubate the plate overnight at $37^{\circ} \mathrm{C}$.

ii. Pick a single colony from the plate and inoculate it with $5 \mathrm{ml}$ of LBampicillin-chloramphenicol medium. Shake the flask at 200 r.p.m. at $37{ }^{\circ} \mathrm{C}$ overnight.

iii. Dilute the 5-ml overnight culture in 1 liter of LB-kanamycin medium in a 2liter flask. Shake the culture flask at 200 r.p.m. at $37^{\circ} \mathrm{C}$ until the OD value reaches $0.6-0.8$.

iv. Induce the culture with IPTG to a $1 \mathrm{mM}$ final concentration. Shake the culture at $37^{\circ} \mathrm{C}$ for $6 \mathrm{~h}$ at 200 r.p.m.

$\triangle$ CRITICAL STEP For maximal protein yield, it is important to induce expression when the OD is $0.6-0.8$

v. Harvest the cells by centrifugation at $7,000 \mathrm{~g}$ for $10 \mathrm{~min}$ at $4{ }^{\circ} \mathrm{C}$. Discard the supernatant by decanting. Keep the cell pellet on ice.

- PAUSE POINT The cell pellets can be flash-frozen and stored at $-80{ }^{\circ} \mathrm{C}$ for at least 1 month.

\section{Preparation of buffers}

All buffers can be prepared beforehand, filtered using a $0.22-\mu \mathrm{m}$ filter and stored without the addition of reducing agents at $4{ }^{\circ} \mathrm{C}$ for up to 2 weeks.

i. Preparation of $\mathrm{His}_{6}$-TEV-S219V lysis buffer: prepare $\mathrm{His}_{6}$-TEV-S219V lysis buffer by mixing $50 \mathrm{mM} \mathrm{Na}_{2} \mathrm{HPO}_{4}, \mathrm{pH} 8.0,100 \mathrm{mM} \mathrm{NaCl}, 10 \mathrm{mM}$ imidazole, $5 \%$ glycerol and $5 \mathrm{mM}$ BME.

A CRITICAL STEP Freshly add BME just before use.

ii. Preparation of $\mathrm{His}_{6}$-TEV-S219V wash buffer: prepare $\mathrm{His}_{6}$-TEV-S219V wash buffer by mixing $50 \mathrm{mM} \mathrm{Na}_{2} \mathrm{HPO}_{4}, \mathrm{pH} 8.0,200 \mathrm{mM} \mathrm{NaCl}, 25 \mathrm{mM}$ imidazole, $5 \%$ glycerol and $5 \mathrm{mM}$ BME.

$\triangle$ CRITICAL STEP Freshly add BME right before use.

iii. Preparation of His $_{6}$-TEV-S219V elution buffer: prepare His $_{6}$-TEV-S219V elution buffer by mixing $50 \mathrm{mM} \mathrm{Na} 2 \mathrm{HPO}_{4}, \mathrm{pH} 8.0,200 \mathrm{mM} \mathrm{NaCl}, 125 \mathrm{mM}$ imidazole, $5 \%$ glycerol and $5 \mathrm{mM}$ BME.

$\triangle$ CRITICAL STEP Freshly add BME right before use. 
iv. Preparation of His $_{6}$-TEV-S219V storage buffer: prepare His 6 -TEV-S219V storage buffer by mixing $50 \mathrm{mM}$ Tris, $\mathrm{pH} 7.5,150 \mathrm{mM} \mathrm{NaCl}, 0.5 \mathrm{mM}$ EDTA, $10 \%$ glycerol and $3 \mathrm{mM}$ TCEP.

$\triangle$ CRITICAL STEP Freshly add TCEP before use. Readjust the $\mathrm{pH}$ to 7.5 after adding TCEP.

\section{Purification of His $_{6}$-TEV-S219V using a TALON cobalt-affinity column}

$\triangle$ CRITICAL STEP Maintain the cell pellet, cell lysate and all buffers on ice at all times to minimize loss of protein activity.

i. Pipette out $14 \mathrm{ml}$ of TALON resin (7-ml bed volume (BV)) in an Econo column. Let the buffer flow through. Wash the resin with $10 \mathrm{BV}$ of water followed by $5 \mathrm{BV}$ of lysis buffer.

A CRITICAL STEP Do not allow the resin to dry.

ii. Pre-equilibrate a GE Healthcare Hiload 26/60 Superdex 200 prep grade column (ID no. 0823027) with $320 \mathrm{ml}$ of storage buffer.

iii. If the pellet is frozen, thaw it on ice. Resuspend the cells in $5 \mathrm{ml}$ of $\mathrm{His}_{6}$-TEVS219V lysis buffer per gram of cell pellet.

$\triangle$ CRITICAL STEP Cell pellets need to be resuspended vigorously. Pipette up and down until no clumps are visible. Clumps of cells can clog the cell disruptor.

iv. Lyse cells by passing the cell suspension twice through the cell disruptor at 13,000 p.s.i.

$\triangle$ CRITICAL STEP Maintain the lysate on ice at all times.

v. Centrifuge the lysate at $30,000 \mathrm{~g}$ for $30 \mathrm{~min}$ at $4{ }^{\circ} \mathrm{C}$. Collect the supernatant in clean glassware.

vi. To remove DNA, add streptomycin sulfate solution to a final concentration of $2 \%$.

$\triangle$ CRITICAL STEP Prepare streptomycin sulfate solution by dissolving the solid in $8-10 \mathrm{ml}$ of chilled $\mathrm{ddH}_{2} \mathrm{O}$. Add streptomycin sulfate solution drop by drop while stirring the supernatant gently at $4{ }^{\circ} \mathrm{C}$. Vigorous stirring can lead to loss of protein activity. You should observe a viscous yellow DNA precipitate upon adding streptomycin sulfate. Discontinue adding streptomycin sulfate white protein precipitate is observed.

vii. Centrifuge the supernatant at $30,000 g$ for $30 \mathrm{~min}$ at $4{ }^{\circ} \mathrm{C}$. Collect the supernatant in clean glassware.

viii. Resuspend the pre-equilibrated TALON resin with the supernatant and transfer it to the clean glassware. Incubate the supernatant with the resin for $50 \mathrm{~min}-1 \mathrm{~h}$ at $4{ }^{\circ} \mathrm{C}$ while gently stirring. 
$\triangle$ CRITICAL STEP A long incubation time can lead to decay of protein activity. A very short incubation can result in inefficient binding and therefore reduced protein yield.

ix. Add the cell lysate-resin mixture back to the Econo column and let the lysate flow through. Avoid letting the column run dry.

x. Wash the resin three times, each with $2 \mathrm{BV}$ of His $_{6}$-TEV-S219V wash buffer.

xi. Elute $\mathrm{His}_{6}$-TEV-S219V from the column using $\mathrm{His}_{6}{ }^{-T E V-S 219 V}$ elution buffer. Collect 1-ml fractions and check for the presence of protein by measuring $\mathrm{A}_{280}$ values. Pool the protein-containing fractions. Concentrate the protein in a 10-kDa-cutoff concentrator to bring the total volume to $10-12 \mathrm{ml}$.

$\triangle$ CRITICAL STEP A concentration that is too high can result in protein precipitation. If the starting volume is too large, protein can be loaded in two batches on the Superdex 200 column.

xii. Load the protein on a pre-equilibrated column for buffer exchange at a flow rate of $1 \mathrm{ml} / \mathrm{min}$.

xiii. Collect fractions corresponding to the protein peaks. Pool the fractions. Concentrate to a final concentration of $4-5 \mathrm{mg} / \mathrm{ml}$. Measure protein concentration using standard protein concentration measurement assays.

xiv. Confirm the purity of $\mathrm{His}_{6}$-TEV-S219V using protein gel electrophoretic analysis. The molecular weight of $\mathrm{His}_{6}$-TEV-S219V is $26 \mathrm{kDa}$.

xv. Divide His $_{6}$-TEV-S219V into aliquots, flash-freeze them and store them at $-80{ }^{\circ} \mathrm{C}$.

PAUSE POINT His 6 -TEV-S219V aliquots are stable at $-80{ }^{\circ} \mathrm{C}$ for at least a year. 


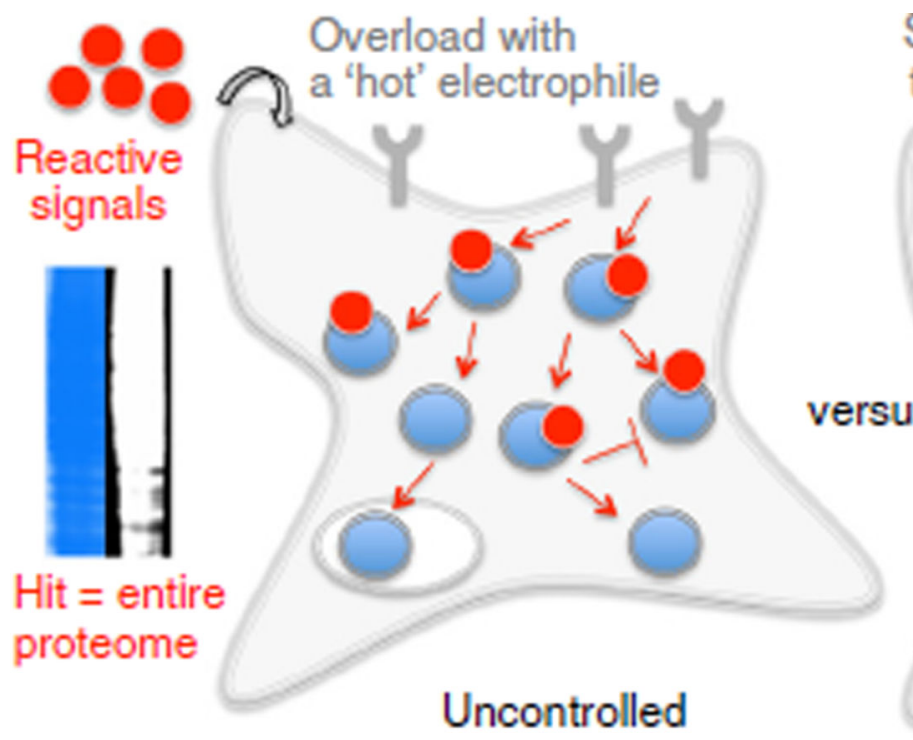

\section{Uncontrolled}

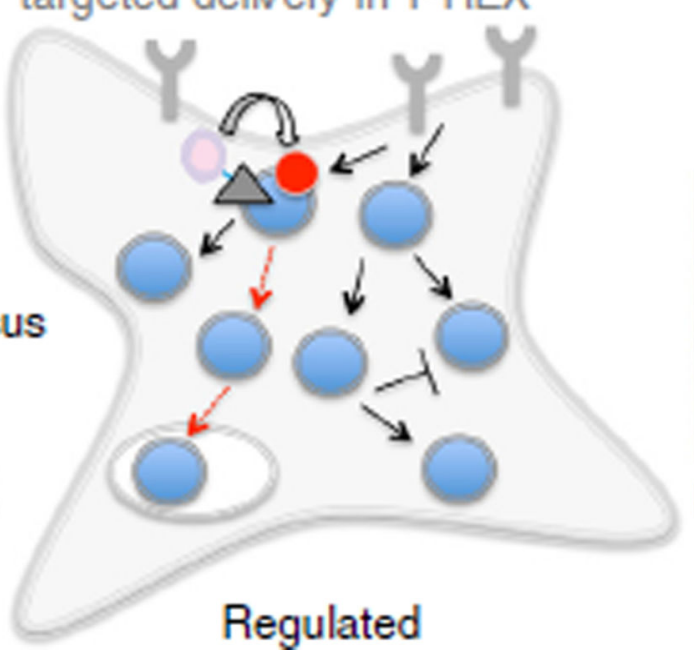

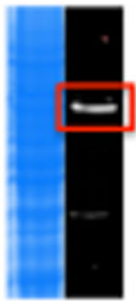

$\mathrm{Hit}=\mathrm{POI}$

Figure 1.

Strategies for studying cellular redox responses. The predominant small molecule-based strategy for studying cellular redox responses typically constitutes bolus dosing of a cell with reactive signals (left panel). T-REX offers a complementary and previously not recognized 'on-demand redox targeting' approach to the study of gain-of-function or dominant loss-of-function consequences of specific redox modifications with precise timing and target specificity (this protocol, right panel). Blue circles designate cellular proteins and red dots are reactive endogenous redox signals. All arrows illustrate representative redox pathways and trajectories (the regular and T-shaped arrows indicate direct/indirect activation and inhibition, respectively). Red arrows signify those that are being perturbed under the respective conditions. The gray triangle with the purple sphere designates a photocaged precursor (see Fig. 2 for chemical structure), and the gray Y-shaped objects represent cellsurface receptors. The accompanying gel-based data demonstrate the specificity in terms of targeted modification achieved in T-REX, which also offers temporal control through lightdriven signal delivery. See Figures 2 and 3 for approaches to probe downstream response. 


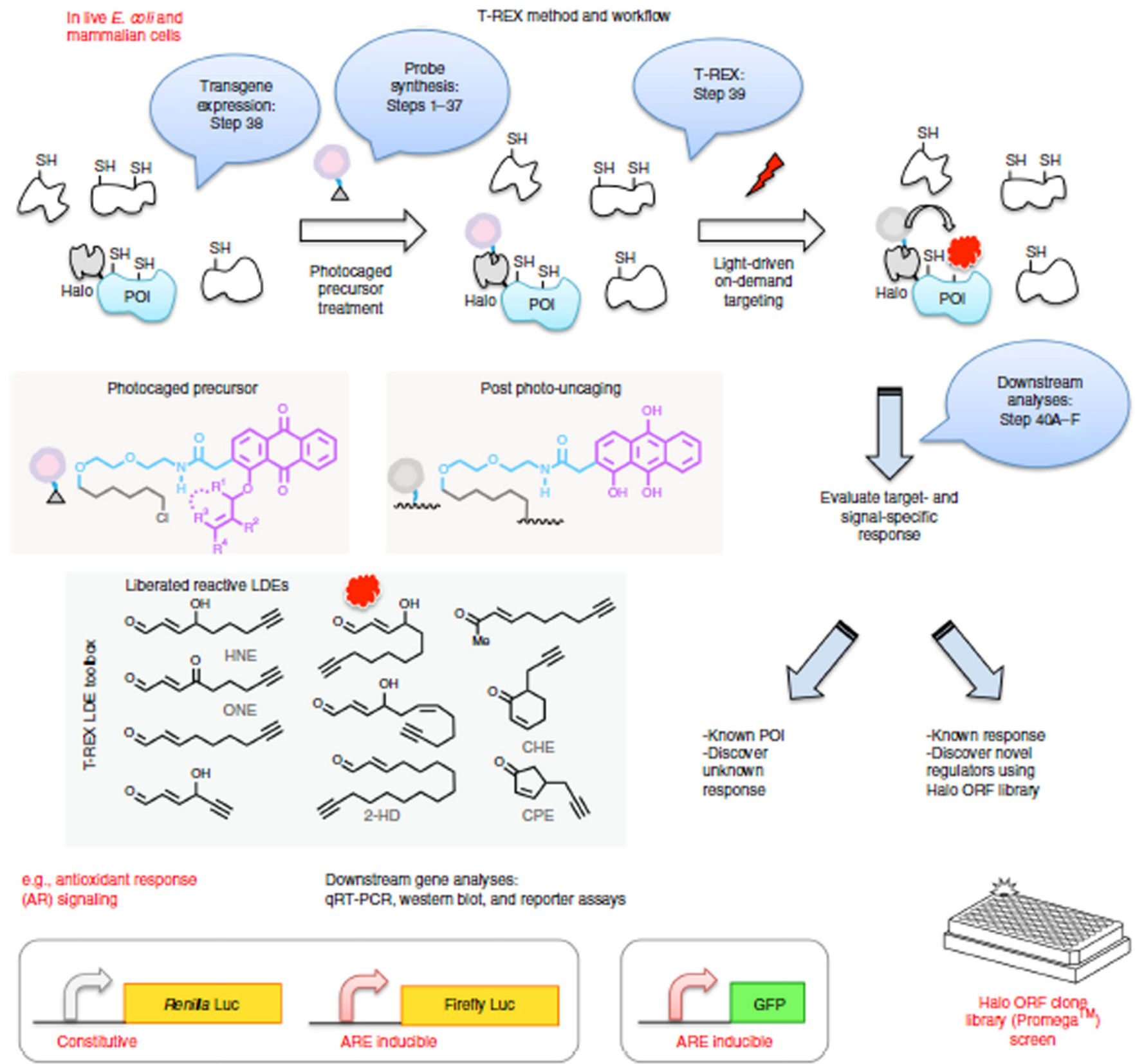

Figure 2.

On-target, on-demand redox signaling enabled by T-REX. Bubbles indicate experimental steps described in the protocol. Either E. coli or mammalian cells expressing HaloTag-fused proteins of interest (POIs) are treated with designated photocaged precursors $(5-25 \mu \mathrm{M}, 2 \mathrm{~h})$ to achieve a 1:1 covalent binding between the HaloTag and the photocaged probe. After rinsing cycles, exposure of the cells (for 3-20 min) to low-energy light $\left(0.3 \mathrm{~mW} / \mathrm{cm}^{2}, 365\right.$ $\mathrm{nm}$ ) at room temperature elicits rapid liberation of a reactive signal (lipid-derived electrophiles (LDEs), inset) from the photocaged probe bound to HaloTag. Proximity enhancement ${ }^{62}$ facilitates on-target, on-demand covalent modification of amino acid residue(s) on the POIs, typically cysteines. HNE is also known to be capable of modifying 
lysine and histidine (see text). Regardless of residue specificity, T-REX is able to ping one potential responsive protein with a precision dose of reactive lipid. Irrespective of residue identity, in-gel fluorescence analysis reports on the presence of HNE modification on the POIs. Residue specificity in POI modification is determined by LC-MS/MS analysis post cell lysis and resin-assisted enrichment (Fig. 5c). Once a specific sensor protein has been earmarked by T-REX, target- and residue(s)-specific post-translational modification can be directly linked to the signaling function of interest in an otherwise unperturbed cellular background. T-REX can (i) interrogate specific redox-linked signaling responses and (ii) discover novel regulators that upon selective lipidation are sufficient to elicit a biologically relevant response. Generality and scope in terms of both target and signal specificity are exemplified with distinct vertebrate sensor proteins (e.g., Keap1, RRM1, HSPB7) and structurally distinct LDEs (inset). Pathway activation is analyzed using dual-luciferase reporter assays or GFP reporter assays by flow cytometry. Endogenous downstream gene activation can be analyzed by qRT-PCR and western blotting. 
a

Percentage of POI molecules modified (POI targeting efficiency) and residues modified (Step 40 options A and B)

(i) Gel-based analysis ${ }^{55-57}$

T-REX TEV-protease cleavage $\longrightarrow$ Click coupling $\longrightarrow$ In-get fluorescence versus

Global Set internal standard Click coupling In-get fluorescence (1:1 Halo Tag and photocaged precursor)

(ii) LC-MS/MS-based analysis ${ }^{56,57}$

Affinity enrichment $\longrightarrow$ Trypsin digest $\longrightarrow$ LC-MS/MS analysis (ion peak integration)

b

Pathway activation analyses

(Step 40 options C-F)

Downstream response reporters such as (i) dual luciferase ${ }^{56,57}$, (ii) GFP reporters (Fig. 6), (iii) immunofluorescence imaging (Fig. 8), (iv) FRET biosensors (Fig. 9), (v) qRT-PCR ${ }^{20}$ and (vi) western blotting analysis ${ }^{20}$

Controls:

Confim ablation of response upon overexpressing HaloTag and POI as two separate proteins ${ }^{56,57}$

Confirm similar response in native cells versus cells overexpressing Halo-POI upon global LDE stimulation $^{56}$

Figure 3.

T-REX approach allows flexibility while enabling quantification of modification and response at numerous points. (a) Validation of protein as redox-sensitive. Biochemical information expected is as follows: (i) identification of the percentage of LDE modification and (ii) residue specificity. (b) Evaluation of pathway activation alongside recommended controls. Functional information expected: (i) global transcriptional response; (ii) cell-to-cell transcriptional response; (iii) changes in endogenous biological species; (iv) perturbation of signaling activities; and (v) alterations in mRNA abundance and (vi) protein levels of downstream genes.

Nat Protoc. Author manuscript; available in PMC 2017 January 24. 


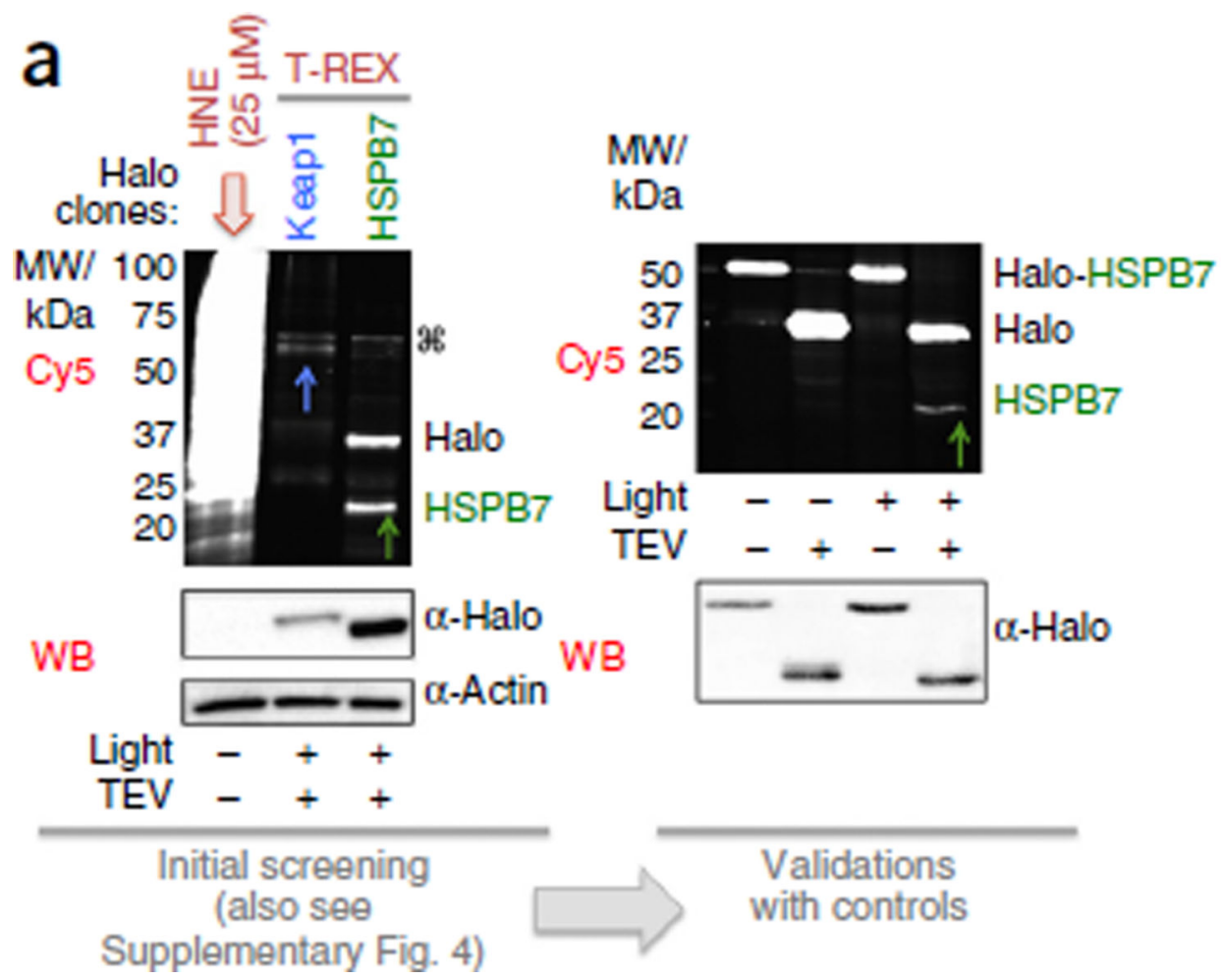

b

Figure 4.

Commercial HaloTag library allows discovery and validation of 'first responders' to a specific LDE using T-REX. The screen first identified first responders to basal amounts of HNE (Supplementary Fig. 4a). This was coupled with T-REX secondary validations using appropriate controls for effects of light alone with or without separation of Halo and POI domains during processing. As an example, T-REX-targeted HNEylation using a panel of ten distinct Halo ORF clones identified (a) zebrafish HSPB7 (theoretical MW $\sim 18 \mathrm{kDa}$ ) and (b) human RRM1 (theoretical MW $\sim 90 \mathrm{kDa}$ ) as novel HNE-sensitive targets. (a) The established Keap1 (theoretical MW $\sim 70 \mathrm{kDa}$ ) targeting was used as a diagnostic positive control (also see Supplementary Fig. 4a). Global HNE shows comparison with established protocols (left panel in a). \& marks a nonspecific band in the data set from a representative rapid initial screen of multiple HaloTag clones (Supplementary Fig. 4a). Secondary validation of HSPB7 HNEylation was performed with a full set of controls (right panel in a). HSPB7 protein identity was confirmed by pulldown (Supplementary Fig. 4b). Actin was used as loading control. Halo antibody was used to evaluate the expression level of Halo fusion proteins. (b) Secondary validation of RRM1 HNEylation (also see Supplementary Fig. 4a for an initial screen). RRM1 protein identity was confirmed by western blotting (top band, Halo-RRM1; bottom, RRM1 post TEV protease-assisted separation of Halo and RRM1). (Note: the expression plasmid vector for Halo-Keap1, Halo-HSPB7 and HaloRRM1 encodes bicistronic expression of an internal fluorescent protein control, DsRed, alongside the Halo-tagged POI, explaining the fluorescent band at $27 \mathrm{kDa}$ in these gels.) WB, western blotting. 
a

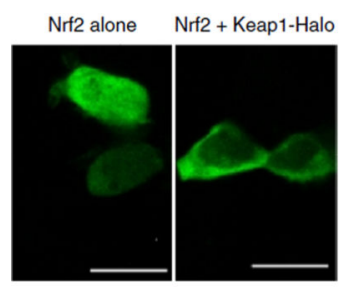

\section{b}

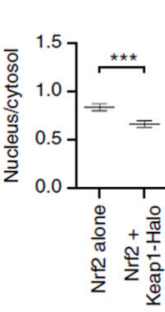

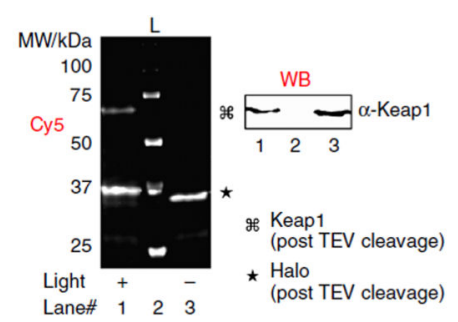

$c$

b2 b3 b4 S-G.V.G-V.A.V.T-M-E.P.C.R

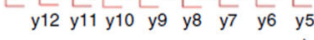

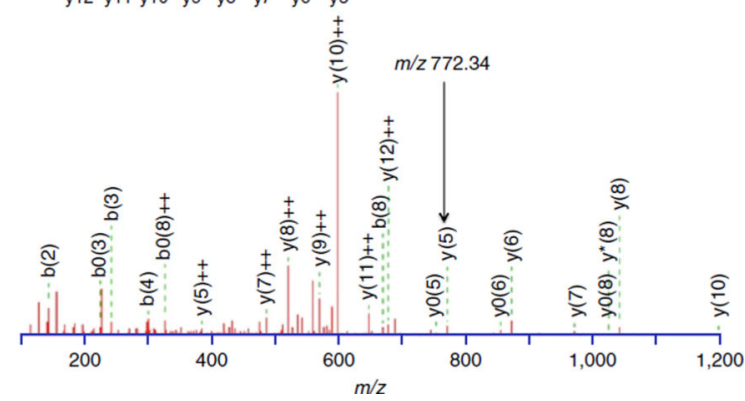

Figure 5.

Assessment of N-versus C-terminal HaloTagging on T-REX functionality, exemplified by Keap1 LDE targeting. Results with Halo-Keap1 were previously reported ${ }^{56,57}$. (a) Live imaging analysis shows that Keap1-Halo promotes Nrf2 nuclear exclusion as with HaloKeap1 (ref. 57). Inset shows quantification performed using ImageJ (NIH). $* * *, P<0.001$. Scale bars, $20 \mu \mathrm{m}$. (b) In-gel fluorescence analysis shows that targeted HNEylation of Keap1 in HEK-293 cells using the Keap1-Halo construct is equally as efficient as using HaloKeap1 (refs. 56,57). L, MW ladder. (c) Ionization spectrum of Keap1 peptide modified by a representative cyclohexenone-derived LDE (CHE, Fig. 2 inset) as a result of T-REX on HEK-293 cells expressing C-terminal HaloTagged Keap1, subsequent enrichment of modified Keap1-Halo from T-REX-treated cells and LC-MS/MS analysis. The same Cys residue (C613) was modified in the corresponding experiment in which $\mathrm{N}$-terminally HaloTagged-Keap1 was used56. Also see Supplementary Tables 1 and 2. Arrow points to the diagnostic $\mathrm{m} / \mathrm{z}$ peak for $\mathrm{C} 613$ modification. 


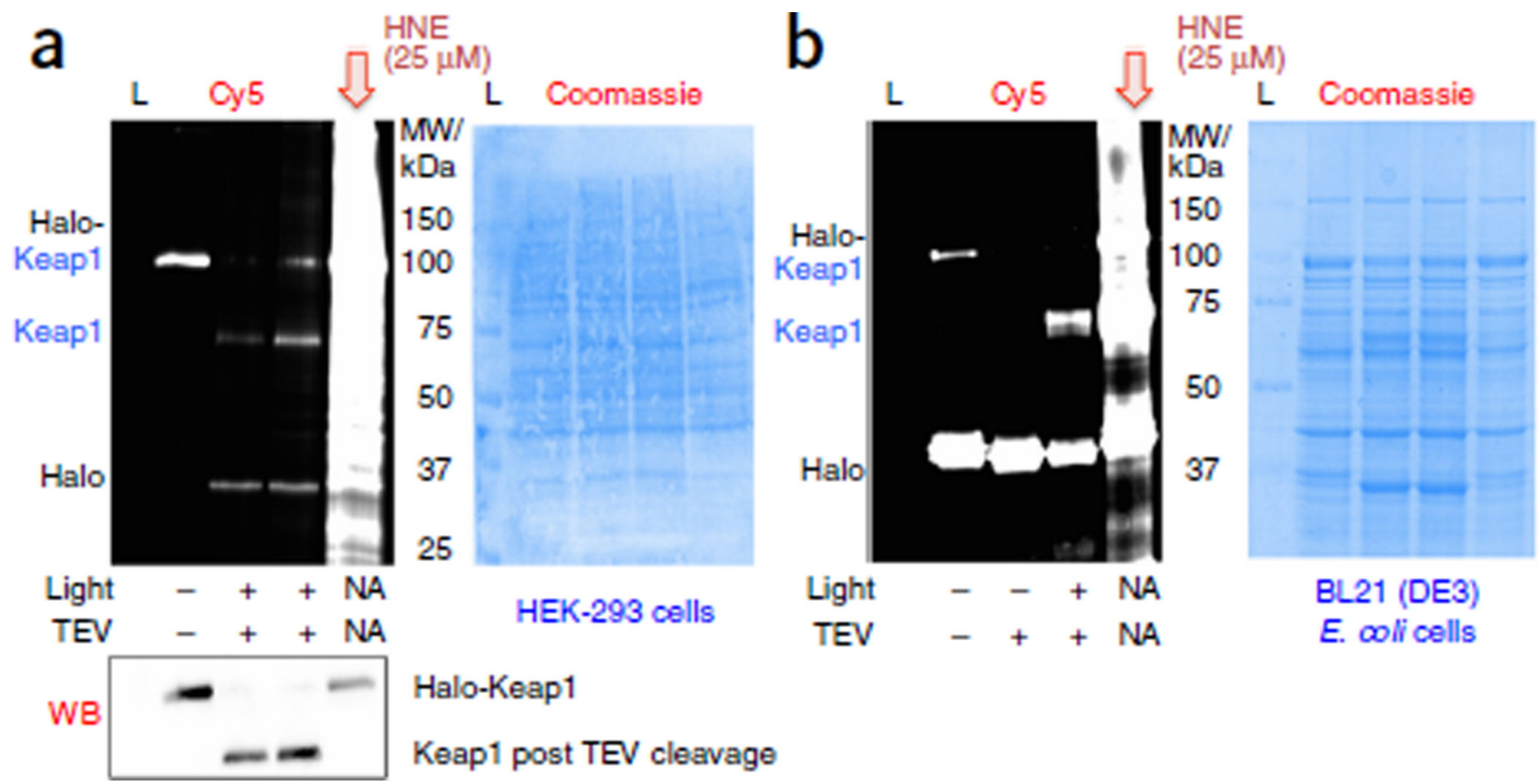

Figure 6.

T-REX targeting is equally efficient in human (HEK-293) cells and E. coli. Halo-Keap1 human protein ${ }^{55-57}$ is used as a model protein. Coomassie-stained membrane is used to evaluate uniform loading of total lysate proteins in each lane. Independent duplicates of Keap1 targeting results are presented in a. Partial cleavage of the fusion protein (into separate Halo and Keap1 proteins) was often observed during standard E. coli growth conditions, accounting for the observed Cy5 signal on the Halo band (see no-light, no-TEV sample lane in b). Theoretical MWs: Halo, $\sim 33$ kDa; Keap1, 70 kDa. L, MW ladder; TEV, TEV protease. 
a

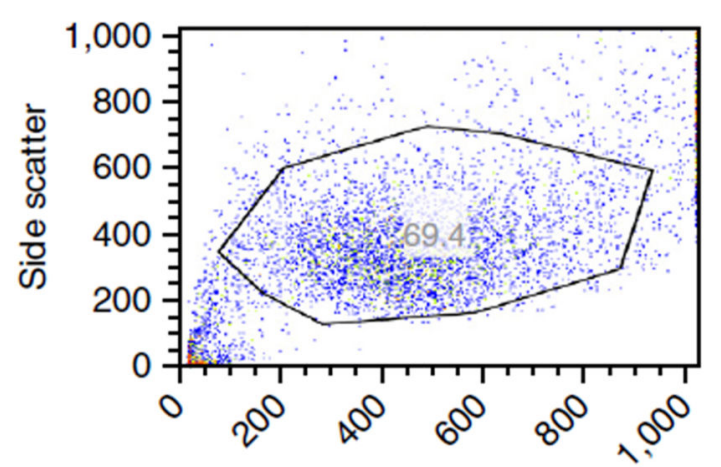

Forward scatter

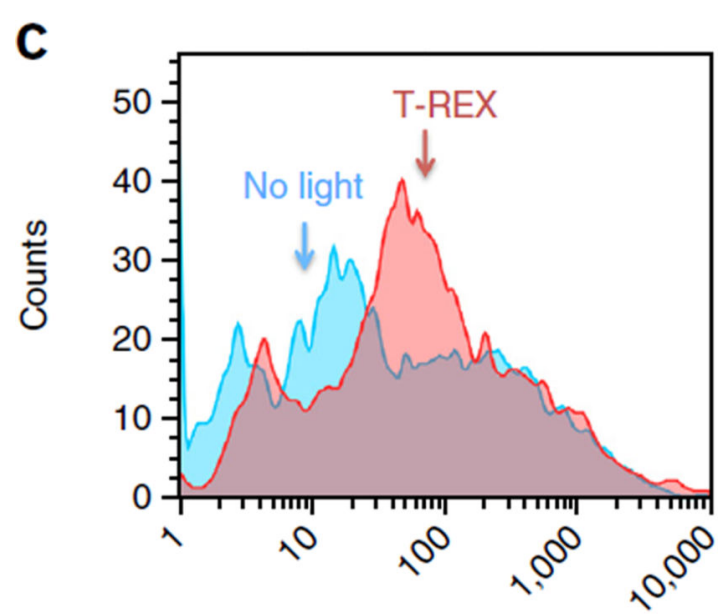

e

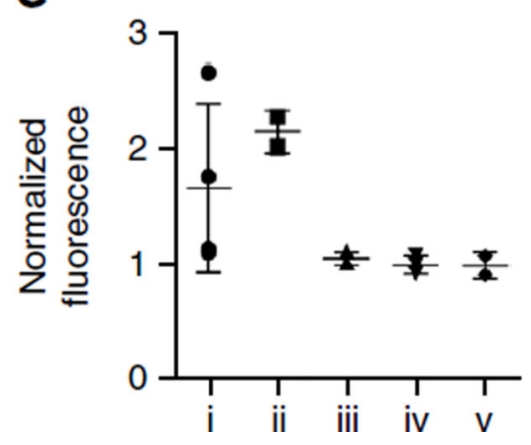

b

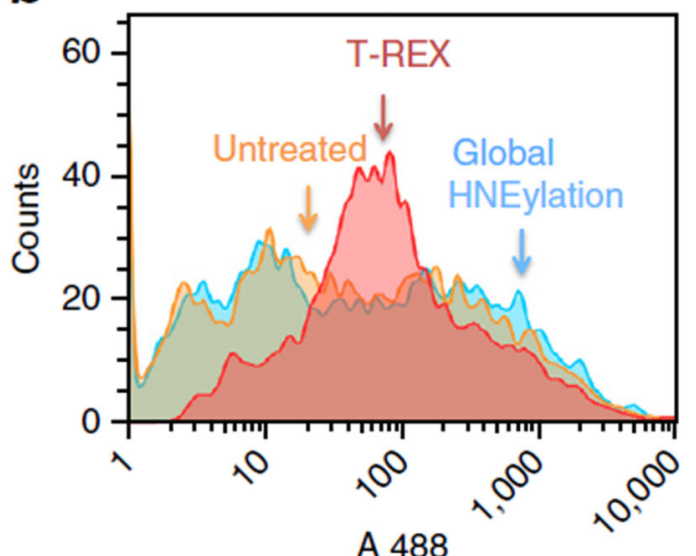

d

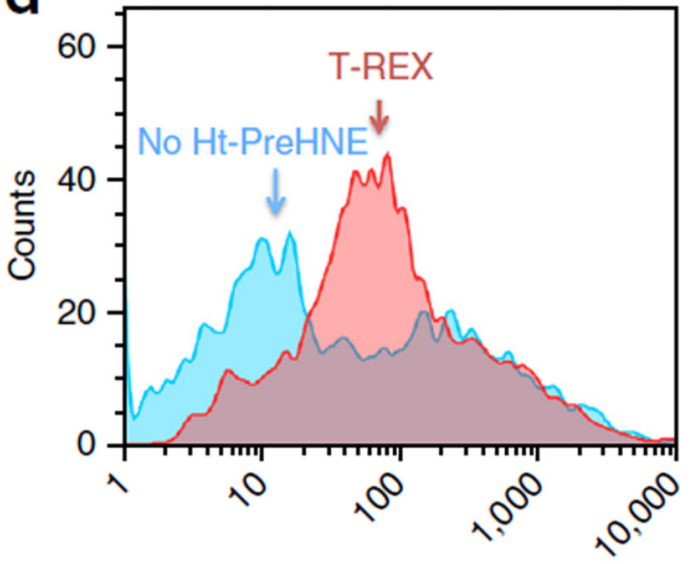

A 488

Figure 7.

Flow-cytometry-based ARE-GFP reporter assay quantifying T-REX-mediated activation of antioxidant response in a subpopulation of live HEK-293 cells. (a) Representative GFP expression level in cells transiently transfected with plasmids encoding Halo-Keap1, Nrf2 and ARE-GFP. (b-d) Representative single-parameter (GFP signal) histograms obtained from cells transiently transfected with plasmids encoding Halo-Keap1, Nrf2 and ARE-GFP that have been treated as indicated. (b) Comparison of the results between whole-cell HNE stimulation (blue), T-REX-assisted Keap1-specific activation (red) and no treatment (no 
photocaged precursor and no light) (orange). (c) Comparison between T-REX (red) and "no light exposure' control (blue). (d) Comparison between T-REX (red) and 'no photocaged precursor' control (blue). (e) Representative data from total fluorescence analysis of GFP signal. Error bars designate s.d. $(n=3)$. 


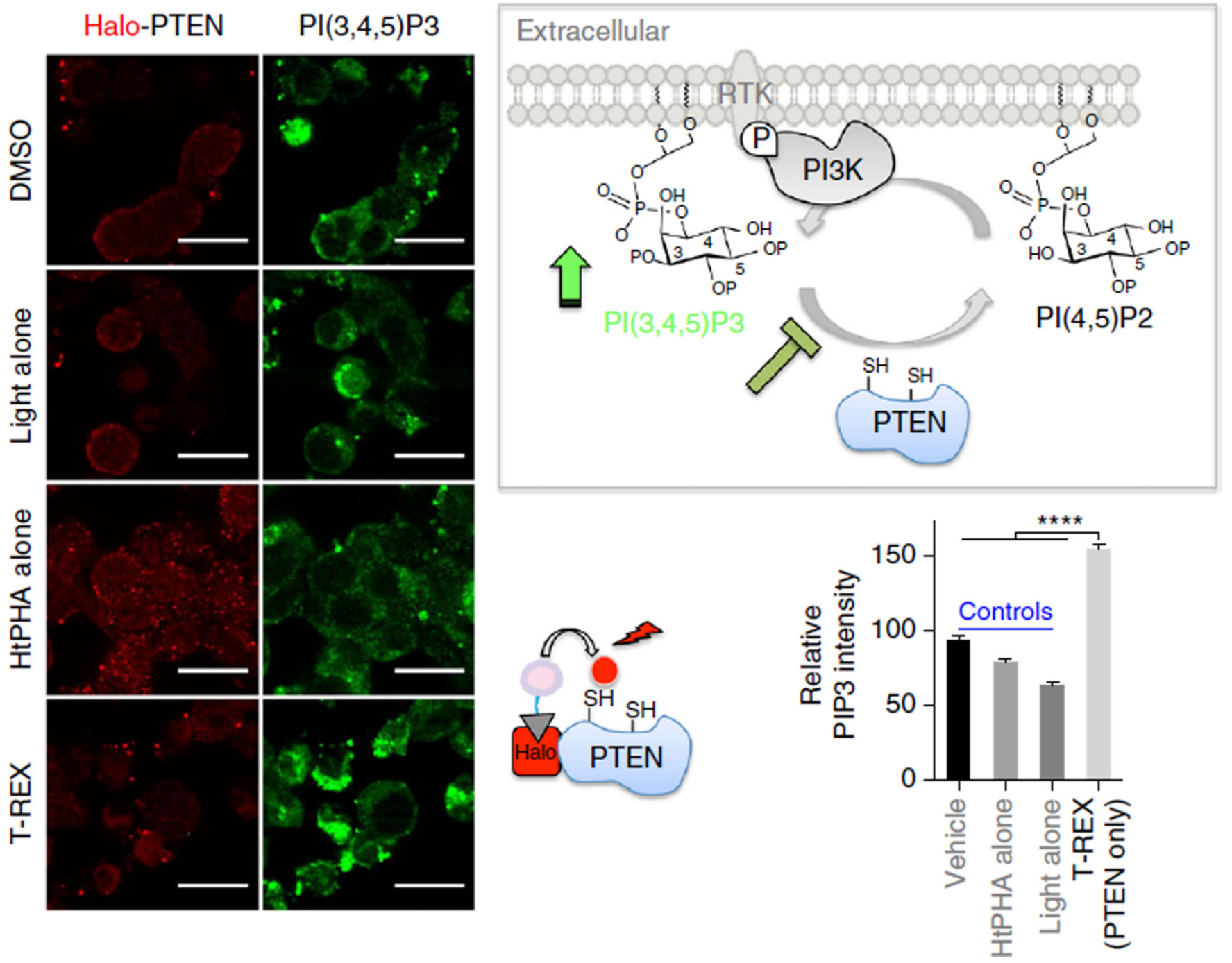

Figure 8.

Immunofluorescence analysis of endogenous PIP3 phosphoinositide in fixed cells subsequent to PTEN-targeted redox modification enabled by T-REX in live cells. Live HEK-293 cells expressing Halo-PTEN were subjected to T-REX-targeted HNEylation of PTEN ${ }^{55}$. Dominant loss-of-function inactivation of PTEN results in upregulation of PIP3. The cells were fixed and immunostained by anti-PIP3 (green) and anti-Halo (red). Error bars represent the standard error of the mean $(N=86)$. Scale bars, $20 \mu \mathrm{m}$. Inset: schematic of the PI3K/PTEN signaling. Partial inactivation of PTEN raises the levels of PIP3. ****, $P<$ 0.0001 . 

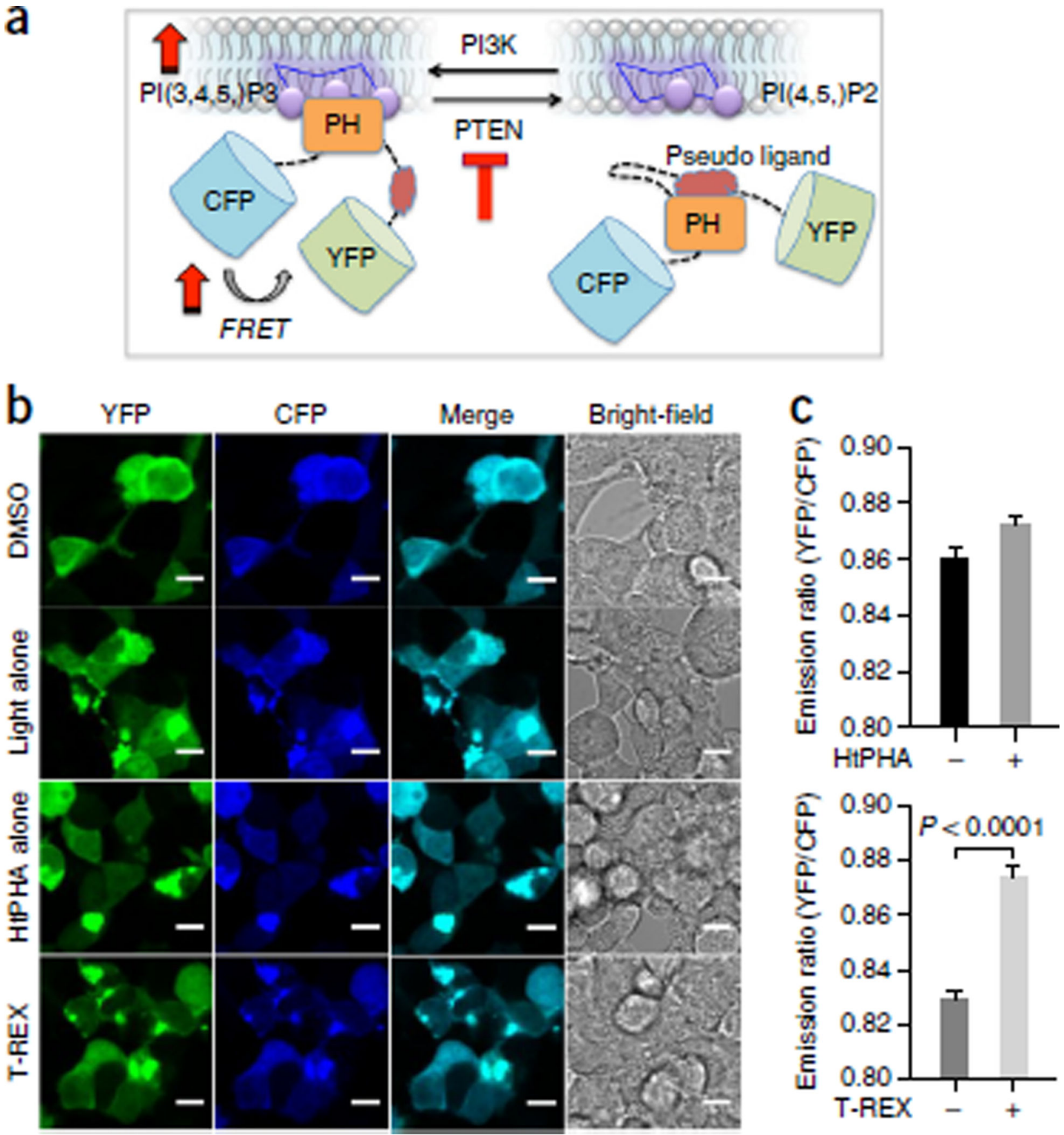

Figure 9.

FRET-based biosensor assay in live cells, reporting the levels of endogenous PIP3 subsequent to PTEN-targeted redox modification enabled by T-REX. (a) Live HEK-293 cells expressing 'InPAkt' FRET biosensor ${ }^{88}$ and HaloPTEN were subjected to T-REX conditions that enabled substoichiometric HNEylation of PTEN ${ }^{55}$. Dominant loss-offunction inactivation of PTEN upregulates the membrane-bound PIP3 phosphoinositide. Increase in cellular PIP3 competitively binds the pleckstrin homology (PH) domain of Akt, displacing the "pseudo ligand" 88 . Conformational change associated with the membrane 
recruitment results in an increase in FRET signal ${ }^{88}$. (b) Representative live-cell images and (c) quantification of the YFP:CFP emission ratio. Scale bars, $20 \mu \mathrm{m}$. Top: Control: HtPHA treatment alone did not perturb the emission ratio appreciably. Bottom: T-REX redox targeting of PTEN selectively enhances FRET signal (right bar) as compared with that of samples exposed to light alone (left bar). Error bars designate the standard error of the mean ( $N=170$ cells). a adapted with permission from Ananthanarayanan B., Ni, Q. \& Zhang, J. Signal propagation from membrane messengers to nuclear effectors revealed by reporters of phosphoinositide dynamics and Akt activity. Proc. Natl. Acad. Sci. USA 102, 15081-15086 (2005). Copyright 2005 National Academy of Sciences, USA. 


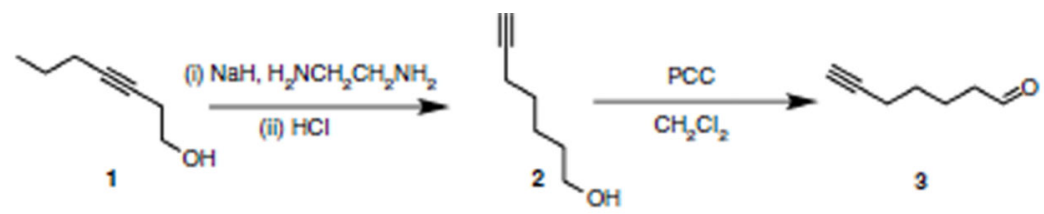<smiles>CCOC(=O)C[S@](=O)c1ccc(Cl)cc1</smiles><smiles>C#CCCCC(O)/C=C/C(=O)OCC</smiles><smiles>C#CCCCC(O)/C=C/C(=O)OCC</smiles><smiles>C#CCCCC(C=CCO)OC1CCCCO1</smiles><smiles>C#CCCCC(/C=C/CBr)OC1CCCCO1</smiles><smiles>Oc1ccccc1</smiles><smiles>C#CCCCC(O)/C=C/CBr</smiles><smiles>C=CCc1ccc2c(c1O)C(=O)c1ccccc1C2=O</smiles>

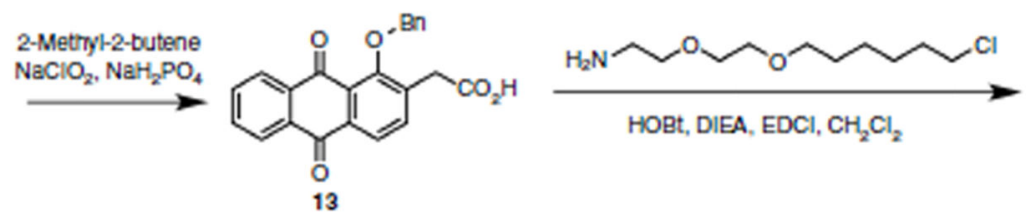<smiles>CCCCCCCOCCOCCNC(=O)Cc1ccc2c(c1OCc1ccccc1)C(=O)c1ccccc1C2=O</smiles><smiles>C#CCC[C@H](O)/C=C/CBr</smiles><smiles>C#CCCCC(O)/C=C/COc1c(CC(=O)NCCOCCOCCCCCCCl)ccc2c1C(=O)c1ccccc1C2=O</smiles>

Figure 10.

Chemical syntheses of HNE(alkyne) ${ }^{55}$ (also see Fig. 1 inset), and HaloTag-targetable caged precursor to HNE(alkyne) ${ }^{55,56}$, also known as Ht-PreHNE ${ }^{56}$ or $\mathrm{HtPHA}^{55}$. 
Table 1

Troubleshooting table.

\begin{tabular}{|c|c|c|c|}
\hline step & problem & possible reason & solution \\
\hline 4 & $\begin{array}{l}\text { Low yield of } \\
\text { alcohol } 2\end{array}$ & $\begin{array}{l}\text { Ethylenediamine is old } \\
\text { Reaction interfered with by } \\
\mathrm{O}_{2} \text { and moisture } \\
\text { Product destroyed during } \\
\text { reaction quenching }\end{array}$ & $\begin{array}{l}\text { Use either re-distilled ethylenediamine or fresh out of the bottle } \\
\text { Make sure that the reaction is protected under dry } \mathrm{N}_{2} \text { or } \mathrm{Ar} \\
\text { The reaction quenching is exothermic; add the quencher }(1 \mathrm{~N} \\
\mathrm{HCl}) \\
\text { slowly and make sure that the flask is well cooled }\end{array}$ \\
\hline 7 & $\begin{array}{l}\text { Low yield of } \\
\text { aldehyde } 3\end{array}$ & Aldehyde $\mathbf{3}$ is volatile & $\begin{array}{l}\text { Avoid excess heating (above } 35^{\circ} \mathrm{C} \text { )of the rotary evaporator } \\
\text { water bath }\end{array}$ \\
\hline $11 \mathrm{~A}(\mathrm{iv})$ & $\begin{array}{l}\text { Low yield of } \\
\text { HNE(alkyne) }\end{array}$ & $\mathrm{HNE}$ (alkyne) is not stable & $\begin{array}{l}\text { It is prone to air oxidation and polymerization. Carry on nonstop } \\
\text { through steps involving reaction workup, rotary evaporator, } \\
\text { chromatography, to final storage }\end{array}$ \\
\hline 11B(viii) & $\begin{array}{l}\text { Product } 7 \text { partially } \\
\text { deprotected }\end{array}$ & $\begin{array}{l}\text { One of the isomers of } \\
\text { product } 7 \text { is not stable }\end{array}$ & $\begin{array}{l}\text { Product } 8 \text { (deprotected } 7 \text { ) can be separated from } 7 \text { by } \\
\text { chromatography on silica gel, or it can be carried through to } \\
\text { the next step }\end{array}$ \\
\hline 30 & Low yield of $\mathbf{1 4}$ & $\begin{array}{l}\text { Reaction yield can be } \\
\text { reduced by adventitious } \\
\mathrm{O}_{2} \text { and/or moisture }\end{array}$ & $\begin{array}{l}\text { Make sure that all the solvents are dry and that the reaction } \\
\text { is protected under dry } \mathrm{N}_{2} \text { or Ar. Thoroughly degas the } \\
\text { solvents used }\end{array}$ \\
\hline 31 & $\begin{array}{l}\text { Incomplete } \\
\text { deprotection } \\
\text { of } \mathbf{1 4}\end{array}$ & $\begin{array}{l}\text { Some of the catalyst } \\
(10 \% \mathrm{Pd} / \mathrm{C}) \text { may be } \\
\text { deactivated }\end{array}$ & $\begin{array}{l}\text { Add more catalyst }(10 \% \mathrm{Pd} / \mathrm{C}) \text { and extend the reaction time. } \\
\text { Typically, high catalyst loading can be tolerated. Ensure that the } \\
\text { reaction is tightly sealed and that an atmosphere of hydrogen is } \\
\text { maintained throughout }\end{array}$ \\
\hline \multirow[t]{2}{*}{36} & $\begin{array}{l}\text { Difficult to } \\
\text { remove impurities } \\
\text { from HtPHA }\end{array}$ & $\begin{array}{l}\text { Polarity of impurities is } \\
\text { close to that of HtPHA }\end{array}$ & $\begin{array}{l}\text { Run flash chromatography with gradient eluent, from 1:3 to 1:5 } \\
\text { (vol/vol, hexanes: EtOAc) }\end{array}$ \\
\hline & $\begin{array}{l}\text { Final product } \\
\text { decomposition }\end{array}$ & $\begin{array}{l}\text { Light-induced photo- } \\
\text { uncaging of the final } \\
\text { product }\end{array}$ & $\begin{array}{l}\text { During the synthesis (especially from } \mathbf{1 4} \text { to } \mathbf{1 5} \text {, and } \mathbf{1 5} \text { to } \\
\text { HtPHA), } \\
\text { protect the reaction flask from stray light }\end{array}$ \\
\hline \multirow[t]{3}{*}{$40 \mathrm{~A}(\mathrm{x})$} & No Cy5 signal on gel & Failure of click coupling & $\begin{array}{l}\text { Check lysate protein concentration. The concentration should be } \\
\text { around } 1.0 \mathrm{mg} / \mathrm{ml} \\
\text { Check each reagent in the click coupling step. Make sure that } \\
\text { all of them are freshly prepared and that the concentrations are } \\
\text { correct. Mix the reaction well } \\
\text { Use cells treated globally with HNE(alkyne) as a positive control }\end{array}$ \\
\hline & High Cy5 background & $\begin{array}{l}\text { Old SDS-PAGE running } \\
\text { buffer }\end{array}$ & $\begin{array}{l}\text { Use fresh SDS-PAGE running buffer } \\
\text { Rinse the gel several times and analyze the gel after each rinse to } \\
\text { obtain the optimal result with highest signal-to-noise ratio } \\
\text { Let the dye font run out completely before imaging the gel }\end{array}$ \\
\hline & $\begin{array}{l}\text { Incomplete TEV } \\
\text { cleavage }\end{array}$ & Loss of TEV activity & $\begin{array}{l}\text { Use a fresh aliquot. Avoid multiple freeze-thaw cycles } \\
\text { Mix well after adding His } 6 \text {-TEV-S219V } \\
\text { Increase TEV amount and incubation time for TEV cleavage }\end{array}$ \\
\hline \multirow[t]{2}{*}{ 40B(xxviii) } & $\begin{array}{l}\text { Low yield of } \\
\text { pulldown protein }\end{array}$ & $\begin{array}{l}\text { Affinity protein purification } \\
\text { condition is not optimal } \\
\text { Protein is not eluting or } \\
\text { eluting prematurely } \\
\text { Protein is unstable after } \\
\text { modification }{ }^{103}\end{array}$ & $\begin{array}{l}\text { This protocol is optimized for } \mathrm{His}_{6} \text {-Halo-TEV-Keap1. Further } \\
\text { optimization may be required for other proteins } \\
\text { Monitor the protein in washes through SDS-PAGE. If premature } \\
\text { elution is observed, decrease the concentration of imidazole in } \\
\text { the wash buffers. Conversely, if no elution is observed, increase } \\
\text { imidazole concentration to } 200-400 \mathrm{mM} \text { or elute with Laemelli } \\
\text { buffer to validate binding } \\
\text { Add a proteasome inhibitor (bortezomib) in the lysis buffer } \\
\text { and/or to cells }\end{array}$ \\
\hline & $\begin{array}{l}\text { Modification } \\
\text { not found }\end{array}$ & $\begin{array}{l}\text { Targeting is not efficient. } \\
\text { Modification is reduced } \\
\text { Inefficient MS conditions }\end{array}$ & $\begin{array}{l}\text { Check modification of protein by Cy5 labeling, as described } \\
\text { in Step 3A } \\
\text { Make sure that TCEP is used instead of DTT in the sample } \\
\text { preparation } \\
\text { Adjust the ionization temperature to obtain optimal results. } \\
\text { A low ionization temperature may lead to poor ionization and } \\
\text { decrease sensitivity. A high ionization temperature may cause } \\
\text { loss of modification }\end{array}$ \\
\hline $\begin{array}{l}\text { 40C(xi); } \\
\text { 40D(viii) }\end{array}$ & $\begin{array}{l}\text { Low Firefly/Renilla/ } \\
\text { GFP signal intensity }\end{array}$ & $\begin{array}{l}\text { Significant loss of cells } \\
\text { during rinsing }\end{array}$ & $\begin{array}{l}\text { Perform the rinsing with care. Add the medium slowly along } \\
\text { the side wall of the culture dish. Adding and removing medium }\end{array}$ \\
\hline
\end{tabular}




\begin{tabular}{|c|c|c|c|}
\hline step & problem & possible reason & solution \\
\hline & & $\begin{array}{l}\text { Excessive cell death } \\
\text { Low transfection efficiency } \\
\text { Instrument setting is } \\
\text { not optimal } \\
\text { Response timing is } \\
\text { not optimal }\end{array}$ & $\begin{array}{l}\text { should be done as gently as possible but also as efficiently } \\
\text { as possible: wash plates sequentially ( } 2 \text { or } 3 \text { plates at a time) } \\
\text { to avoid drying out. Mark the position on the plate where cells } \\
\text { are washed } \\
\text { Use the suggested cell density for transfection. If using a } \\
\text { different transfection reagent or different cells, optimize } \\
\text { transfection conditions } \\
\text { Optimize transfection conditions for the cell type and the } \\
\text { reagent used } \\
\text { Run a positive control. For flow cytometry, cells transfected } \\
\text { with GFP can be used. Adjust gain (i.e., laser power) if } \\
\text { necessary } \\
\text { Set up a time course for measurements (recommended time } \\
\text { points for pilot trials: } 4 \text { h, } 12 \mathrm{~h}, 18 \text { h post T-REX light } \\
\text { exposure) }\end{array}$ \\
\hline & $\begin{array}{l}\text { Batch-to-batch } \\
\text { variability in targeting/ARE } \\
\text { results }\end{array}$ & $\begin{array}{l}\text { Difference in experimental } \\
\text { setup and execution }\end{array}$ & $\begin{array}{l}\text { Count cells and seed the numbers as specified in the protocol. } \\
\text { Transfect and perform experiments at similar confluence } \\
\text { Use cells at lower passage number (lower than 6-7 continuous } \\
\text { passages) }\end{array}$ \\
\hline & $\begin{array}{l}\text { Activation of } \\
\text { ARE-luciferase with } \\
\text { light alone or with } \\
\text { pre-HNE alone }\end{array}$ & $\begin{array}{l}\text { Release of pre-HNE due } \\
\text { to stray light } \\
\text { Stressed cells }\end{array}$ & $\begin{array}{l}\text { Protect photocaged-precursor-treated samples from stray light } \\
\text { Count cells before seeding. A cell density that is too low or } \\
\text { too high can stress the cells, leading to higher background }\end{array}$ \\
\hline
\end{tabular}

